Florida International University

FIU Digital Commons

$11-4-2019$

\title{
An Examination of Cuban-American Social Studies Teachers' Cultural Consciousness Relative To Their Identity, Educational Beliefs, And Curricular Decisions: A Critical Latino Theoretical Perspective
}

Victor Barrios

vbarr003@fiu.edu

Follow this and additional works at: https://digitalcommons.fiu.edu/etd

Part of the Curriculum and Instruction Commons, Curriculum and Social Inquiry Commons, Educational Sociology Commons, Junior High, Intermediate, Middle School Education and Teaching Commons, Race and Ethnicity Commons, Regional Sociology Commons, Secondary Education and Teaching Commons, and the Sociology of Culture Commons

\section{Recommended Citation}

Barrios, Victor, "An Examination of Cuban-American Social Studies Teachers' Cultural Consciousness Relative To Their Identity, Educational Beliefs, And Curricular Decisions: A Critical Latino Theoretical Perspective" (2019). FIU Electronic Theses and Dissertations. 4341.

https://digitalcommons.fiu.edu/etd/4341

This work is brought to you for free and open access by the University Graduate School at FIU Digital Commons. It has been accepted for inclusion in FIU Electronic Theses and Dissertations by an authorized administrator of FIU Digital Commons. For more information, please contact dcc@fiu.edu. 


\section{FLORIDA INTERNATIONAL UNIVERSITY}

Miami, Florida

\section{AN EXAMINATION OF CUBAN-AMERICAN SOCIAL STUDIES TEACHERS' \\ CULTURAL CONSCIOUSNESS RELATIVE TO IDENTITY, EDUCATIONAL BELIEFS, AND CURRICULAR DECISIONS: A CRITICAL LATINO THEORETICAL \\ PERSPECTIVE}

A dissertation submitted in partial fulfillment of

the requirements for the degree of

DOCTOR OF EDUCATION

in

TEACHING AND LEARNING

by

Victor M Barrios Jr. 
To: Dean Michael R. Heithaus

College of Arts, Sciences and Education

This dissertation, written by Victor M. Barrios Jr., and entitled An Examination of CubanAmerican Social Studies Teachers' Cultural Consciousness Relative to Identity, Educational Beliefs, and Curricular Decisions: A Critical Latino Perspective, having been approved in respect to style and intellectual content, is referred to you for judgment.

We have read this dissertation and recommend that it be approved.

Eric Dwyer

Thomas Reio

Jorge Duany

Aixa Perez-Prado

Sarah Mathews, Major Professor

Date of Defense: November 4, 2019

The dissertation of Victor M Barrios Jr. is approved.

Dean Michael R. Heithaus

College of Arts, Sciences and Education

Andrés G. Gil

Vice President for Research and Economic Development and Dean of the University Graduate School 
(C) Copyright 2019 by Victor M Barrios Jr.

All rights reserved. 


\section{DEDICATION}

I dedicate this dissertation to my Mother who without her I would have never completed

this journey

Mami,

Te quiero mucho 


\section{ACKNOWLEDGMENTS}

I would to acknowledge the following people who have helped me complete this dissertation:

Foremost, I would like thank Dr. Sarah A. Mathews who chaired my committee and stuck with me throughout all these years providing constant advice. I will always remember the first day we met in your new office room and all the books you had me read.

To my committee members for participating in this endeavor and for being there when I needed advice: Dr. Eric Dwyer, Dr. Jorge Duany, Dr. Aixa Perez-Prado, and Dr. Thomas Reio.

To my teacher-participants and Cuban-American friends who shared their perspectives with me who shared their beliefs with me in profound ways.

To my family, my Tia Conchi, my stepfather Jose, and my brother Alex who provided me with support throughout this process.

And of course, to my brother Alfred, who endured a great hardship in life. How could I have given up when you were strong enough to survive.

And I like to thank all the people we meet in life that may go unacknowledged but who make a difference.

Lastly, I would like to acknowledge the FIU Fellowships and Copyright permissions. 


\begin{abstract}
OF THE DISSERTATION
AN EXAMINATION OF CUBAN-AMERICAN SOCIAL STUDIES TEACHERS'

CULTURAL CONSCIOUSNESS RELATIVE TO IDENTITY, EDUCATIONAL

BELIEFS, AND CURRICULAR DECISIONS: A CRITICAL LATINO THEORETICAL

PERSPECTIVE
\end{abstract}

by

Victor M. Barrios Jr.

Florida International University, 2019

Miami, Florida

Professor Sarah Mathews, Major Professor

The purpose of the present research was to examine how five self-identified CubanAmerican social studies teachers in Miami, a city where they are considered the dominant culture, described their ethnic and cultural identity, expressed educational beliefs on teaching and learning, promoted culturally inclusive pedagogy, and approached the official curriculum relative to their cultural consciousness. The study used a qualitative research design with cross-case analysis. Critical Latino theory was the theoretical framework employed for social and cultural categories pertinent to Latinx groups. The study found that the teacher-participants reflected a dominant cultural ideology within Miami, which influenced their pedagogical beliefs, instructional practices, and curricular decisions. The teacher-participants strongly affiliated to a Cuban-American cultural identity, utilized mostly teacher-centered pedagogy, rarely challenged the official curriculum, and did not sufficiently develop a culturally inclusive pedagogy. Teachers need to study their biases to become better culturally competent educators. 


\section{TABLE OF CONTENTS}

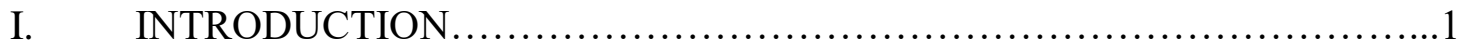

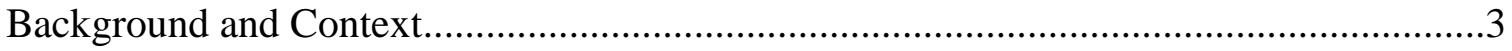

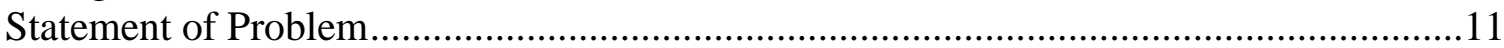

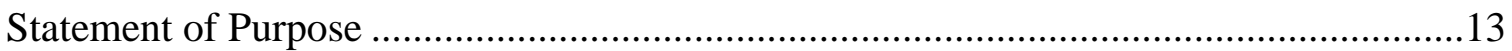

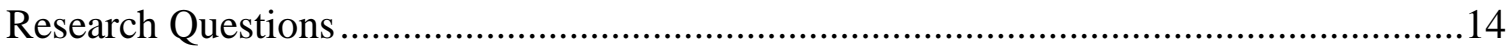

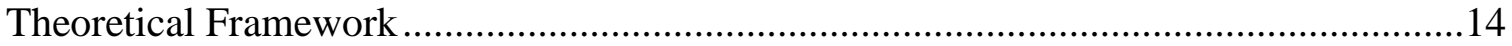

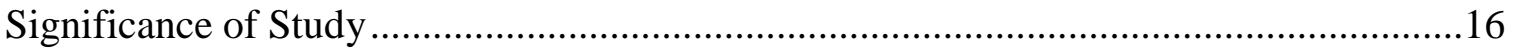

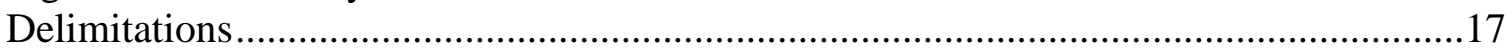

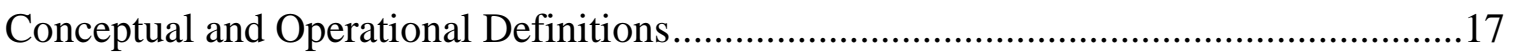

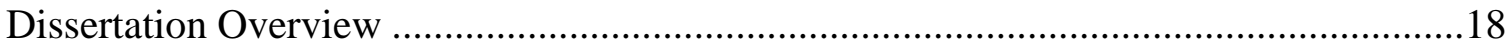

\section{LITERATURE}

REVIEW ................................................................. 20

Construct of Cultural Consciousness and Cultural

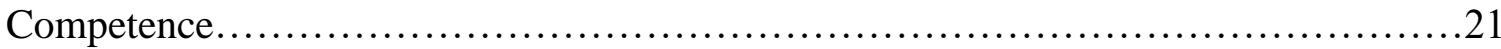

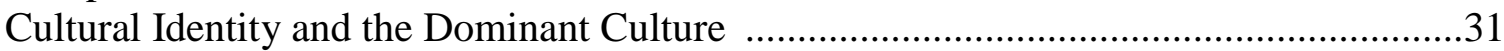

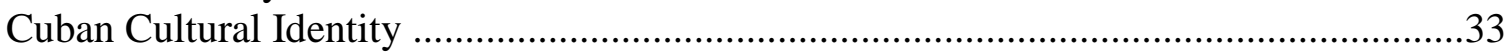

Educational Beliefs on Teaching and Learning ………...............................................47

The Official Curriculum .....................................................................................50

Discussions on Challenging the Official Curriculum ………........................................57

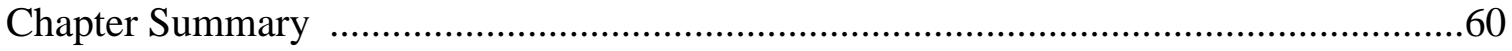

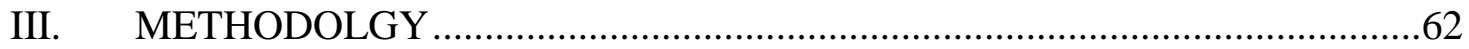

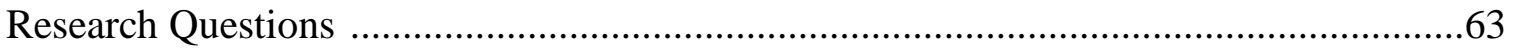

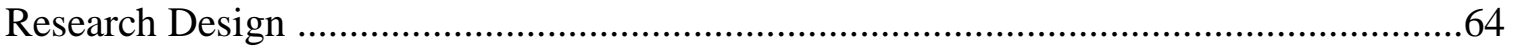

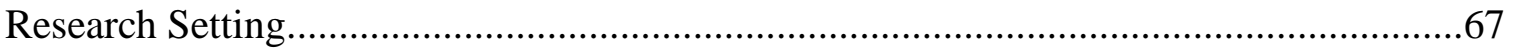

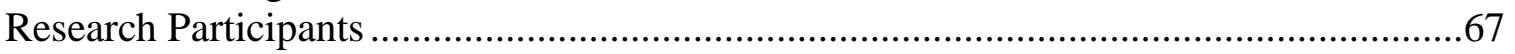

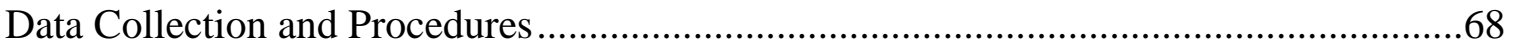

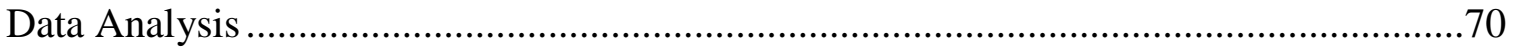

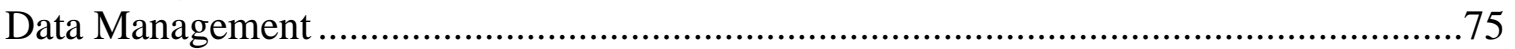

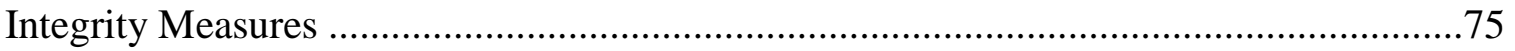

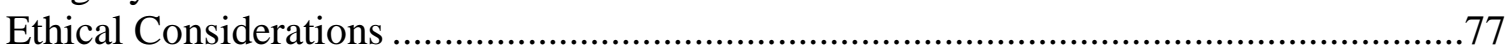

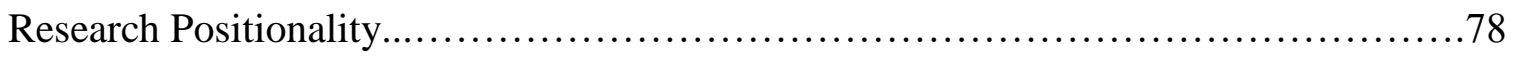

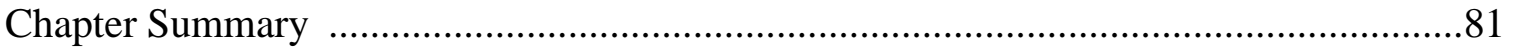

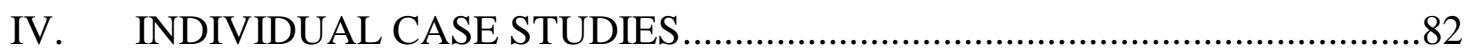

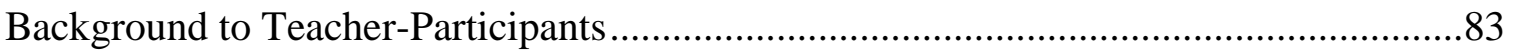

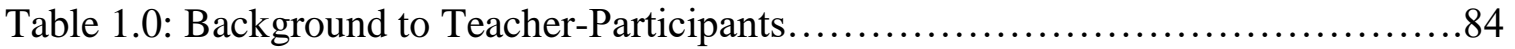

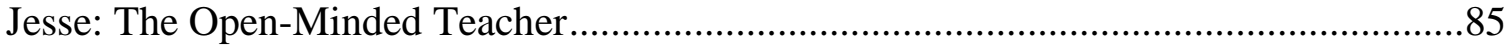

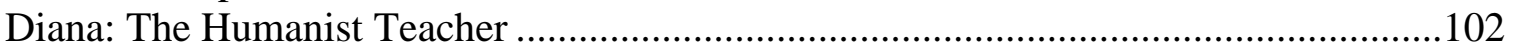




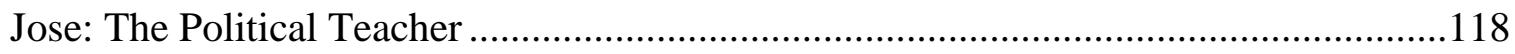

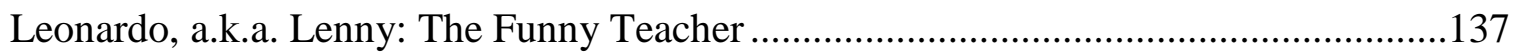

Yaimirylis, a.k.a. Yaimi: The Expressive Teacher...................................156

V. CROSS-CASE ANALYSIS: ASSUMPTIONS AND FINDINGS .........181

Theme \#1: Strength of Ethnic and Cultural Identity ......................................................183

Finding \#1: Teacher-Participants Developed A Dominant Cuban-American Cultural

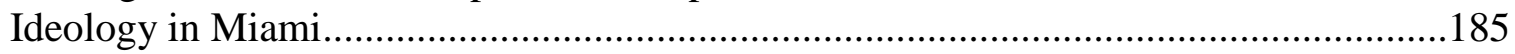

Theme \#2: Educational Beliefs on Student Learning and Teaching...............................201

Finding \#2: Teacher-Participants Believed in Student-Centered Pedagogy, but

Provided Examples of Teacher-Centered Instruction .....................................................202

Theme \#3: Perceptions of The Official Curriculum …………….................................207

Finding \#3: Teacher-Participants Accepted the Official Curriculum with Some

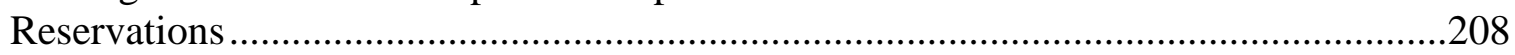

Finding \#4: Each Teacher-Participant Lacked Sufficient Skills and Dispositions in

Cultural Consciousness and Cultural Competence ……….........................................215

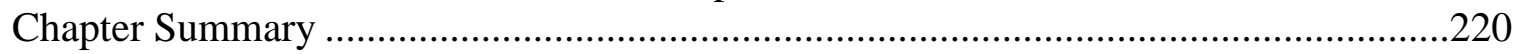

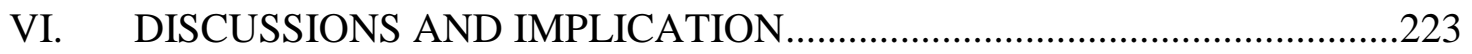

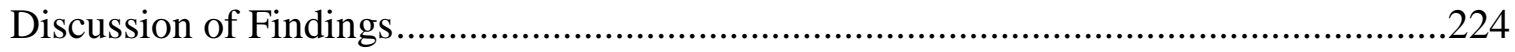

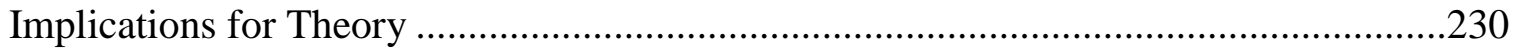

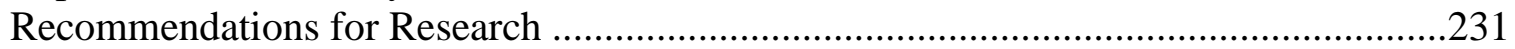

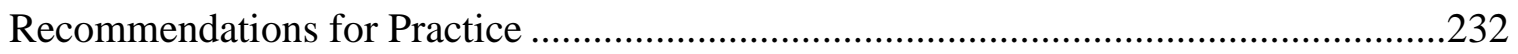

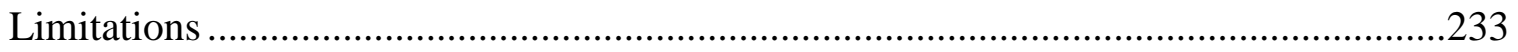

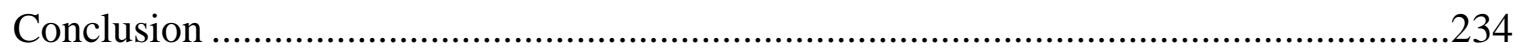

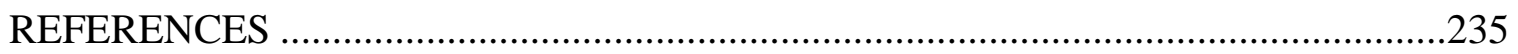

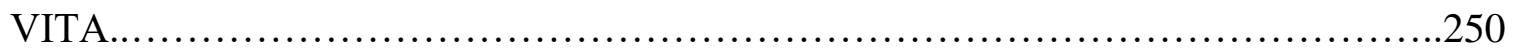




\section{CHAPTER I}

\section{INTRODUCTION}

As the student population of the United States grows increasingly diverse, teachers need to become knowledgeable of their ethnically, racially, culturally, and linguistically diverse students. Researchers agree that teachers' beliefs about teaching and learning influence and guide their educational ideologies, pedagogical practices, and curricular decisions (Davis, 2019; Fives, Lacatena, \& Gerard, 2015; Pajares, 1992; Yilmaz, 2008). Social studies teachers also interject their own interpretations, perspectives, and worldviews into their pedagogy and practices, which influence how they teach topics related to students' diversity and impact how students view social studies (Busey \& Rusell, 2016; Chandler, 2015; Epstein, 2009; Howard, 2003; Mathews, 2013; Peck \& Herriot, 2015; Salinas \& Castro, 2010; Scheiner-Fisher \& Busey, 2013). Educational researchers advocate for social studies teachers to become culturally competent educators in order to provide an inclusive and transformative pedagogy that accounts for these demographic changes (Banks, 2006; Busey, 2017; Busey \& Russell, 2016; Cruz, 2002; Epstein, 2009; Estes, 2016; Davis, 2019; Gay, 2010; 2018; LadsonBillings, 1995; Mathews, 2013; Nieto, 2004; Sanchez, 2007; Shares, 2017). An important aspect to becoming a culturally competent teacher and integrating a culturally inclusive pedagogy is a teacher's awareness of their own beliefs, perceptions, and prejudices. Gay $(2010 ; 2015 ; 2018)$ called to become aware of one's biases and perceptions as cultural consciousness.

However, studies have shown differences in cultural consciousness between nonHispanic White teachers, non-Hispanic Black teachers, and Latina/o/x teachers (Estes, 
2016; Gay, 2010; 2018; Ladson-Billings, 1995; Salinas \& Castro, 2010). Non-Hispanic White teachers, who represent most public-school teachers in the United States, have been shown to be largely lacking in cultural consciousness, cultural competence, and pedagogical skills to sufficiently instruct students of diverse backgrounds (Chen, 2016; Epstein, 2009; Estes, 2016; Gay, 2010; 2018; Ladson-Billings, 1995; Logan, 2017; Pitre \& Clark, 2016). Many Latino/a/x teachers, on the other hand, are said to teach from a sociocultural perspective of cultural inclusiveness because of similarities in their personal and cultural experiences (Chen, 2016; Dantas-Whitney \& Waldshmidt, 2009; Epstein, 2009; Estes, 2016; Gay, 2010: Gay \& Kirkland, 2003; Salinas \& Castro, 2010).

Nevertheless, the research in the field of cultural consciousness within the Latina/o/x community of teachers relating to the intersectionality of ethnic, cultural, social and experiential factors pertinent to them is limited (Davis, 2019; Salinas \& Castro, 2010; Solorzano \& Delgado-Bernal, 2001; Valdes, 1996; Villegas \& Lucas, 2002). The cultural, ethnic, social, and experiential intersectionality includes studies on Latina/o/x teachers' cultural, ethnic, racial, and linguistic identity, as well as immigration, discrimination, language preferences, geographic place, and cultural differences (Solorzano \& DelgadoBernal, 2001; Villegas \& Lucas, 2002).

One such Latina/o/x group of teachers who are often omitted from the existing scholarship are Cuban-Americans. The omission of Cuban-American teachers does not serve well the growing research of the Latina/o/x community of scholars. The current study examined the experiences of five self-identified Cuban-American social studies teachers' cultural identity in Miami, a place where they are considered the dominant 
group, for their educational beliefs on teaching and learning, pedagogical practices, and curricular decisions relative to their cultural consciousness to add to Latina/o/x research.

\section{Background and Context}

The United States Department of Education in their Digest of Educational Statistics 2017 reported that non-Hispanic Whites for the first time represented a minority of enrolled elementary and secondary public-school students; however, they made up $80 \%$ of all public-school teachers. Hispanics, Blacks, and Asians accounted for $51 \%$ of the total United States elementary and secondary public-school population, constituting for the first time a pluralistic culturally, racially, and linguistically diverse student body. In this new majority group, Hispanics or Latina/o/x students made up the largest share at $26 \%$, yet only comprised $9 \%$ of the teacher population (Digest of Educational Statistics, 2017). More importantly, Hispanic or Latina/o/x students continued to have lower achievement rates (reading and mathematics) and higher dropout rates than non-Hispanic Whites, non-Hispanic Blacks and Asians (Digest of Educational Statistics 2017; Krogstad, 2015; National Center for Educational Statistics, 2012).

Studies have shown that Latina/o/x and students of Color often felt isolated in classrooms because these institutions failed to account for their cultural, racial, ethnic, and linguistic diversity (Cruz, 2002; Davis, 2019; Gay, 2015; 2018; Ladson-Billings, 1995; Levy, 2014; Nieto, 2004; Tatum, 2017; Valenzuela, 1999). Increasingly, educational researchers have called for a more culturally responsive, relevant, and inclusive pedagogy that accounts for students of diverse backgrounds' histories, languages, cultures, ethnicities, interests, and lived experiences (Banks, 2006; Busey \& Rusell, 2016; Gay, 2010; 2018; Ladson-Billings, 1995; Mathews, 2013; Nieto, 2004). 
Culturally relevant and responsive pedagogy requires that teachers have the knowledge, skills, and attitudes to teach for cultural competence by developing a sociocultural and critical perspective, embracing multicultural education, practicing inclusive pedagogy, and engaging in a spirit of inclusivity in their classrooms (Clausen 2016; Estes, 2016; Gay, 2010; Ladson-Billings, 1995; Mathews, 2013; Nieto, 2004).

\section{Cultural Consciousness and Cultural Competence}

One important aspect of cultural consciousness is for teachers to first self-reflect, question, and develop an awareness of their own racial, ethnic, linguistic, and cultural beliefs and worldviews, as well as their own perspectives, biases, and prejudices on other different cultural, racial, ethnic, and linguistic groups (Bennet, 2007; Gay, 2010; 2018; Gay \& Kirkland, 2003; Hanvey, 2004; Pitre \& Clark, 2016; Shares, 2017). It is also important for teachers to reflect on their pedagogical practices and to build lessons that are tailored to the cultures, perspectives, and histories of student of diverse backgrounds (Banks, 2004; Davis, 2019; Epstein, 2009; Mathews, 2013). In addition, teachers need to instill a spirit of inclusivity and an affirming attitude toward instructing ethnically, racially, and linguistically diverse students so that they can make connections and build cultural bridges between them and their students (Antrop-Gonzalez, 2006; Clausen, 2016; Epstein, 2001; Estes, 2016; Gay, 2018; Ladson-Billings, 1995; Villegas \& Lucas, 2002). Educational researchers believe that developing a cultural consciousness is an integral first step in creating the predispositions, skills, and decision-making attributes needed to effectively teach the growing number of culturally, racially, ethnically, and linguistically diverse students in the United States (Chen, 2016; Davis, 2019; Gay, 2010; 2018; Gay \& Kirkland, 2003; Logan, 2017; Shares, 2017). 
Regrettably, some non-Hispanic White American teachers have been shown to be insufficiently aware of their cultural consciousness and sociocultural perspective in teaching students of diverse backgrounds (Epstein, 2009; Estes, 2016; Gay, 2010; 2018). Teachers who lack sufficient cultural awareness usually hold superficial or little knowledge of racial and ethnic groups' histories and cultures, were unprepared professionally to appropriately instruct diverse students, and failed to develop an ideology of intercultural understanding (Adams \& Busey, 2017; Chen, 2016; DantasWhitney \& Waldshmidt, 2009; Epstein, 2009; Estes, 2016; Gay, 2010; Gay \& Kirkland, 2003; Mathews, 2013). These teachers used a variety of techniques to deny or dismiss the existence of racial categories and differences, blamed individuals or groups for social inequalities, and avoided controversial subjects and discussions about racism (Gay, 2010; 2015; 2018; Gay \& Kirkland, 2003; Logan, 2017; Mathews, 2013; Shares, 2017). One technique that these teachers adopted was color-blindness, that is, to profess equality by treating all students the same and ignoring the cultural, racial, and linguistic needs of students of diverse backgrounds (Gay \& Kirkland, 2003; Logan, 2017; Shares, 2017).

However, teachers who shared a similar culture, race, or language with their students were found to better communicate, understand, and successfully instruct these students (Estes, 2016; Salinas \& Castro, 2010). Particularly, having a similar ethnicity, culture, or language helped Latina/o/x social studies teachers use their cultural competence, personal experiences with diversity and discrimination, and different learning opportunities to teach for cultural, racial, ethnic, and linguistic inclusiveness and affirm the cultural, racial, and linguistic identities of students of diverse backgrounds (Antrop-Gonzalez, 2016; Au \& Blake, 2003; Chen, 2016; Galindo, 1996; Salinas \& 
Castro, 2010; Tellez, 1999). Some researchers concluded that social studies teachers must be attentive of their cultural consciousness to incorporate a more inclusive and affirming culturally, ethnically, and racially diverse pedagogy in order to become culturally competent educators (Davis, 2019; Gay \& Kirkland, 2003; Nieto, 2004; Pitre \& Clarke, 2016 Salinas \& Castro, 2010).

Cultural similarities between teachers and students may not necessarily lead to cultural competence because teachers may hold values, beliefs, and perspectives that are more aligned to those of the dominant mainstream American cultural perspective (Au \& Blake, 2003; Tellez, 1999). In addition, Gay (2015) found that some Latina/o/x teachers who were from middle-class backgrounds tended to be lacking in cultural consciousness and typically instructed as non-Hispanic White teachers who were also unaware of their cultural biases and prejudices. Additionally, some educational researchers have pointed out that most teachers, regardless of race or ethnicity, lacked adequate culturally inclusive pedagogical training in their preservice university courses, had limited multicultural knowledge, and developed an unwillingness to change or adjust their beliefs and practices to positively educate students of diverse backgrounds (Busey \& Russell, 2016;

Gay, 2018; Mathews, 2013; Shares, 2017; Yilmaz, 2008). Clearly, developing a cultural consciousness is an important factor for improving social studies teachers' cultural competence and in developing an inclusive pedagogy for all their students.

\section{Cuban-American Cultural Identity}

Gay (2018) advised that to study a teacher's cultural consciousness, a thorough and in-depth examination of their cultural and ethnic identity is first warranted. An individual's cultural and ethnic identity can be viewed as the shared and collective 
characteristics of a group, which may include language, race, ethnicity, food, values, norms, and religion (Banks, 1996; Delgado-Gaitan \& Trueba, 1991; Nieto, 2004; Shares, 2017; Villegas \& Lucas, 2002; Weisman, 2001). Ethnic groups transmit their cultural characteristics through a socialization process recognized by the individual members (Barth, 1968). In Miami, Cuban-Americans' cultural and ethnic identity is characterized by a common history against communism and Castro, favorable immigrant experiences, bifurcation by time of arrival, bicultural acculturation and accommodation to mainstream American cultural traits, and concentration in a geographic place (Aranda, Hughes, \& Sabogal, 2014; Grenier \& Stepick, 1992; Pedraza, 2007; Perez, 1992; Portes \& Armony, 2018; Portes \& Rumbaut, 2001; 2014). The intersectionality of cultural identity formation, unique histories of ethnic groups, immigration experiences, and ethnic group solidarity with individual characteristics, like gender, sexual orientation, and degree of acculturation are important factors in the development of the teacher-participants' cultural identity and cultural consciousness.

\section{Pedagogical Beliefs and Instructional Approaches}

A teacher's cultural and ethnic identity is an influential factor in his or her pedagogical beliefs, instructional practices, and curricular decisions (Gay, 2018; Hilburn, Journell, \& Buchanan, 2016; Pajares, 1992). Teachers' educational beliefs and practices are often associated between student-centered and teacher-centered pedagogical approaches (Fives et al., 2015). Student-centered pedagogy involves an educational belief and instructional approach that students actively construct their own understandings, meanings, and knowledge in the learning process through sociocultural interactions where the teacher acts as a facilitator (Ashman \& Gillies, 2003; Fostnot, 2005; Mascolo, 
2009; Weimer, 2013; Yilmaz, 2008). Teacher-centered pedagogy involves an educational belief and instructional approach that the primary role of teaching is the dissemination of knowledge and skills from an expert or authoritative source to a passive and receptive student (Mascolo, 2009; Weimer, 2013; Yilmaz, 2008). Researchers acknowledge that student-centered pedagogy is mostly constructed around cooperative and collaborative group activities; whereas, teacher-centered pedagogy uses lectures as the primary activity of instructional practice (Cornbleth, 2001; Fostnot; 2005; Mascolo, 2009; Weimer, 2013; Windschitl, 2002). The choice of teachers' pedagogical practices is an important indicator of their cultural competence.

For instance, educational researchers have found that student-centered pedagogy has positive influences and higher qualities of learning on teachers and students because it was enjoyable, engaging, motivational, and relevant to students' lives (Sharan \& Shaulov, 1990; Weimer, 2013; Weinstein, 1989; Yilmaz, 2008) More importantly, student-centered pedagogy has been shown to benefit ethnic, racial, and linguistic minorities because it was consistent with their cooperative values, provided for exchanges of different ethnic and racial viewpoints, and allowed for sociocultural legitimacy within a small group dynamic (Busey \& Russell, 2016; Kagan, 1985; LadsonBillings, 1995; Sharan, 1990). On the other hand, studies have shown that teachercentered pedagogy contributed to rote-learning, note-taking, and boring lectures, which created social distancing between students of diverse backgrounds and White students through a lack of cultural diversity in the curriculum (Busey \& Russell, 2016; Sharan, 1990). However, some educational researchers noted that most teachers may hold ambiguous, simultaneous, and competing beliefs about the meanings and practices 
between student-centered and teacher-centered pedagogies (Fives et al., 2015; Mascolo, 2009; Windschitl, 2002). Regardless, teachers who are culturally conscious of their pedagogical beliefs and practices and their students' learning process may be better equipped to instruct from a culturally inclusive and competent perspective.

\section{Social Studies Teachers' Curricular Decisions on the Official Curriculum}

In the United States, the official curriculum comprises the state sanctioned standards, district pacing guides, state and district assessments, social studies textbooks, curricular resources, and the American historical narrative that social studies teachers use as guidelines for their ideology, pedagogy, and curricular decisions (Davis, 2019; Evans, 1989; Salinas \& Castro, 2010; Spring, 2011). The official curriculum is often viewed by researchers as representative of a dominant White, Male, Protestant, Middle-Class mainstream ideology, which often excludes, misrepresents, and stereotypes marginalized groups (Acuna, 1988; Apple, 2000; 2004; Davis, 2019; Foster, 1999: Journell, 2009; Loewen, 1995; Mathews, 2013; Noboa, 2012; Novoa, 2007; Sleeter \& Stillman, 2005; Stanley \& Longwell, 2004; Spring, 2011; Urrieta, 2005; Zinn, 2003). Social studies teachers' cultural consciousness, as reflected in their beliefs, perspectives, worldviews, political positions, are highly influential in the content they choose and their curricular decisions regarding the official curriculum and official knowledge (Gay, 2018; Hess, 2008; Peck \& Herriot, 2015; Mathews, 2013; Salinas \& Castro, 2010).

Studies on state standards have been shown to influence the official knowledge of the American story by the emphasis, whether favorable or unfavorable, it places on specific content (Davis, 2019; Heilig, Brown, \& Brown, 2012; Mathews, 2013; Sleeter \& Stillman, 2005). The state standards have also been shown to omit, minimize, mispresent, 
and generalize stories of marginalized groups into a broader unchallenged unified story of American history (An, 2016; Davis, 2019; Hilburn, et al., 2016; Mathews, 2013; Noboa, 2012; Novoa, 2017; Shear, Knowles, Soden, \& Castro, 2015; Sleeter \& Stillman, 2005; Urrieta, 2015). State tests have also been shown to influence social studies teachers' choice of content and level of adherence to the official curriculum (Grant, 2001; Hilburn et al., 2016; Vogler \& Virtue, 2007). Additionally, a critical examination of social studies textbooks found them to be lacking and devaluing of cultural diversity, reinforcing Eurocentric dominant views of official history, and omitting, misleading, and stereotyping the histories and cultures of marginalized groups (Almarza, 2001; Anderson, 2013; Busey \& Russell, 2016; Epstein, 2009; Hilburn \& Fitchett, 2012; Journell, 2008). Studies conducted on the most utilized social studies textbooks in Florida and across several states revealed that Latina/o/x groups were usually absent from pictorials and context relative to White Europeans, lacked racial and ethnic perspectives, and depicted Latina/o/x groups in negative stereotypical generalizations (Cruz, 2002; Foster, 1999; Garcia, 1980; Noboa, 2012; Novoa, 2007). As for Cubans in the American story, they were limited to only a few historical events where their participation went unacknowledged, immigration was solely for political reasons, and were depicted in dehumanizing words, such as 'herding them in camps' (Cruz, 2002). If social studies teachers believe in the truthfulness of the American story and the dominant ideological perspective found in the American history textbooks, then they reduce the Latina/o/x story to an inferior position which can have negative repercussions for Latina/o/x students (Cruz, 2012; Mathews, 2013). Hilburn, Journell, and Buchanan (2016) argued 
that social studies teachers who lacked an awareness of their cultural consciousness were more inclined to accept the official curriculum in their pedagogical beliefs and practices.

Salinas and Castro (2010) noted that Latina/o/x social studies teachers who instructed from an oppositional and disruptive pedagogy challenged the official knowledge. That is, teachers who opposed or challenged the official curriculum taught American history from an alternative interpretation, rarely utilized American history textbooks, and provided counter-stories in their instructional practices (Daniels, 2011; Epstein, 2009; Gay, 2010; 2018; Mathews, 2013; Salina \& Castro, 2010). Conversely, teachers who adhered to the information found in the state standards and American history textbooks taught from a dominant cultural perspective and were viewed as accepting the tenants of the official curriculum.

Hilburn et al. (2016) stated that teachers make the final decisions on curriculum. Subsequently, to better serve students of diverse backgrounds it is imperative that social studies teachers develop an interpretative worldview that challenges the status quo found in the official curriculum and official knowledge (Cruz, 2002; Davis, 2019; Epstein, 2009; Hilburn et al., 2016; Mathews, 2013; Salinas \& Castro, 2010). In examining teachers' beliefs through their cultural consciousness, social studies teachers may be better equipped to teach from a culturally competent and culturally inclusive perspective.

\section{Statement of the Problem}

Previous research conducted on the intersectionality and national groups of Latina/o/x teachers' cultural identity have been scarce or have tended to focus on Mexican-American or Puerto Rican teachers, lumping all other Latina/o/x teachers under one pan-ethnic category (Davis, 2019). The umbrella label does not help readers fully 
identify the individual complexities of Latina/o/x groups' histories, national origins, races, ethnicities, languages, acculturations, immigration status, gender, social classes, education, or geographic place (Aranda et al., 2014; Davis, 2019; Gimenez,1992; 2014; Salinas \& Castro, 2010). Additionally, studies on Latina/o/x teachers did not closely scrutinize them through the lens of critical Latino theory (LatCrit), that is closely examining the social and cultural concepts pertinent to Latina/o/x groups, such as favorable or unfavorable immigrant experiences, process of assimilation, acculturation, or accommodation into American society, and racial, ethnic, cultural, and linguistic discrimination (Daniels, 2011; Cobas, Duany, \& Feagin, 2009; Fernandez, 2002; Salinas \& Castro, 2010; Solorzano \& Delgado-Bernal, 2002). Additionally, these studies also failed to consider place as more than a geographical location, instead of as a space where Latina/o/x groups are influenced by the dynamics and interactions of other ethnic, racial, and cultural groups within a region (Aranda et al., 2014).

Another problem is that many researchers assume that Latina/o/x teachers are better equipped to teach from a culturally inclusive perspective and oppositional stance because of similarities in culture, experiences, and backgrounds with their students of diverse backgrounds (Estes, 2016; Rueda \& Monzo, 2002; Salinas \& Castro, 2010). However, few studies have pointed out that cultural similarities may not always necessitate a culturally inclusive pedagogy because Latina/o/x teachers may hold values and beliefs closer to mainstream American culture (Au \& Blake, 2003; Gay, 2015; Tellez, 1999; Weisman,2001). The problem is that research studies have failed to provide in-depth studies of subgroups of Latina/o/x teachers' beliefs and prejudices with subsections of cultural and ethnic identity, educational beliefs, and perspectives on curricular 
decisions (Pajares, 1992). In other words, Latina/o/x social studies teachers rarely reflect on their educational beliefs and instructional practices and how these may be perpetuating the dominant discourse. Additionally, Davis (2019) noted that most Latina/o/x social studies teachers do not critically examine the state standards, district pacing guides, and American history textbooks; therefore, they tend to accept the tenets of the official curriculum without question (Mathews, 2013). More research is needed to address the deeper insights into the nuances of Latina/o/x teachers' cultural consciousness in relation to their pedagogical practices and curricular decisions.

\section{Statement of Purpose}

The purpose of the present cross-case study was to provide an in-depth examination of how five Cuban-American social studies teachers in Miami, a city where they are viewed as the dominant culture, reflected on their ethnic and cultural identity, expressed educational beliefs on teaching and learning, made curricular decisions, and promoted culturally inclusive pedagogy relative to their cultural consciousness. Teachers must become aware of their cultural, ethnic, linguistic, racial biases and prejudices to enact an inclusive pedagogy for culturally, ethnically, racially, and linguistically diverse students. Although studies reported that Latina/o/x teachers have higher levels of cultural consciousness, this may not be applicable to all Latina/o/x groups (Au \& Blake, 2003; Nieto, 2004; Salinas \& Castro, 2010; Tellez, 1999). The examination was meant to provide information and analysis on the intersectionality of one group of Latina/o/x social studies teachers to better understand their cultural and ethnic identity, express their educational beliefs and practices, and make their curricular decisions. 


\section{Research Questions}

The following main research and sub questions were used to examine five selfidentified Cuban-American social studies teachers' cultural consciousness:

1. How did each teacher-participant describe his or her ethnic and cultural identity?

a. How did each teacher-participant describe his or her immigrant experience?

b. How did each teacher-participant define and characterize his or her cultural and ethnic identity?

c. What encounters and perceptions with ethnic, racial, linguistic or cultural discrimination did each teacher-participant experience inside or outside of Miami and within their ethnic and cultural group?

2. What was each teacher-participant's educational and epistemic beliefs on learning, teaching, and social studies?

3. What was each teacher-participant's perspective on teaching linguistically, racially, and ethnically diverse students and controversial issues?

4. What was each teacher-participant's view toward the official curriculum?

\section{Theoretical Framework}

The study utilized critical Latino theory (LatCrit) as its theoretical framework, encapsulated through the teacher-participants cultural consciousness. Critical Latino theory is considered a branch of critical Race theory (CRT) but prioritizes conceptual categories of social and cultural factors that are pertinent to Latina/o/x groups (Solorzano \& Delgado-Bernal, 2001; Valdes, 1996). Critical Latino theoretical categories include 
language, cultural and ethnic identity, immigration, phenotype, and sexuality. It places marginalized people at the center of analysis to capture their life histories and raise the individual's consciousness (Fernandez, 2002; Solorzano \& Delgado-Bernal, 2001; Valdes, 1996). The intersectionality of racism, sexism, and classism is explored to address forms of power and oppression. The narratives of the Cuban-American social studies teachers presented in the current study were framed around ethnic and cultural identity, lived immigrant experiences, stories with discrimination in the United States, and language acculturation, which are used to analyze Latina/o/x groups through a LatCrit perspective.

The categories of ethnic and cultural identity formation, educational beliefs, and curricular decisions were examined using Solorzano and Delgado-Bernal's (2001) five themes of LatCrit research. First, the teacher-participants' descriptions of their ethnic and cultural identity were analyzed as to whether they acculturated or assimilated into the dominant mainstream American culture. Also, alignment to a dominant American cultural identity, Cuban identity, pan-ethnic identity, or any other identity was explored. The immigrant experience was also examined through favorable or unfavorable lived experiences. Second, educational beliefs and practices were placed within a studentcentered or teacher-centered pedagogical approach. The purpose of the classification was to fully understand whether the teacher-participants believed and utilized instructional activities corresponding to culturally inclusive pedagogy. Finally, the teacherparticipants' curricular decisions were examined to see if the teacher-participants opposed, disrupted, or challenged the official curriculum and its dominant ideological 
narrative. Cuban-Americans in Miami represent a Latina/o/x sub-group, and their unique ethnic and cultural experiences were analyzed through LatCrit principles.

\section{Significance of Study}

The present study provides information to educational researchers, educational leaders, social scientists, scholars, teachers, students, and interested readers. For social scientists, the current study allows for discussions on cultural identity and the use of the pan-ethnic labels of Hispanic and Latina/o/x. For researchers on teachers' cultural consciousness, the current study demonstrates how a group of Cuban-American teachers use their cultural identity for pedagogical practices and curricular decisions. For educational researchers, the current study shows the importance of educational beliefs on teaching and learning. For Cuban-American scholars, the current study explores the characteristics of Cuban-American teachers' cultural identity formation and the significance of Miami as a unique cultural place for identity formation and maintenance. For social studies teachers and students, the current study helps build cultural bridges between teachers and students and allows for an inclusive pedagogy that considers all histories. More importantly, in keeping with the premise of LatCrit, the present study contributes to the research literature by adding a subgroup of Latina/o/x teachers' beliefs to LatCrit's narratives. In so doing, the current study may help open discussion on what it means to be a Latina/o/x teacher in the United States. The present study may help empower all teachers to understand their cultural biases and prejudices and challenge the official curriculum. 


\section{Delimitations}

The following study has the following delimitations:

1. The present study only focused on self-identified Cuban-American social studies teachers in Miami. The study could have expanded the region of interest to the rest of South Florida or to another city; however, the researcher selected teachers who were primarily raised in Miami because it is a city with the most Cubans or of Cuban descent in the United States. Also, in Miami, Cubans are considered the dominant culture. Additionally, Miami is a minority-majority city where Latina/o/x groups are the majority population.

2. The current study only focused on middle and secondary school social studies teachers because the researcher wanted teachers who were teaching or had taught American history classes to gain perspectives on their views of the American historical narrative and social studies curriculum. Middle and secondary school social studies teachers have also completed college courses that have focused on American history as a requirement for certification.

\section{Conceptual and Operational Definitions}

The following conceptual and operational definitions were used throughout this research study:

Acculturation-transfer of cultural norms, values, and customs from cultural and ethnic group to another usually more dominant one.

Assimilation-when one cultural group's language and customs are absorbed by another usually more dominant group 
Bicultural- selecting both cultural traits from the dominant mainstream American culture and Cuban culture, such as being fluent on both English and Spanish Color-blindness- Teach all students the same by professing equality and ignoring the cultural, racial, and linguistic needs of students of diverse backgrounds Cultural competence- having the multicultural knowledge, instructional skills, and predispositions to teach students of diverse backgrounds Cultural consciousness- a self-reflection on one's racial, ethnic, and cultural beliefs, biases and prejudices, as well as perspectives on other racial and ethnic groups. Culturally inclusive pedagogy- using students of diverse backgrounds' history, culture, race, and language in a culturally relevant, responsive, and sustaining fashion Dominant mainstream American culture- represented as White, Western European descent, English-speaking, Protestant official curriculum- are the state sanctioned standards, district pacing guides, state and district assessments, social studies textbooks, curricular resources, and the American historical narrative that social studies teachers use as guidelines for their ideological, pedagogy, and curricular decisions.

Selective acculturation- immigrant or cultural groups acquire certain cultural practices from the dominant cultural group, while maintaining their own ethnic culture. For CubanAmericans in Miami, learning English and maintaining Spanish is an example.

\section{Dissertation Overview}

The chapter provided a summary of the study's background and problem statement, purpose of study, research questions, theoretical framework, conceptual definitions, and its significance. Chapter two reviews recent literature of cultural 
consciousness, cultural and ethnic identity, educational beliefs on teaching and learning, and the official curriculum which are relevant to the study. Chapter three focuses on the rationale and significance for qualitative multiple case and cross-case analysis used in the study's methodology. It also defines critical Latino theory as a framework for analysis, as well as research design, research site, participant information, data collection methods and analysis, and researcher positionality. Chapter four provides analysis of the individual cases prior to cross-case analysis. Each case-study is a biographical account of each teacher-participant's answers to the research questions centered around the main themes of the study. Chapter five describes the assertions and findings after cross-case analysis. Chapter six discusses this study's findings and provides implications and recommendations for future research along with limitations. 


\section{CHAPTER II}

\section{LITERATURE REVIEW}

The purpose of the present study was to examine how five Cuban-American social studies teachers in Miami, a city where they are viewed as the dominant culture, reflected on their ethnic and cultural identity, expressed educational beliefs on teaching and learning, made curricular decisions, and promoted culturally inclusive pedagogy relative to their cultural consciousness. First, the researcher wanted to examine the ethnic and cultural identity of each self-identified Cuban-American social studies teachers through their individual ethnic and cultural beliefs and characteristics and how they viewed other cultural and racial groups relative to their cultural consciousness (Gay, 2010;2015). Second, the study also examined each teacher-participant's educational beliefs and perspectives on pedagogical and instructional practices in association with student-centered and teacher-centered pedagogies. Third, each teacher-participant's perspective on their curricular decision-making was explored. Finally, a summation of how each-teacher-participants instructed their culturally, racially, ethnically, and linguistic students was analyzed. A literature review is presented as a context for this study.

The review of the literature presents the conceptual framework of cultural consciousness through the formation of cultural identity and its influences on educational beliefs on teaching, learning, and curricular decisions. Chapter II is divided into three sections. The first section describes the need for an examination of teachers' cultural consciousness and the development of a culturally relevant, responsive, and inclusive pedagogy. The first section also provides the characteristics of Cuban-American cultural 
identity formation. In the case of Cuban-Americans, cultural factors, such as pan-ethnic labels, histories, national origin, race, language, traditions, norms, acculturation, socioeconomic status, immigration status, and immigration experience are described relative to other Latina/o/x groups. Also, the relationship of experiences with discrimination and place (Miami) is discussed as integral for cultural and ethnic identity formation.

The second section describes the meaning of educational beliefs on teaching and learning. The dichotomous interpretation of student-centered and teacher-centered pedagogies is described and presented. The third section looks at the official curriculum, which comprise the state and district sanctioned standards, American history textbooks and narrative, state and district assessments, and resources that social studies teachers are supposed to follow. Finally, a discussion on the importance of cultural consciousness follows.

\section{Construct of Cultural Consciousness and Cultural Competence}

As the United States has grown more culturally, racially, ethnically, and linguistically diverse, educational researchers have called for teachers to develop culturally responsive, relevant, and inclusive pedagogy to improve academic achievement, provide a spirit of inclusivity, and build cultural bridges between students, teachers, and schools (Epstein, 2009; Estes, 2016; Gay, 210;2018; Ladson-Billings, 1995; Nieto, 2004). Culturally inclusive pedagogy refers to the incorporation of students of diverse backgrounds' histories, languages, cultures, and lived experiences into the curriculum and pedagogy in order to effectively teach to their needs (Gay, 2000; 2018; Estes, 2016; Shares, 2017). Therefore, to become a culturally competent educator, a 
teacher must possess the intercultural skills, multicultural knowledge, sociocultural awareness, and utilize students of diverse backgrounds' culture, history, race, and language in the classroom, while having an affirmation for cultural diversity (Clausen, 2016; Estes, 2016; Mathews, 2013; Moule, 2011; Shares, 2017; Villegas \& Lucas, 2002).

Cultural competence can be defined as having the pedagogical ability to effectively implement and instruct culturally, ethnically, racially, and linguistically diverse students (Chen, 2016; Estes, 2016; Gay, 2010; 2018; Moule, 2011). LadsonBillings (1995; 2003) contended that culturally relevant pedagogy requires that the curriculum connects students' cultural life experiences and family knowledge with a curriculum that empowers for knowledge and academic success. In culturally relevant pedagogy, teachers honor the cultural heritages of students of diverse backgrounds while also teaching critical consciousness to question the status quo of social inequalities (Ladson-Billings, 1995; 2003). Teaching is the means by which the curriculum becomes relevant to students of diverse backgrounds, while pedagogy becomes the means to teach the skills, attitudes, and intelligence needed for student empowerment.

Gay (2018) defined culturally responsive teaching as "using the cultural knowledge, prior experiences, frames of reference, and performance styles of ethnically diverse students to make learning encounters more relevant to and effective for them" ( $p$. 36). Culturally responsive pedagogy requires the teacher to incorporate multicultural information, knowledge, and resources and draw on students' cultural heritages, community values, life experiences, and language strengths to improve students' academic achievement and self-efficacy. It means that teachers use a variety of instructional strategies for different student learning styles. Culturally responsive teachers 
approach issues from multicultural, multiethnic, multiracial, and multiple perspectives, which challenge the institutionalized policies that cause social inequalities (Gay, 2018).

More recent literature also provided justifications for becoming culturally competent educators. First, Estes' (2016) study of teacher preparation programs found that teachers need to develop beliefs for inclusiveness so that they can work with all their students to build an integrated approach to pedagogy. Similarly, Shares (2017) informed that teachers need to acknowledge, respect, and understand the cultures of students of diverse backgrounds so that they can better communicate with them. Clausen's (2017) study of student-centered practices in his classroom found that incorporating the cultures of students of diverse backgrounds helped in teaching and learning. Clausen also implied that this type of multicultural learning helped to maintain students of diverse backgrounds' own culture while integrating them into mainstream American culture. Villegas and Lucas (2002) alluded that to become a competent cultural educator, and to effectively provide culturally inclusive pedagogy, a teacher must develop a sociocultural perspective, that is, to understand that teaching is influenced by race, ethnicity, social class, and language.

\section{Cultural Consciousness}

Gay $(2010 ; 2018)$ called this type of sociocultural perspective as cultural consciousness. Cultural consciousness requires that teachers self-reflect on their own racial, ethnic, cultural, and linguistic prejudices, biases, and perspectives and how they view other cultural, racial, ethnic, and linguistic groups (Epstein, 2009; Gay, 2010; Ladson-Billings, 2003; Weisman, 2001). Teachers need to understand that their cultural beliefs and prejudices influence and shape their pedagogical practices, curricular 
decisions, and interactions with students (Gay \& Kirkland, 2003; Pitre \& Clarke, 2016; Shares, 2017). Hanvey (1982) expressed his view on sociocultural perspective in Attainment of a Global Perspective by instructing individuals to question their own stereotypes, explore their own cultural upbringing, and recognize their different cultural worldviews.

Ladson-Billings (1995) similarly surmised that teachers need to express their uncertainties and regrets regarding biased and prejudiced ideas and the impact it has on their students of diverse backgrounds. Ladson-Billings also regarded the attainment of cultural consciousness as a requisite part of becoming a competent cultural educator and for incorporating a culturally inclusive pedagogy because it effectively reveals their own biases, perspectives, and prejudices in their educational beliefs, practices, and curricular decisions. In other words, developing a cultural consciousness shows how teachers view their culturally, racially, ethnically, and linguistically diverse students. Developing a cultural consciousness benefits teacher in the process of developing an inclusive pedagogy.

\section{Non-Hispanic White Teachers' Cultural Consciousness}

However, studies showed that many non-Hispanic White teachers were lacking in cultural consciousness to effectively instruct students of diverse backgrounds within a sociocultural framework (Epstein, 2009; Castro, 2010; Gay, 2010; Hollins \& Guzman; 2005; Sleeter, 2008). Additionally, Estes' (2016) review of studies conducted on mostly non-Hispanic White teachers in pre-service or teacher preparation programs, found that most of the teachers had little or superficial multicultural knowledge and were lacking in appropriate skills to effectively instruct students of diverse backgrounds. Milner's (2003) 
study administered a cultural diversity awareness inventory (CDAI) measurement to 99 non-Hispanic White teachers and found that although the teachers agreed with the premise of cultural inclusion, most did not have adequate knowledge to integrate it into pedagogy. Russell and Russell's (2004) study also administered the CDAI to mostly nonHispanic White science teachers and found that most did not see differences between their culture and those of their culturally diverse students. Stanley's (1996) research administered the pluralism and diversity attitude assessment (PDAA), which found that most teachers believed in the concept of culture but thought it was complex because of its different components. Dee and Henkin's (2002) study similarly administered the PDAA and discovered that most teachers were strong proponents of equity and social values associated with classroom diversity. Finally, Tatto (1996) and Mathew's (2013) studies found that non-Hispanic White teachers' beliefs and values were difficult to change. One conclusion that can be drawn from the studies is that there were inadequate strategies to make meaningful change in teachers' cultural consciousness and cultural competence.

The previous studies also demonstrated that non-Hispanic White teachers used various techniques to avoid developing cultural consciousness. Logan's (2017) study spelled out some of these techniques. First, teachers often dismissed the significance of race and culture and focused on other conditions to explain disparities. Second, teachers avoided or were silent on critical discussions on race to skirt controversial social issues. Third, some teachers felt guilty over past social injustices and oppressions by committing themselves to equality and treating all students the same, regardless of racial and cultural differences. Logan also found that teachers used examples of outliers, like Obama's election to the presidency, as indicative of the end of racial inequalities. 
A strategy frequently used by non-Hispanic White teachers is colorblindness, where teachers profess that they do not see race, that there are no cultural differences, that they treat all students the same, and that they use the same instructional programs for everyone (Bonilla-Silva, 2014; Logan, 2017). Therefore, teachers who taught from a color-blind perspective avoided opportunities to critically talk about and analyze sociocultural inequalities and institutionalized school racism (Logan, 2017; Mason, 1993; Shares, 2017). The strategy of color-blindness often leads to sociocultural mismatches between teachers and students. It is an important factor in how teachers who lacked cultural consciousness approached their pedagogical beliefs and practices.

Studies showed that some social studies teachers who lacked cultural consciousness failed to critically examine the textbook, accepted the state-sanctioned curriculum, were found to have superficial knowledge and distorted perceptions of different groups and cultures, and taught history from a dominant mainstream American cultural perspective (Busey \& Russell, 2016; Chen, 2016; Daniels, 2011; Dantas-Whitney \& Waldshmidt, 2009; Davis, 2019; Epstein, 2009; Gay, 2010; Hilburn et al., 2016; Mathews, 2013; Spring, 2011). Epstein's (2009) observations of six non-Hispanic White social studies teachers found that they had inadequate training on developing different interpretations of American history, did not provide alternative explanations to events, and failed to critically examine issues like racism. Epstein noted that non-Hispanic Black students interpreted American history as a "White Man's history".

In contrast, Epstein (2009) found that non-Hispanic White students viewed American history as progressive. Epstein attributed this incongruity in interpretation to a lack of sociocultural consciousness in non-Hispanic White social studies teachers' 
cultural identity. In other words, the non-Hispanic White social studies teacher in her study lacked multicultural knowledge, intercultural skills, and experiences to effectively instruct from a culturally inclusive perspective. Gay (2018) acknowledged that teachers who did not engage in cultural consciousness lived in different worlds from their culturally diverse students.

\section{Latina/o/x Teachers' Cultural Consciousness}

However, researchers found that Latina/o/x teachers and non-Hispanic Black teachers developed cultural consciousness through their racial, cultural, and linguistic similarities and experiences with students of diverse backgrounds (Estes, 2016; Rueda \& Monzo, 2002). For Latina/o/x teachers, cultural similarities included shared personal experiences with diversity and discrimination, family and community norms and values, and multicultural knowledge that helped in promoting a culturally inclusive pedagogy with different learning opportunities (Au \& Blake, 2003; Chen 2016; Gay \& Kirkland, 2003; McLaren, 2006; Nieto, 2004; Tellez, 1999; Villegas \& Lucas, 2002). Additionally, Latina/o/x social studies teachers who were culturally conscious often challenged assumptions found in the social studies textbooks, opposed the standard curriculum, and taught from an alternative interpretation of American history (Gay, 2010; 2018; Salinas \& Castro, 2010).

Latina/o/x social studies teachers' cultural consciousness was especially evident in how some of them approached the official curriculum. The official curriculum is found in the curricular resources sanctioned by the state and is often representative of a White Male Protestant middle-class dominant culture, which has been found to exclude, distort, and misrepresent marginalized groups (Acuna, 1988; Adams \& Busey, 2017; Apple, 
1992; 2000; 2004; 2008; Busey \& Russell, 2016; Cruz, 2002; Davis, 2019; Foster, 1999:

Loewen, 1995; Mathews, 2013; Noboa, 2012; Novoa, 2007; Sleeter \& Stillman, 2005;

Stanley \& Longwell, 2004; Spring, 2011; Urrieta, 2005; Zinn, 2003). The following paragraphs reviews three research studies that reflect on how Latina/o/x social studies teachers used their cultural consciousness to disrupt and oppose information in the official curriculum, challenge cultural family norms and values, and build community cultural connections.

First, Salinas and Castro's (2010) study of two Latina/o/x social studies teachers found that they each used their past and present cultural experiences with racism, discrimination, and inequities to develop a pedagogy that challenged the information in the social studies textbooks, utilized discussions that with multiple interpretations, and provided an alternative version of the dominant historical narrative. The Latina/o/x teachers in Salinas and Castro's study recognized exclusions and stereotypes in history, understood deficit thinking, and provided competing narratives through their own prior experiences. Both Latina/o/x social studies teachers used their own counter-stories from their lived experiences to share issues of discrimination and inequality. Therefore, the teachers in Salinas and Castro's study made cultural connections with their students of diverse backgrounds by legitimizing their culture, sharing similar lived experiences, and providing a different version of American history.

Second, Tellez (1999) studied four self-identified Mexican-American female preservice teachers and found that they used their cultural knowledge and cultural competence to challenge Latina/o/x family norms and values through their own experiences. The Latina teachers in Tellez's study attacked the norm of machismo, the 
notion in which the older male is the authoritative voice of the family and the role of the female is to marry and have kids. They also challenged the role of women in society, strong parental authority, and the control it had over them. All four of the Latina female teachers in Tellez's study reported that the curriculum lacked any cultural relevance for Mexican Americans, found ways to challenge and oppose it, and taught for empowerment and social equality through their shared cultural experiences.

Third, Au and Blake's (2003) study found that social studies teachers' pedagogical beliefs and practices were influenced by the degree to which they viewed themselves as cultural insiders or outsiders within the communities they served. Being an insider in the community created a deeper understanding of social justice issues and the obstacles their students encounter in schools. The teachers demonstrated empathy, caring, and participated inside the community. Being an outsider made it tougher for the Latina/o/x social studies teachers in Au and Blakes' study to critically understand the circumstances and challenges of their students. However, both inside and outside teachers stated that they wanted to add elements of cultural diversity and cultural identity to the curriculum. The authors added influences of social class, ethnicity, and community membership to the development of cultural consciousness.

\section{Discussion of Cultural Consciousness}

Regardless of the benefits of cultural, racial, ethnic, and linguistic similarities between teachers and students of diverse backgrounds, some researchers pointed out that Latina/o/x teachers may not be culturally conscious to instruct in culturally competent fashion (Au \& Blake, 2003; Gay, 2015; Tellez, 1999). One reason is that belonging to a Latina/o/x group is complex because of different educational levels, reasons for 
immigrating, differences in lived experiences, prioritization of English and devaluation other languages, and cultural differences (Chen, 2016; Valenzuela, 2002;Villegas \& Lucas, 2002) Gay (2015) also noted that some Latina/o/x teachers may hold the same beliefs and values as their non-Hispanic White teacher counterparts, especially if they are part of the same middle-class. Latina/o/x teachers may also feel more aligned to the dominant mainstream American culture (Au \& Blake, 2003; Tellez, 1999). Latinx teachers who feel aligned to the dominant American culture may not choose to instruct in culturally inclusive ways, therefore, lacking in cultural competence.

Therefore, to study a teachers' cultural consciousness, Gay (2018) first called for an examination of a teachers' cultural identity. Gay $(2010 ; 2018)$ advised that teachers needed to develop clarity about their beliefs associated with ethnically, racially, culturally, socially, and linguistically diverse students, communities, heritages, and education. Gay advocated for teachers to self-reflect on their own values, customs, traditions that influence their beliefs. For Gay, teachers needed to critically examine their predispositions, biases, attitudes, stereotypes, and prejudices on other cultural, ethnic, racial, and linguistic groups (Barnes, 2006; Gay, 2010; 2018; Tatto \& Coupland, 2003).

The purpose of developing a cultural consciousness was to reveal a teacher's worldviews, multicultural understanding, and relations with students of diverse backgrounds to better instruct and make more informed decisions in their pedagogical practices (Epstein, 2001; 2009; Gay \& Kirkland, 2003; Pitre \& Clarke, 2016). Teachers must be able to see cultural diversity in their students as an asset to shape their sociocultural perspectives on teaching and learning (Epstein, 2009; Mason, 1993; Villegas \& Lucas, 2002). The next section is a general discussion on culture, dominant 
mainstream American culture, and cultural identity including main cultural and social factors concerning Cuban-American cultural identity formation.

\section{Cultural Identity and the Dominant Culture}

A teacher's cultural consciousness can be examined through an individual's cultural and ethnic identity (Gay, 2010; 2018). It is first useful to identify the different definitions of culture to gain a better perspective of what forms cultural and ethnic identity. Nieto (2004) defined culture as "the values, traditions, social and political relationships, and worldview created, shared, and transformed by a group of people bound to a common history, geographic location, language, social class, religion, or other shared identity" (p. 146). Delgado-Gaitan and Trueba (1991) added that culture represents shared codes and maps, norms and behaviors, and assumptions about lifestyles. Similarly, Shares (2016) identified cultural markers, such as dress, appearance, upbringing, background, foods, habits, values, norms, beliefs, and attitudes as indicative of cultural and ethnic groups. Banks (1996) noted that culture is deeply influenced by factors such as race, class, ethnicity, and social class, with language serving as an important cultural marker because it is how all these characteristics are transmitted from people to people and group to group (Weisman, 2001). In each of the definitions culture represents shared characteristics, which are acknowledged by members of the group.

When cultural groups are bounded in place, they form an ethnic group. Barth (1969) articulated that ethnic groups form their own cultural identity, and that these characteristics are ascribed to each member. Moore (1990) added that ethnic identity is an emergent collective identity characterized by how members of a group see and define themselves and how others define and see the group. Andrade (1990) also added that 
ethnic groups share a common history, culture, and a distinctive language while living in different places. By defining themselves through unique cultural conceptions, ethnic groups establish themselves as different from other ethnic groups. In a defined place, distinctive groups and large population numbers create ethnic and cultural enclaves.

However, the definition of cultural groups can also be problematic. What occurs when ethnic groups incorporate characteristics of another group? Do ethnic and cultural groups cease to identify with their original ethnic and cultural group and join the dominant one, or do they isolate themselves within their own ethnic and cultural identity? Also, are some cultural characteristics, such as race or language, a greater influence on one's cultural identity and ethnic identification? Clausen (2016) noted that culture is fluid and constantly changing according to the individual. Therefore, the formation of ethnic and cultural identity is not static but is increasingly influenced by the beliefs of the individual, as well as the passage of time or the degree of racial prejudice and discrimination against that group (Gay, 2010; Pajares, 1992).

The United States is considered a multicultural society; however, there exists a dominant mainstream American culture characterized as non-Hispanic, middle-class, and Protestant with values and notions of individualism, competition, work ethic, and English as the standard language (Spring, 2011). In terms of cultural and ethnic identity, an individual may be considered assimilated according to the traits they share with the dominant mainstream American cultural group (Au \& Blake, 2003). Therefore, there exists a collective mainstream American cultural identity, which all other cultural and ethnic groups are judged according to shared characteristics with the dominant culture (Bonilla-Silva, 2014). Individuals may develop their cultural and ethnic identities 
dependent on how close they feel aligned to the dominant culture. Some characteristics include color of skin, phenotype, social-class, and education level. For teachers, aligning to the dominant culture may influence the nature of their cultural and ethnic identity, but also impacts their educational beliefs and pedagogical practices (Gay, 2010).

\section{Cuban Cultural Identity}

Culture and ethnic identity are formed through shared cultural characteristics, experiences with other ethnic and cultural groups, and geographic concentration. To understand the makeup of Cuban-American culture in Miami, it is noteworthy to identify which characteristics make up Cuban and Cuban-American culture. Cuban cultural identity will be examined through its relationship with other Latina/o/x groups which have settled in the south Florida region. The topics under investigation include: (a) immigrant experience; (b) association to pan-ethnic labels; (c) perception of race; (d) language adaptation; (e) educational achievement; (f) acculturation or assimilation; (g) experiences with discrimination; (h) relationship to the dominant culture.

\section{Immigration Experience}

For Cuban-Americans, the year of arrival to the United States is the most salient feature in their immigrant experience. Cuban researchers have identified five significant immigration waves: (a) Golden Exiles (1959-1962); (b) Freedom Flights (1970’s); (c) Mariel exodus of 1980; (d) Balseros of the 1990's; (e) "wet foot/dry foot" policy from 1995 to 2017. Each wave was diverse and encompassed different sociocultural classes

(Aranda et al., 2014; Pedraza, 2007; Perez, 1992; Portes \& Armony, 2018). Each Cuban immigrant wave represented a different version of Cuban culture. 
The first Cuban immigrants arrived from 1959-1962 after Castro’s communist revolution. They are often called the Golden Exiles because they were composed mainly of the elites in Cuban society (Pedraza, 2007; Perez, 1992). The first wave was mostly White, middle class, and professional with a strong animosity against Castro and communism (Pedraza, 2007; Perez, 1992). Some Cuban researchers credit the Golden Exiles and their offspring with creating a powerful politically, economically, socially, and culturally Cuban enclave in Miami (Eckstein, 2009; Cortina, 1990; Garcia, 1996; Pedraza, 2007; Perez, 1992; Portes \& Armony, 2018). The Cuban enclave was established in a geographical area that had an educated and bilingual workforce, which allowed for economic development and subsequently political and cultural power (Portes \& Armony, 2018).

The second wave from 1965 to 1974 was mostly composed of the lower-tomiddle class and those who already had family members residing in the United States (Perez, 1992). These Cuban migrants had lived under Castro for a few years and were often jailed or forced into work camps because of their political and religious beliefs (Pedraza, 2007; Perez, 1992). The first two waves of Cuban immigrants are considered privileged relative to Cuban society. They were provided with material support by the United States government because they fled communism during the Cold War (Duany, 2011).

The first two waves of Cuban immigrant groups initially experienced discrimination in the United States by the mostly non-Hispanic White Miami leaders in Miami through the anti-bilingual movement and the Miami Herald's editorializing (Portes \& Stepick, 1993). The discrimination and hostility encountered by the first two 
waves of Cuban immigrants living in Miami during the 1970s and 1980s contributed to the development of ethnic solidarity, stronger cultural bonds, and a purpose to improve their self-image (Portes, 2010; Portes \& Stepick, 1993). Portes (2010) noted, the discrimination felt by Cubans during the 1970s and 1980s, helped shape their cultural identity. Portes and Stepick (1993) added that the emergence of reactionary formation, the solidarity around discrimination aimed at them, created stronger bonds, which helped to build a strong Cuban community. It is also responsible for the emergence of CubanAmerican biculturalism. However, Portes and Armony (2018) added that the bifurcation of the Cuban community began with the arrival of the third wave of Cuban immigrants in 1980.

The third wave was the Mariel exodus of 1980, a massive boatlift from the port of Mariel in Cuba that brought an estimated 125, 000 Cuban refugees between April and October of that year to Miami (Pedraza, 2007; Perez, 1992). These Cuban immigrants were starkly different than the previous Cuban immigrant waves, with a larger share of dark skinned, single, young, male, working-class persons, who left Cuba primary for economic reasons (Pedraza, 2007; Perez, 1992). Portes and Stepick (1993) pointed out that the older Cubans, those from the first two waves of Cuban immigrants, distanced themselves from these newly arrived Marielitos. Thus, began the social and cultural distancing between the first two waves of Cuban immigrants and the subsequent waves of Cuban immigrants (Aranda et al., 2014; Pedraza, 2007; Portes \& Armony, 2018).

The fourth wave is often referred to as the Balseros because the Cuban immigrants trickled into Miami throughout the 1990s sometimes in improvised boats (Pedraza, 2007). The Balseros were mostly young men and comprised all the Cuban 
social classes and racial compositions of Cuba (Pedraza, 2007). They had lived under Castro and communism, sometimes for their entire lives, and left Cuba primarily for economic reasons (Pedraza, 2007). Because each Cuban immigrant group represents different economic, political, racial, social, and even cultural groups, they can be divided into a pre-Mariel and post-Mariel group of Cuban immigrant groups with different immigrant experiences (Aranda et al., 2014; Portes \& Armony, 2018).

The fifth wave is typically called the "wet foot/dry foot" period form 1995 onward until its repeal by the Obama administration in 2017. The policy allowed Cubans to legally enter the United States if they set "foot" on land. If they were caught at sea, they were repatriated back to Cuba. Portes \& Armony (2018) contended that Castro allowed this to continue because of the remittances sent from the Cubans fleeing the island. Therefore, most of the refugees were leaving Cuba primarily for economic reasons. In the current study, not one teacher-participant is a "wet foot/dry foot" Cuban immigrant.

The immigration experience in the following section will be defined as to how each Latina/o/x group was treated materially and socially upon its arrival to the United States. The immigrant experience will be referred to as mode of incorporation. First, Portes and Rumbaut's (2014) study reviewed four categories for mode of incorporation in both governmental terms, how the U.S. received migrants, and societal, how American society viewed them.

The categories are: (a) favorable, (b) hostile, (c) prejudiced, and (d) neutral. The favorable category refers to groups composed of legal refugees and asylees. These groups were provided with economic assistance in order to incorporate faster and easier 
into the American economic and social system. They usually experienced very little discrimination and were considered a positive addition to American society. The prejudiced category included groups perceived as being involved with the drug trade and crime, and usually defined as non-White immigrants. These groups experienced extensive discrimination, whether they were legal or illegal immigrants, in terms of stereotypes and racial biases. The neutral category refers to legal immigrants defined as mostly White. These groups experienced some discrimination. The hostile category refers to groups suspected of having large unauthorized immigrants and targets for deportation usually from Mexico. These groups were provided with little or no assistance by the United States government and vilified by American society. They experienced the highest level of discrimination.

Portes and Rumbaut's (2014) study demonstrated the uniqueness of the CubanAmerican case for mode of incorporation. Out of all the Latina/ox groups in the governmental category, pre-Mariel Cubans claimed the only favorable rating. In contrast, Mexicans, Colombians, and Nicaraguans all received hostile ratings. It is important to note that Cubans also received a rating of hostile for those who belonged to the postMariel group. In societal terms, Cubans received the only neutral rating. All the other Latina/o/x nationalities received prejudiced scores. Once again for post-Mariel Cuban immigrants this score dropped to prejudiced.

The favorable governmental and societal ratings the pre-Mariel Cuban immigrants received may indicate that they were accepted without discrimination into Miami. However, as Portes and Stepick (1993) recounted in City on the Edge, Cubans in Miami from their initial arrival up until the 1980s did experience cultural and linguistic 
discrimination. Portes and Stepick pointed out that the anti-bilingual amendment and the negative campaign by the Miami Herald during the 1970s contributed to a coalescing of the Cuban community in bonded solidarity. Cubans' collective action strengthened their political, economic, and subsequently social and cultural power within Miami and helped to create the Cuban enclave (Aranda et al., 2014; Cortina, 1990; Perez, 1992; Portes \& Stepick, 1993; Portes \& Armony, 2018: Stepick, et al., 2003). Consequently, the strengthening of the Cuban-American community may partly be categorized as having favorable modes of incorporation experienced by the pre-Mariel group of Cuban immigrants. More will be discussed about this later in the study.

\section{Association to the Pan-Ethnic Labels Hispanic and Latina/o/x}

Both Pan-ethnic labels of Hispanic, and Latino (the use of Latino instead of Latina/o/x in this section is because of historical precedent) refer to a mixing of people who may share a common language and other characteristics with people who have different histories, nationalities, races, generations, social class, and locations under one umbrella (Gimenez, 1992; Itzigsohn \& Dore-Cabral, 2000; Lopez \& Espiritu, 1990). Most of the research agrees that the Hispanic, Latino, and recent Latinx pan-ethnic labels are a political and social construction (Espiritu, 1992: Padilla, 1984; 1985). A brief description of how each of these pan-ethnic labels were enacted is worth noting.

The label Hispanic has its political start from Public Law 94-311in 1976. It was placed as a separate category for the first time in the United States Census of 1980. The United States government, pressured mainly by Mexican and Puerto Rican groups during the Civil Rights era, created a Hispanic category to answer the question of both race and ethnicity (Fergus, Noguera \& Martin, 2010). However, as Gimenez (2014) pointed out, 
the Hispanic pan-ethnic label was also for government statistical purposes used for comparability of samples and greater population data. It was easier for researchers to label one group of people under the guise of one category than to separate them into a more detailed definition of their ethnic characteristics. The problem is that there is no self-identifiable group called Hispanic. Instead, Hispanic groups are made up of many histories with no single coherent community, different races, many ethnicities, religions, social classes, generations, and even languages with the only commonality being that Hispanics are of Spanish and Latin American origin (Gimenez, 2014; Denton \& Massey, 1989; Massey, 1993).

In response, some groups chose instead to be called Latino because they saw Hispanic as colonialist and imperialist (Acuna, 1988). Some Latina/o/x scholars postulated that the term Hispanic was a method to place South Americans, Central Americans, and Spanish-speaking Caribbean, within the American racial binary classification system, White and Black, by defining a similar phenotype, language, and cultural characteristics as a racial group (Bean \& Tienda, 1987; Bonilla-Silva, 2014; Cobas, Duany, \& Feagin, 2009; Cornell \& Hartmann, 1998). Padilla (1984) named this new Latino ethnic consciousness as Latinidad or Latinismo, meaning a congregation of a diverse group of people with different languages and cultures, yet sharing the same history and colonial heritage, and emigrating from Central America, South America, and Caribbean.

The Latino label is also problematic because it lumps people that do not share the histories of oppression into the same minority status as those that did experience them, such as Portuguese speaking Brazilians or Antillean Caribbean people (Gimenez, 2014). 
Some groups, including Cuban-Americans, associated Latino primarily with Mexican and Puerto Rican and sought to dissociate themselves from such a label (Wortham, Murillo, \& Hamman, 2002). Nevertheless, pan-ethnic researchers agree that most Latinos or Hispanics prefer to identify with their country or family's country of origin (Duany, 2003; Portes \& MacLeod, 1996; Portes \& Rumbaut, 2001; 2014).

Latinx is a label recently used to denote a gender-neutral label. It seeks to erase the colonial aspects of the Spanish masculine, Latino, and instead add other identities, such as queer and transgender to end gender-biases. A Google search of the term revealed many issues ranging from confusion to outright hostility for its use and incorporation into research. For the purposes of the current study, Latina/o/x is used to avoid any confusion with the label.

Portes and Rumbaut (2014) conducted a survey of second-generation immigrant groups in Miami. The subjects had to choose between being self-identified as a foreign national, a hyphenated American, or a pan-ethnic label. Portes and Rumbaut study found that Cubans were the least likely to choose the pan-ethnic label. Instead, Cubans overwhelmingly chose at $78 \%$ to be identified with the Cuban-American label. No other Latina/o/x group reached 30\% for hyphenated American. Cubans also were the highest percentage groups to select the non-hyphenated American category at 10\%. The two largest Latina/o/x groups that chose foreign national origin were the Mexicans and Nicaraguans. The two largest groups in the pan-ethnic category of Hispanic were Dominicans and Colombians.

The results indicate that Cuban-Americans view themselves as having both a Cuban and American culture than any other pan-ethnic Hispanic or Latina/o/x group. 
Aranda, Hughes, and Sabogal, (2014) noted that most Cubans in Miami do not feel a solidarity with any other Latina/o/x group. Cortina (1990) reported that Cubans in Miami usually did not want to share with other pan-ethnic groups the economic, political, and social power that they have acquired; therefore, they refused to build coalitions of interest with them. The lack of pan-ethnic identification and solidarity has led Cuban-Americans between 1980 and 2010 to focus on their national identity, although this may be changing to a pan-Hispanic label because of intermarriage amongst Latina/o/x groups in Miami.

Some pan-ethnic researchers proposed that the Latina/o/x groups chose pan-ethnic labels as a form of ethnic or racial identifier for political power, common interests, and interethnic relations; however, since Cubans in Miami had the largest demographics, this interethnic union did not materialize (Itzigsohn \& Dore-Cabral, 2000; Padilla, 1984; 1985; Portes \& MacLeod, 1996). Lastly, Vidal de Haymes (1997) stated that labeling Cuban-Americans as an economic success story, created hierarchical divisions with other Latina/o/x groups and prevented the building of multiethnic coalitions to fight oppressive institutions. The results indicate that Cuban-Americans in Miami traditionally viewed themselves as unique, thus shunning the pan-ethnic labels of Hispanic or Latina/o/x.

\section{Perceptions on Race}

In 2010, the United States Census reported that $85 \%$ of Cubans identified as White, the highest of all Hispanic groups. The second largest group reported as White were the Mexicans and Puerto Ricans at $47 \%$. Dominicans were the largest group to identify as Black. The results of these racial surveys are noteworthy because CubanAmericans often see themselves as racially White relative to other Latina/o/x groups. As the study below shows, this is especially the case in Miami. 
Portes and Rumbaut's (2014) survey indicated that Cubans in Miami were the largest group of Latina/o/x that reported themselves as White at $93 \%$. The next largest Latina/o/x group in Miami who reported as White were the Nicaraguans at $68 \%$.

However, Mexicans, who constitute a majority of Latina/o/x groups in the United States, reported only $6 \%$ as White.

Cobas, Duany, and Feagin (2009) in How the United States Racialize Latinos surmised that the American racial classification system racialized Latina/o/x groups in generalizable terms by their physical characteristics, negative views of Spanish and bilingualism, stereotypical images of poverty, and unfavorable mode of incorporation. In the racial binary hierarchical system, non-Hispanic Whites are placed at the top and nonHispanic Blacks at the bottom, with Latina/o/x in the middle (Garcia, 2009; Rumbaut, 2009). Bonilla-Silva (2014), however, alluded that Cubans have become Honorary Whites in the American racial classification system. Bonilla-Silva affirmed that Cubans have benefited economically, socially, politically, and culturally from being defined as White by mainstream American culture. In Miami, Aranda et al. (2014) argued that Cubans have taken the place of non-Hispanic Whites in Miami's racial hierarchical system because of their historical backgrounds and their higher social, political, and legal status over other Latina/o/x groups. The belief that Cuban-Americans are at the top of the racial classification system within Miami, has led Aranda, Chang, and Sabogal (2009) to name it a "myth of Cuban cultural superiority" in the region. Portes and Armony (2018) cautioned, however, that the social and political benefits of being classified as White was applicable to mostly the pre-Mariel group of Cuban immigrants and their second and third generation offspring. 


\section{Language Adaptation to English}

Language is considered the most important cultural marker because it is the vehicle for cultural transmission (Banks, 2006; Fairclough, 1989; Linn, 2011; Weisman, 2001). English is also considered the language of the dominant culture in the United States (Spring, 2011). Portes and Rumbaut (2014) measured language discrimination and adaptation through levels of bilingualism in Latina/o/x groups. The levels were: (a) fluent bilingualism which represents knowing English very well and at least knowing Spanish well; (b) English dominant which represents having fluency in English, but much weaker in Spanish; (c) foreign dominant which means speaking Spanish very well but less fluent in English; (d) limited bilingualism, which means having lost fluency in Spanish, but have not acquired command of English.

The highest percentage of fluent bilinguals were Cuban-Americans at $67 \%$. In comparison, no other Latina/o/x group reached $50 \%$ in fluent bilingualism. Portes and Rumbaut (2014) found that these great disparities between Cuban-Americans and other Latina/o/x groups were reflective of their ethnic and cultural identity as well as their concentration in the bilingual city of Miami. Most Cuban-Americans in Miami have learned the language of the dominant mainstream American culture while maintaining Spanish, the dominant language of Miami (Aranda et al., 2014).

\section{Levels of Educational Achievement}

Cuban-Americans have the highest education and student achievement rate of any Latina/o/x group in the United States. At 25\%, they hold the most college degrees, which is twice the average of any other Latinx groups (Portes \& Rumbaut, 2014). Portes and Rumbaut (2014) also found that Cuban-Americans had the annual average salaries over 
50,000 a year, more than any other Latina/o/x group. The results indicate that CubanAmericans have higher socioeconomic status than any other Latina/o/x group because they hold higher levels of education. It also means that they are more likely to belong to the middle-class.

\section{Acculturation}

Acculturation or accommodation refers to how well an immigrant person adapts to mainstream American life, and how an ethnic or cultural group leaves behind its home culture or forms a different one (Portes \& Rumbaut, 2014). Portes and Rumbaut (2014) identified three levels: dissonant acculturation, consonant acculturation, and selective acculturation. Dissonant acculturation represents the lowest level, where both parents and children fail to adjust to American culture, which may lead to intercultural confrontations. Consonant acculturation represents a middle ground, where the loss of

the home culture is roughly occurring at the same time as acquiring an American culture. Selective acculturation represents the highest level, where a co-ethnic community with enough size slows down cultural change and conflict while retaining parts of the home culture.

Unsurprisingly, Portes and Rumbaut (2001; 2014) found that Cubans selectively acculturated because they chose to learn English and maintain Spanish as their home language, thus becoming fluent bilinguals. Portes and MacLeod (1996) added that for Cuban-Americans in Miami's selective acculturation slowed down the process of acculturation through the development of a bicultural identity, which embraced both Cuban and American cultural traits (Portes \& Stepick, 1993). Apart from Spanish, Cuban-Americans in Miami were also able to retain Cuban cultural norms, practices, 
traditions, food, and the exile ideology, which stipulates an enmity towards Castro and communism reinforced through the bonds of ethnic nationalistic solidarity (Grenier \& Perez, 2003; Pedraza, 2007; Perez, 1992). Therefore, many Cuban cultural characteristics were passed down to their acculturated second-generation Cuban-American children (Portes \& Armony, 2018).

The research on cultural characteristics also makes apparent that CubanAmericans increasingly align themselves to mainstream American culture. They selfidentified as both Cuban and American in hyphenated form and disassociated from panethnic group identification. Most Cuban-Americans saw themselves as White in America's racial classification system and had higher education rates which led to middle-class status. Moreover, Perez (1992) found that Miami Cubans also built support for the Republican party and focused on electoral participation in U.S. politics after obtaining United States citizenship. Through the experience of exile, Cuban-Americans in Miami maintained their national identity and chose which American cultural characteristics best served them economically, politically, culturally, and socially in the Cuban enclave of Miami.

\section{Cuban-Americans in Miami as the Dominant Culture}

The 2010 United States Census reported that Hispanics make up 60\% of the people living in Miami-Dade County, with more than half identifying as Cuban, Cubanborn or of Cuban descent (Portes \& Armony, 2018; U.S. Census, 2015). Cubans in Miami have the demographic, political power, and cultural influence to be called the dominant culture in Miami (Aranda et al., 2014; Cortina, 1990; Stepick et al., 2003). 
Therefore, Cubans have made Miami their preferred place of residence (Aranda et al., 2014).

Portes and Armony (2018) called Miami a focus of acculturation in reverse because Cuban and Hispanic customs, institutions, language, and toleration for immigrants are the norm, leading to biculturalism. In this context, Cubans in Miami have redefined Americanness because Latin American and Caribbean minorities have become the majority, and the power structure is governed by Cuban migrants and their offspring (Portes \& Armony, 2018). Portes and Amory called the mainstream of Miami completely Hispanic, with Cubans in power.

Subsequently, Cubans in Miami were the least likely Latina/o/x group to report feeling discriminated (Aranda et al., 2014). In comparison, Mexicans, the most populous minority group in the United States, reported feeling discriminated $66 \%$ of the time (Aranda et al., 2014; Portes \& Rumbaut, 2001; 2014). However, Aranda, Hughes, and Sabogal (2014) also discovered that non-Cuban Latina/o/x groups often felt discriminated by Cubans in Miami. Experiences with discrimination may show whether a cultural and ethnic group is accepted by American mainstream culture. Therefore, the feeling of discrimination by non-Cuban Latina/o/x groups reinforces the notion that CubanAmericans are the dominant cultural group in Miami.

Additionally, Cubans who arrived in the two Cuban immigrant waves prior to Mariel in 1980 frequently discriminate against the post-Mariel Cuban immigrants in what may be referred to as the bifurcation of the Cuban community (Aranda et al., 2014; Portes \& Armony, 2018). The bifurcation of Cuban immigrant groups created cultural and social distancing where the pre-Mariel group harbored negative feelings toward the 
post-Mariel group over differences in race, social class, education, political ideologies, and the strength of animosity toward Castro and communism (Aranda et al., 2014; Eckstein, 2009; Garcia, 1996; Pedraza, 2007; Perez, 1992: Portes \& Armony, 2018). The older generation exhibited feelings of cultural superiority over the post-Mariel group because they had fled Castro and communism; whereas, members of the post-Mariel group had lived under Castro and communism (Aranda, Chang, \& Sabogal, 2009). The pre-Mariel group typically see themselves as political exiles and look down at the postMariel group as economic migrants. The demographic, political power, and sociocultural dominance demonstrate Cuban-Americans, especially those from pre-Mariel group and their children, are the dominant cultural group in Miami.

\section{Educational Beliefs on Teaching and Learning}

Research has indicated that teachers' beliefs shape their educational ideology, pedagogical practices, and curricular decisions (Barton \& Levstik 2014; Davis, 2019; Fives et al., 2015; Gay, 2018; Pajares, 1992; Salinas \& Castro, 2010; Yilmaz, 2008). Pajares (1992) noted that all teachers hold beliefs about their roles and responsibilities, their students, and the subject matter (Evans, 1988; 1989; Pajares, 1992; Peck \& Herriot, 2015). Beliefs are also a product of our past and present experiences, cultural transmissions of knowledge, and decisions made throughout our lives (Bandura, 1986, Nespor, 1987; Pajares, 1992; Salinas \& Castro, 2010). Teacher beliefs influences the curriculum, instruction, and pedagogy (Busey \& Russell, 2016; Epstein, 2009; Hilburn et al., 2016; Mathews, 2013; Peck \& Herriot, 2015; Porter \& Freeman, 1986). However, teachers' educational beliefs are complex, but are an important aspect of teachers' instructional practices and curricular decisions. 
Fives et al. (2015) pointed out that teachers' beliefs about teaching and learning serve as filters which guide practices and instruction (Busey \& Russell, 2016; Mathews, 2013). Previous schooling experiences with teachers also influence the beliefs of teachers and their instructional practices (Windschitl, 2002). Therefore, before teachers enter the classroom, they already have beliefs on how students learn, which methods are appropriate for instruction, and how they will plan, implement, and evaluate the curriculum. Generally, teachers ask questions, such as (a) how instruction should be performed, (b) what methods are effective, (c) who is responsible for knowledge, and (d) which type of assessment works best (Fives, et al., 2015).

\section{Student-Centered Pedagogy and Teacher-Centered Pedagogy}

Fives et al. (2015) acknowledged that most teachers' educational beliefs on teaching and learning are grounded between the dichotomous view of student-centered and teacher-centered pedagogy. Student-centered pedagogy is sometimes referred to as constructivist learning theory (CLT) because it consists of students' active engagement in constructing their own knowledge (Fives, et al. 2015; Fostnot, 2005). Student-centered pedagogy involves sociocultural interactions between students and teachers and transformation of existing knowledge into new information for meaningful learning (Mascolo, 2009; Windschitl, 2002; Yilmaz, 2008). In student-centered pedagogy the teacher acts as a facilitator by guiding instruction to students' interests and needs (Weimer, 2013).

Student-centered pedagogy often leads to activities that are learner-centered. The purpose of student-centered pedagogy is to assist students in self-direction, engage in sociocultural experiences with other students, challenge existing beliefs, and develop an 
outlook of multiple perspectives for student ownership of the learning process (Ashman \& Gillies, 2003; Fostnot, 1996; Mascolo, 2009; Weimer, 2013; Villegas \& Lucas, 2002; Yilmaz, 2008). Some notable teacher-centered pedagogical activities include cooperative/collaborative learning that involve individual or small group goals, division of labor, and group rewards (Ashman \& Gillies, 2003; Knight \& Bohlmeyer, 1990; Sharan, 1990). Additional activities pertain to problem-based learning where groups of students collaborate to solve a problem and experiential learning where groups of students use direct action, experience, and reflection as inquiry into issues.

Teacher-centered pedagogy follows the theoretical basis that the transmission of knowledge is passed down from a knowledgeable and more experienced source to a less knowledgeable and novice recipient (Cicelli, 1983; Mascolo, 2009). The teachers' role is to guide by establishing and enforcing rules, determining task involvement and completion, explaining lesson objectives, and summarizing conclusions of lessons (Mascolo, 2009). Some teacher-directed pedagogical activities include reading textbooks, answering standardized worksheets, and note-taking. The most common used teacherdirected instructional activity is the lecture, where the teacher communicates new knowledge, gains feedback through right/wrong answers in discussion, and uses recall and recognition for assessment, usually in a competitive atmosphere (Mascolo, 2009).

Most educational researchers acknowledged that student-centered pedagogy provided a positive influence to learning because it was enjoyable, engaging, and motivational for students and teachers (Sharan \& Shaulov, 1990; Weimer, 2013; Yilmaz, 2008). Student-centered pedagogy also benefited students of diverse backgrounds because it made learning relevant to diverse students' lives, was consistent with their 
cooperative values, and allowed for multiple perspectives to challenge the status quo and to affirm their identities (Busey \& Russell, 2016; Davis, 2019; Kagan, 1985; LadsonBillings, 1995; Nieto, 2004; Sharan, 1990). In opposition, teacher-centered pedagogy was depicted as contributing to rote-learning, direct instruction, long lectures, and has been attributed to social and cultural distancing between White students and students of diverse backgrounds (Busey \& Russell, 2016; Cuban, 1991; Lucy, Shifflet, \& Weilbacher, 2014; Windschitl, 2002). However, despite the positive attributes of studentcentered pedagogy, most teachers continue to utilize teacher-centered pedagogy as their main instructional activity (Busey \& Russell, 2016; Cuban, 1991; Windschitl, 2002; Yilmaz, 2008).

Windschitl (2002) discovered that teachers plan for instruction with activities in mind first, rather than think of how students learn. They also chose teacher-centered and collaborative activities, like projects, but in a teacher-controlled setting (Hargreaves, 1994). Windschitl also blamed the ubiquitous use of teacher-centered pedagogies on how teachers are primarily educated, through traditional teacher-directed activities, which they later find difficult to break away from. Weimer's (2013) contentions were that many teachers liked being the center of instruction, believed that student-centered pedagogy diminished their role as educators, and developed a feeling of importance for making curricular decisions. However, as Fives et al. (2015) cautioned, teachers simultaneously hold competing and different beliefs about teaching and learning in various situations.

\section{The Official Curriculum}

For social studies teachers, instructional practices and curricular decisions are often influenced by the official curriculum as represented in the state standards, district 
curriculum, and the dominant American historical narrative found in American history textbooks that is sanctioned and codified by the state (Apple, 2000; 2004; 2008; Davis, 2018; Mathews, 2013; Salinas \& Castro, 2010; Spring, 2011). The official curriculum is viewed by some researchers as the guidelines social studies teachers' use for their pedagogy, which is often representative of the dominant White, Male, Middle-Class, and Protestant dominant cultural ideology (Apple, 2000, 2004; Busey \& Russell, 2016; Davis, 2019; Epstein, 2009; Evans, 1989; Loewen, 1995; Mathews, 2013; Stanley \& Longwell, 2004; Salinas \& Castro, 2010; Urrieta, 2005; Zinn, 2003).

The official curriculum has also been shown to exclude, misrepresent, generalize, and stereotype marginalized groups in favor of perpetuating an European American perspective and a dominant unified American story (Acuna, 1988; Adams \& Busey, 2017; Busey, 2017; Cruz, 2002; Davis, 2019; Epstein, 2009; Foster, 1999; Hilburn et al., 2016; Mathews, 2013; McClaren, 2000; Su, An, \& Forest, 2017; Urrieta, 2005; VanSledright, 2002). Teachers rarely challenged or critically examined the official curriculum because they lack appropriate knowledge and the information makes it easier for them to follow (Mathews, 2013; Sleeter \& Stillman, 2005). More importantly, because many social studies teachers are unaware of their cultural consciousness, that is their beliefs, biases, and perspectives, they tend to teach toward the official curriculum (Davis, 2019; Epstein, 2009; Gay, 2018; Hilburn et al., 2016; Mathews, 2013; Salinas \& Castro, 2010). The importance of the official curriculum for social studies teachers' pedagogy is evident and worth critically examining. 


\section{State Standards}

The social studies state standards are often used to develop district guidelines, standardized tests, and are referenced when states choose textbooks (Davis, 2019). They are often contentious because of the battle over multiple interpretations of knowledge and on the representation of American history (Apple, 1992; Mathews, 2013; Spring, 2011). The standards represent sanctioned knowledge and are extremely political (Apple, 1992; Epstein, 2009; Spring, 2011). They are enacted through government channels, without much civilian control, usually in the form of appointed committees (Davis, 2019; Spring, 2011). They are designed to provide greater state control over the school curriculum and the content of instruction (Apple, 2004; Spring, 2011).

Studies on state standards showed how immigrants are portrayed and the frequency minority groups are mentioned. In an analysis of the California State Standards, Sleeter and Stillman (2005) found no mention of culturally relevant knowledge, multicultural justice, or sociocultural approaches. Sleeter and Stillman's study also revealed that the standards avoided any conflicts, and when racial, cultural, and linguistic diversity were mentioned, it was usually in a hierarchical structure, making marginalized groups inferior to the dominant culture. Sleeter and Stillman also noted that when the state standards added immigration, it was contained through an immigrant paradigm which placed immigrants in the American historical narrative in search of the American dream. Mathew's (2013) qualitative study noted that the immigrant paradigm largely depicted minority groups as dependent on European Americans, ignored various historical reasons for immigration, and provided an illusion that America had moved past racial, class, gender, and sexual inequalities. In other words, the state standards largely 
ignored the perspectives of immigrant and marginalized groups, denied any mention of alternative histories, or placed them within a Eurocentric perspective.

Hilburn et al.'s (2016) content analysis of 18 state standards using a critical race methodology revealed three tensions among themes of: (a) a unified American story versus local histories; (b) immigration presented in historical terms versus immigration as a civic issue; (c) favorable versus unfavorable presentations of immigrant groups. Immigrant groups were presented only if they did not disrupt the American story, which was epitomized by hard work, assimilation, and economic contributions (McLaren, 2000; Su et al., 2015; VanSledright, 2010). Hilburn, et al.'s findings indicated that state standards followed mostly a nationalist discourse on immigration, blamed cultural conflict on immigration, and depicted immigrant groups through homogeneous characteristics.

Davis' (2019) qualitative and quantitative examination of the Florida state standards, or the Next Generation Sunshine State Standards (NGSSS), found that Latina/o/x groups were limited to themes of war, immigration, and Whiteness. Davis' frequency counts showed that only 8 benchmarks out of 1,186 in the K-12 curriculum were dedicated entirely to Latina/o/x people. Additionally, Shear et al.'s (2015) study found that indigenous people were usually portrayed negatively. An's (2016) analysis discovered the invisibility of Asian-Americans in the American story. Noboa (2012) indicated that the Texas essential knowledge and skills (TEKS) were Eurocentric and largely omitted the histories of Mexican-Americans. The results of the studies indicate that state standards continue to misrepresent, exclude, stereotype, generalize, and 
marginalize immigrant groups, such as Latina/o/x groups, in favor of a White European American perspective and narrative.

\section{State and District Assessments}

Barnes, Fives, and Dacey (2015) conducted a study of peer-reviewed articles about teachers' beliefs about assessment practices. The results indicated that teacher beliefs fell along a continuum between pedagogical and accountability measures. On one extreme, the pedagogical group generally felt that assessment was useful for both the teacher and student because it facilitated learning, was used for teachers' decisions and actions, and put students on notice for their progress in class. On the other extreme, the accountability group felt that assessments were worthwhile because they make students and schools accountable through evaluation and student performance, provided reports to parents, and documented student and teacher progress. Barnes et al (2015) noted that teachers' beliefs on assessment usually fell between both the pedagogical and accountability categories. Barnes et al. also noted that some teachers found the state and district assessments irrelevant because they interfered with teaching and learning, provided little useful information, and was an inaccurate form of student and teacher assessment.

Hilburn et al. (2016) postulated that since state assessment measures are tied to the state standards, social studies teachers' instructional practices are often influenced by the guidelines. Therefore, social studies teachers prioritize state standards by adhering to the official curriculum (Vogler \& Virtue, 2007). Journell (2010) argued that the information in the state standards takes precedence over other perspectives because it is 
state tested. The influence of state assessments is to make certain that social studies teachers are following the state-sanctioned knowledge found in the official curriculum.

\section{American History Textbooks and The Historical Narrative}

American history textbooks are the most used resource by social studies teachers because almost every state requires them and teachers usually rely on them for information, which influences their curricular decisions (Cornbleth, 2001; Cruz, 2002; Evans, 1988; 1989) An examination of American history textbooks revealed that the grand narrative, the story line presented through the texts, is reflective of a dominant nonHispanic White European American culture (Acuna, 1988; Cruz, 2002; Davis, 2019; Epstein, 2009; Foster, 1999; Journell, 2009; Nieto, 2004; Noboa, 2012; Spring, 2011; Stanley \& Longwell, 2004; Urrutia, 2005; Zinn, 2003). Loewen (1995) examined numerous American history textbooks and noted that most of the contributions, experiences, and interpretations of history were attributed to elite White men. Zinn (2003) added that the representation of other groups, such as Blacks, Hispanics, and Women were biased, taken from the perspective of the non-Hispanic White dominant class. The discourse is that of a narrative of progress, opportunity, freedom, and shared values (Foster, 1999; Loewen, 1995).

Research on the American history curriculum has also pointed out that the historical narrative found in American history textbooks painted a glowing picture of American exceptionalism, progressivism, capitalism, and heroism (Epstein, 2009; Loewen, 1995; Stanley \& Longwell, 2004; Urrieta, 2005; VanSledright, 2002). Epstein (2009) stated, "textbooks reinforce dominant views of national development in which racism has receded, rights expanded, and the US is the most enlightened nation in the 
world today" (p.117). Foster (1999) called American history textbooks a social construction that encompassed cultural, political, and economic beliefs and values of the dominant group without reflection, critical analysis, and cultural diversity. Urrieta (2005) argued that social studies textbooks use the dominant ideology to keep students civically illiterate by accepting this knowledge as natural.

Curriculum researchers have also found that American history textbooks excluded marginalized communities by omitting racial, cultural, and economic oppressions in their histories (Acuna, 1988; Adams \& Busey, 2017; Anderson, 2013; Cornbleth \& Waugh, 1999; Cruz, 2002; Foster, 1999; Journell, 2009; Zinn, 2003). However, when Latina/o/x and other marginalized groups were represented in American history textbooks, they were often displayed with stereotypes, misconceptions, and omissions (Almarza, 2001; Busey, 2017; Epstein, 2009; Cruz, 2002; Foster, 1999; Garcia, 1986; Nieto, 2004). Foster (1999) found that American history textbooks used three techniques to incorporate Latina/o/x into American history. First, they used mentioning, in which Latina/o/x groups were included in the text but without altering the textbooks' grand narrative. They also used contributions to place Latina/o/x history in the context of what they contributed to mainstream America. Third, the textbooks used progress as a struggle for equality by Latina/o/x groups.

Additionally, Cruz's (2002) review of Florida's most utilized social studies textbooks in K-12 revealed that Latina/o/x groups were portrayed no more than $2 \%$ of the time, whereas non-Hispanic Whites represented up to $82 \%$ of the social studies content. Cruz also showed that Latina/o/x groups were often portrayed as violent, passive, and lazy unwilling to assimilate into American culture. In most of the social studies textbooks 
that Cruz reviewed, Latina/o/x groups were portrayed in a subservient or enslaved role, were not shown to have a significant part in U.S. history, and were reduced to only contributions, such as bringing in different foods, like tacos and burritos into American culture.

Cruz's (2002) study on the representation of Latina/o/x groups in Florida's social studies textbooks also revealed some of the same omissions, misrepresentations, and generalizations on the representations of Cubans in American history. Cruz found that Cubans were limited to a few historical events. For example, when Cubans were presented in the Spanish-American War there was little mention of their participation in the war effort, no mention of Cuban heroes, and no discussions on American imperialism. Cruz also found that American history textbooks used dehumanizing words and suggestions of prejudice, such as "herding" and "penned" as descriptions of them. Instead, the textbooks depicted the United States as solely responsible for victory in the Spanish-American War, American military leaders were the true heroes, and no mention of the human toll on the Cuban population. Also, Cuban immigration to the United States before and after 1959 was presented as a political act. These textbooks failed to mention that Cubans have been present in the United States since the 1800s and that some of them migrated for economic reasons. The importance of Cruz's study was that since Cubans make up a sizable number of Americans living in Florida, it should be apparent that their history be included more systematically in American history textbooks.

\section{Discussions on Challenging the Official Curriculum}

Some scholars have supported the official curriculum because it builds a unified culture in the United States. Schlesinger (1992) advocated for this type of assimilationist 
history taught through the Eurocentric story line whose values are of Western civilization. Schlesinger also noted that the American story has taken cultural aspects of immigrant groups and placed them within American culture. Hirsch (1986) also advocated for a common culture by identifying a list of prominent Americans in history and culture to unify the nation under one culture. In other words, by teaching an official curriculum, students will embrace one unified American culture, instead of disparate ideas of being American. However, the question to ask is which culture and perspective is going to be taught?

Many other scholars have called for social studies teachers to challenge, disrupt, and oppose the official curriculum (Busey \& Russell, 2016; Cruz, 2002; Davis, 2019; Hilburn et al., 2016; Mathews, 2013; Salinas \& Castro, 2010). One major reason is that the official curriculum leaves students of diverse backgrounds out of the American story, thus making them feel that they are not legitimate members of the United States (An, 2016; Davis, 2019). Cruz (2002) added that portraying students of diverse backgrounds as lazy, incompetent, and ungrateful in the official curriculum creates a devaluing effect which destroys their self-esteem, leads to alienation from school, and often causes them to drop out. Mathews (2013) noted that the absence of minority students in the curriculum may lead to greater social distancing between non-Hispanic White students and students of diverse backgrounds.

Unfortunately, social studies teachers often are the perpetrators of teaching to the official curriculum (Almarza, 2001). When social studies teachers do not challenge the negative discourses in the official curriculum, this causes students of diverse backgrounds to view American history through negative perceptions (Epstein, 2009). Journell and 
Castro (2011) stated that if students of diverse backgrounds can study issues that are relevant to them, then these students may become more engaged in school. The acknowledgement and affirming attitude of the students of diverse backgrounds' racial and ethnic identities in the official curriculum can build positive self-esteem, improve school performance, and may increase sociocultural attachment to their school (AntropGuzman, 2006).

The power to challenge, disrupt, and oppose the official curriculum rests with social studies teachers as the gatekeepers in the dissemination of knowledge (Hilburn et al., 2016). Daniels (2011) called on social studies teachers to critically examine American history textbooks and curricular resources to provide an equitable perspective of society and history. Davis (2019) called for social studies teachers to create an upheaval in social studies to challenge the dominant cultural script of the official curriculum through counter-perspectives, more stand-alone benchmarks that include different nationalities, and recognition of resistance and collective actions by minority groups. Mathews' (2013) transformative historical inquiry asked social studies teachers to interrogate dominant discourses, build interpretative frame of references from multiple perspectives, and teach contemporary issues within historical events. Both Busey and Russell (2016) and Hilburn et al. (2016) wanted teachers to instruct for the heterogeneity of Latina/o/x groups and address contemporary racial and ethnic issues.

The literature review has pointed out the biases inherent in the official social studies curriculum. The issue of who gets to decide which culture is represented becomes an area for pedagogical contestation. In a world that has become increasingly multicultural, it is important for social studies teachers to challenge the dominant 
ideology found in the official curriculum. Students of diverse backgrounds need to realize that their histories and cultures are an integral part of the American story.

However, the incorporation of the racial, ethnic, and linguistic histories and cultures of students of diverse backgrounds into the official curriculum is a daunting task because it is difficult to change or alter (Davis, 2019). Therefore, social studies teachers need to use their power in the classroom to teach the content, skills, and perspectives to challenge, disrupt, or oppose the official curriculum (Hilburn et al., 2016). Having social studies teachers become aware of their biases through an examination of their cultural consciousness is an important first step in becoming culturally competent educators. Social studies teachers can then be better able to use culturally affirming pedagogical practices which challenge the official curriculum (Bennet, 2007; Hilburn et al., 2016).

\section{Chapter Summary}

The purpose of the literature review was to provide a conceptual framework for cultural identity, educational beliefs on teaching and learning, culturally conscious pedagogy, and curricular decisions. Teachers' cultural consciousness is a self-reflection and awareness on one's racial, ethnic, and cultural beliefs, biases and prejudices, as well as perspectives on other racial and ethnic groups. Cultural consciousness can be examined through a teachers' cultural identity, experiences with discrimination, and the locality they reside. Educational beliefs on teaching and learning can be examined through constructivist student-centered and teacher-directed principles. Whether social studies teachers accept, disrupt, or oppose the official curriculum is influenced by their cultural consciousness. The current study sought to examine these presuppositions. 
The literature review also shows that developing teachers' cultural consciousness helps in promoting culturally responsive and relevant pedagogies. However, the literature review also shows limited research on the study of Latina/o/x social studies teachers' cultural consciousness. It also indicates that when Latina/o/x teachers are studied they are not representative of the multiple ethnic identities and characteristics found in Latina/o/x groups. There exist few studies that problematize Latina/o/x groups and Latina/o/x social studies teachers in research. Particularly, few studies have focused specifically on the experiences of Cuban-American social studies teachers. The purpose of the present study was to examine Cuban-American social studies teachers' cultural identity, educational beliefs on teaching and learning, and curricular decisions relative to their cultural consciousness in Miami, a region where they are considered the dominant culture. 


\section{CHAPTER III \\ METHODOLOGY}

Pajares (1992) stated that teachers' beliefs can be inferred through qualitative methods, such as interviews, by examining the words, intentions, and perspectives used to describe their behaviors and actions. The purpose of the present study was to present a qualitative multiple case and cross-case analysis of how five self-identified CubanAmerican social studies teachers in Miami, a city where they are viewed as the dominant culture, demonstrated their ethnic and cultural identity, expressed educational beliefs on teaching and learning, approached the official curriculum, and promote culturally diverse pedagogy relative to their cultural consciousness. The results of the study will provide insights on cultural identity, cultural and ethnic characteristics, and the importance of geographic place in identity formation.

The research on educational beliefs on teaching and learning may help to better understand teachers' instructional and curricular decisions. More importantly, the use of critical Latino theory (LatCrit) in the current study can problematize the suppositions inherent in the theory's beliefs on Latina/o/x teachers. In doing so, the study adds to the research literature on LatCrit. Finally, the study brings to light the need to build cultural bridges (Gay, 2018) between teachers and their culturally, ethnically, racially, and linguistically diverse students despite whether they are non-Hispanic White teachers, Latina/o/x teachers, or non-Hispanic Black teachers.

Although studies on cultural identity, educational beliefs, and curricular decisions have been conducted quantitatively, or through mixed methods, the present study utilized a methodology prioritizing multiple and cross-case qualitative research design. The 
approach was chosen because it allowed for an understanding of the teacher-participants' beliefs, experiences and perspectives in their own voice, which are not easily handled through statistical procedures (Bogdan \& Biklen, 2007; Denzin \& Lincoln, 2005). Data collection methods were primarily through multiple in-depth interviews (Seidman, 2013). The data collected of each teacher- participant were analyzed first through individual case study as narratives and after through multiple and cross-case analysis (Creswell, 2013; Stake, 2006). The study utilized critical Latino theory (LatCrit) as its theoretical framework to prioritize conceptual categories of sociocultural factors that are pertinent to Latina/o/x groups (Fernandez, 2002; Solorzano \& Delgado-Bernal, 2001).

The chapter describes and discusses this study's research methodology to answer the research questions. The chapter is organized around the following discussion and procedures: (a) research questions; (b) research design and rationale for qualitative research design and multiple and cross-case analysis; (c) research setting; (d) selection of research participants; (f) data sources and data collection; (e) data analysis; (f) data management; (g) integrity measures; (h) ethical considerations; and (i) researcher positionality. The chapter concludes with a brief summary.

\section{Research Questions}

The following main research and sub questions were used to examine five selfidentified Cuban-American social studies teachers' cultural consciousness:

1. How did each teacher-participant describe his or her ethnic and cultural identity?

a. How did each teacher-participant describe his or her immigrant experience? 
b. How did each teacher-participant define and characterize his or her cultural and ethnic identity?

c. What encounters and perceptions with ethnic, racial, linguistic or cultural discrimination did each teacher-participant experience inside or outside of Miami and within his or her ethnic and cultural group?

2. What was each teacher-participant's educational and epistemic beliefs on learning, teaching, and social studies?

3. What was each teacher-participant's perspective on teaching linguistically, racially, and ethnically diverse students and controversial issues?

4. What was each teacher-participant's view toward the official curriculum?

\section{Research Design}

The study utilized qualitative research design with a multiple case study approach and cross-case analysis (Stake, 2006). Individual cases were bounded within the description of Cuban-American social studies teachers in the South Florida region where demographically they are the most populous group (Stake, 2006; Portes \& Armony, 2018). The five research participants were chosen for maximum variation in age, gender, years of teaching, and arrival in the United States to represent the sociocultural differences between the five major waves of Cuban migration (Garcia, 1996; Patton, 1980; 1990; Pedraza, 2007). Interviews were the primary means of data collection. Critical Latino theory was used as the study's theoretical framework.

\section{Rationale for Qualitative Research Design}

Qualitative research design was used because it helps to understand the social construction of individuals through interaction with their context. Interactions are 
realities shaped by individuals' past and present experiences (Merriam, 2002). Creswell (2013) noted that qualitative research uses an interpretative framework that addresses the meanings of participants in a social setting through inquiry, collection of data, and data analysis that establishes themes. The findings are the voices of the participants and the reflections of the researcher. All information and data collected is told through a holistic account of the issues involved, the factors that helped shape the problem, and the painting of a picture that reflected situational interactions.

A qualitative research design is appropriate to answer the research questions in the study. First, qualitative research design provides for a rich thick descriptive understanding (Denzin \& Lincoln, 2005) of Cuban-American social studies teachers’ cultural identity, life experiences, beliefs on teaching and learning, and curricular decisions in their own words, which are essential to data collection (Bogdan \& Biklen, 2007). Second, the study relies on interviews for data collection and data analysis through multiple and cross-case analysis in a comparative process for themes (Creswell, 2013; Stake, 2006). The study also utilized the theoretical framework of critical Latino theory (LatCrit). The present study reports the findings of one group of social studies teachers to provide descriptive interpretation of their beliefs and perspectives on cultural identity, pedagogy, and curricular decisions relative to their cultural consciousness.

\section{Rationale for Multiple Case Study and Cross-Case Analysis}

To understand the multiple realities of the teacher-participants in the study, a qualitative multiple case study was conducted. A qualitative case study approach interprets the complex factors, in a real-life setting, which provides meaning through indepth data collection and analysis (Creswell, 2013; Stake, 1995; 2006). Stake (1995; 
2006) and Creswell (2013) suggested that an analysis of comparable cases is first warranted to paint a picture and provide a detailed description of themes within each case prior to cross-case and multiple case analysis. One form of analysis is to gather individual experiences and stories through interviews and narrative methods as case study (Creswell, 2013). Therefore, the current study was first conducted through individual case study prior to multiple and cross-case analysis.

A multiple case study concerns a close examination of two or more subjects of data that are linked together (bounded) and provide an examination of individuals in a setting or a unit of analysis (Merriam, 1998; Stake, 2006). A multiple case study is a fundamental method that involves selecting multiple cases for analysis and comparisons (Stake, 2006). Creswell (2013) supported a detailed examination of within individual case themes followed by an analysis across all cases to search for patterns and themes from the data. Therefore, after an analysis of single cases, a cross-case analysis was conducted to search for themes across cases. These themes became part of multiple case analysis.

In the present study, five self-identified Cuban-American social studies teachers constituted the individual cases. The areas of interest were the teacher-participants' descriptions of cultural identity, educational beliefs on teaching and learning, and curricular decisions. The small amount of individual cases in the study allowed for a more in-depth information of data collection. Additionally, the exclusive use of interviews for data collection denoted each teacher participant's voice, beliefs, perspectives, decisions, interpretations, thoughts, and emotions as a legitimate source of 
knowledge and research in a thorough manner (Creswell, 2013; Gay, 2018; Stake, 1995; 2006).

\section{Research Setting}

The study was conducted in Miami-Dade County, Florida, where it is estimated that Hispanics make up $67 \%$ of the population. Cuban-Americans, Cuban born, and Cuban-descendants make up a third of the Hispanic population in Miami (Portes \& Armony, 2018). Researchers have labeled Miami as a majority Latina/o/x city with Cubans as the dominant ethnic, political, social, and cultural group (Aranda et al., 2014; Cortina, 1990; Grenier \& Perez, 2003: Portes \& Armony, 2018; Stepick et al., 2003).

Although the study was not conducted within any of the schools in the MiamiDade Public School System (MDCPS), the demographic makeup of the district's schools is important to the research setting because each teacher-participant was teaching or taught in the district. Miami Dade County Public Schools is the fourth largest school district in the United States. The MDCPS Statistical Highlights of 2014-2015 showed that the student population was $68 \%$ Hispanic, with $42 \%$ of the students being Cuban immigrants and their descendants (Shneyderman, 2015). Hispanic teachers represented $49 \%$ of all instructional staff (Shneyderman, 2015). Although no data were provided for Hispanic teachers' national origins, it can be inferred that most of these teachers are also of Cuban heritage because Cubans represent the largest Latina/o/x group in the region.

\section{Research Participants}

Case study and multiple case studies methodology utilizes purposeful sampling to select participants. Case study and multiple case study is appropriate because they are bounded systems (Creswell, 2013; Stake, 1995). Patton $(1980,1990)$ noted that 
purposeful sampling is appropriate when the researcher wishes to understand something about select cases without generalizing to all such cases. In specifically selecting research participants in the current multiple case study, the researcher used Patton's proposed notion of maximum variation, selecting extreme cases in order to yield the greatest amount of variation in experiences, and provide the greatest impact on understanding. Stake $(1995 ; 2006)$ noted that the selection of cases should be about balance and variety, which allow for the phenomena to be studied in different contexts in order to provide better understandings and descriptions.

In the present study, the selection of cases utilized purposeful sampling and followed Patton's $(1980 ; 1990)$ approach for maximum variation. The teacherparticipants were recruited through snowballing by using contacts from previous subjects to obtain future ones. The teacher-participants were also restricted to a criterion that provided representation of different genders, ages, years teaching, and year of arrival.

One criterion was that the teacher-participants were currently teaching or have taught at least one class of American history. The teacher-participants ranged in ages from early 20 s to late 50 s. They all had varying years of teaching experience from two to 30 years. Two of the teacher-participants were born in Cuba, while two were born in Miami, and another born in Boston and migrated to Miami as a child. Four of the teacherparticipants represented the children of the pre-Mariel group Cuban immigrants, while one immigrated after 1980 and belonged to the post-Mariel group.

\section{Data Collection and Procedures}

Multiple case study has interviews as the dominant strategy in data collection because they provide multiple interpretations and describe an episode (Stake, 2006). 
Interviews are "used to gather descriptive data in the subject's own words, so that the researcher can develop insights on how subjects interpret some piece of the world" (Bogdan \& Biklen, 2007, p. 103). In qualitative research methods, interviews capture an individual's perspectives and experiences (Creswell, 2013; Denzin \& Lincoln, 2005; Marshall \& Rossman, 1995). The main purpose of interviews is to make meaning from these experiences and perspectives (Kvale, 1996). Patton (1990) noted that interviews offer an opportunity to make these perspectives and experiences knowable and explicit. Seidman (2013) called this an understanding of one's lived experience where context is a crucial part of creating a representation for behavior and action.

\section{Interviews as Data Collection}

In the present study, interviews were the main source of data collection. Interviews are central to understanding the beliefs and perspectives of the participants through the creation of narratives as a legitimate source of research (Gay, 2018). Interviews offer primary means of investigating and examining participants' individual accounts of their past and present experiences (Merriam \& Associates, 2002). Interviews are essential as the voice of the participants as stories and narratives interpreted by the researcher. Therefore, multiple in-depth interviews were used as the primary source of data collection in this study.

\section{Interview Procedures}

Seidman's (2013) protocol of three semi-structured interviews was used for data collection. The researcher set up a meeting at a location and time of the participant's convenience. The spacing between each interview was approximately three to four weeks apart. Participants were given chances to refuse to participate, or to forego answering any 
questions. Before the start of the interview, the researcher asked for permission to record the interview with a digital sound recorder. Each interview was transcribed verbatim prior to the next interview. A university consent form, in conjunction with the university's Institutional Review Board (IRB), was provided and signed prior to the interviews.

Three to four 60-90-minute semi-structured interviews were conducted with each teacher-participant to better understand their beliefs, perspectives, and experiences in context and behavior (Seidman, 2103). The first interview was used to gather background information about the participants' cultural identity, prior experiences, and beliefs about schooling. The second interview focused on past and present experiences, beliefs on teaching and learning, and reflections on curriculum resources. The third interview was used to reflect on critical incidents in the classroom, perspectives on teaching culturally, ethnically, racially, and linguistically diverse students, and summing up or clarifying any other pertinent information. Additional interviews were conducted as clarification of ideas or perspectives.

The interviews were transcribed and coded according to the themes associated with LatCrit. These themes were written and analyzed as individual case narratives. After, cross-case analysis was conducted and presented as assertions. The assertions were further analyzed for themes and presented as findings.

\section{Data Analysis}

In qualitative research, data analysis is described as a process of looking for patterns in the data collection through inductive and holistic interpretations (Bogdan \& Biklen, 2007; Creswell, 2013). It is ongoing and simultaneous and leads to themes, 
assertions, and findings (Stake, 1995). In the present multiple case study, the use of individual case study and cross-case analysis were the primary means for data analysis. This involved an interpretative and comparative analysis between single and two or more cases (Creswell, 2013; Stake, 2006). For its theoretical framework, the current study also utilized critical Latino theory (LatCrit) for its theoretical framework of analysis.

\section{Critical Latino Theory}

The present study utilized critical Latino theory (LatCrit) as its theoretical analysis. The basis for LatCrit is to "prioritize social categories, such as race, gender, and sexuality and recognize them not only as social constructions but also as categories that have material effects on real people" (Fernandez, 2002, p. 46). Solorzano and DelgadoBernal (2001) added that categories of language, immigration, ethnic and cultural identity, sexual orientation, and phenotype are essential in utilizing LatCrit because they are pertinent to Latina/o/x. Additionally, LatCrit used the intersections of racism, sexism, classism to address forms of oppression. Daniels (2011) noted that researchers use LatCrit as a lens to critically examine textbooks, curricular resources, and teacher's instructional practices to inquire if cultural histories are representative of an equal perspective of society and history. Critical Latino theory also works for social justice by questioning and challenging the power relations in schools, oppression of marginalized groups, and improvement of the social condition (McLaren, 2006). The themes in the present study were derived from the narratives of the individual cases and cross-case analysis utilizing the principles of LatCrit.

The current study followed Solorzano and Delgado-Bernal's (2001) five themes of LatCrit research to question the teacher-participants. The intersectionality of the 
teacher-participants' descriptions of their ethnic and cultural characteristics was placed within an assimilation or accommodation framework. That is, the question asked was whether the teacher-participants aligned themselves to a dominant mainstream White American cultural identity or did they ascribe to a more Latina/o/x one or other identity. Also, immigration experiences and racial, cultural, ethnic, gender, and linguistic discrimination experiences were explored. The study was conducted through the creation of narratives by having the teacher-participants retell their stories and descriptions.

Each teacher-participant's description of his or her educational beliefs and pedagogical practices was examined through the paradigm of a dominant cultural ideology. That is, the teacher-participants were questioned whether they ascribed to pedagogical beliefs and practices that silenced the voices of resistance pedagogy. These pedagogical beliefs and practices were placed within a student-centered or teachercentered approaches to teaching and learning. A student-centered approach is often associated with multiple and alternative interpretations of history, recognition of exclusions and stereotypes of marginalized groups, utilization of experiences to make connections with students, critically questioning the official curriculum mainly conducted through group activities (Estes, 2016; Epstein, 2009; Fostnot, 2005; Mascolo, 2009; Mathews, 2013; Salinas \& Castro, 2010; Tellez, 1999). A teacher-centered pedagogy believes that the teacher is the expert and authority in the transmission of knowledge and instruction is usually conducted through lectures (Mascolo, 2009). Since teachers often hold simultaneous, ambiguous, and competing educational beliefs (Fives et al., 2015; Mascolo, 2009; Windschitl, 2002), in the present study teachers' educational beliefs and 
pedagogical practices were analyzed through the emphasis each teacher-participant placed on their pedagogical stance.

Perspectives on curricular decisions were examined as to whether the teacherparticipants accepted, disrupted, or opposed the official curriculum. Each of the tenets of the social studies' official curriculum, the state sanctioned standards, district pacing guides, state and district assessments, social studies textbooks, and the American historical narrative were examined as to whether each teacher-participant believed and acknowledged the veracity of them or saw them as oppressive. An acceptance of the official curriculum is seen as promoting a pedagogy from the dominant cultural perspective. The teacher-participants who disrupted or challenged parts of the official curriculum may have had issues, reservations, or disagreements with some of the information, requirements, or implementation. Teacher-participants who opposed the official curriculum may show that they believed the information, state requirements, and implementation were wasteful, unfair, and misrepresentative of their cultural group.

Through a LatCrit examination of the Cuban-American social studies teachers, the current study attempted to paint a picture of the intersectionality of the social, economic, and cultural factors, which form an individual's cultural and ethnic identity. The study also attempted to examine the teacher-participants' pedagogical beliefs and practices to see if they taught in a culturally inclusive and transformative fashion. The study also looked at the teacher-participants' curricular decisions and whether they accepted, disrupted, or opposed the dominant ideology of the official curriculum. Because Cuban-Americans may be considered a Latina/o/x group, it is appropriate to use LatCrit as theoretical framework for an examination of them. 


\section{Data Analysis Procedures}

Stake (1995) indicated that the purpose of multiple case and cross-case analysis was to gather in-depth information about each case of interest in a comprehensive and systematic manner. However, Stake (1995; 2006) and Creswell (2013) suggested that an analysis of comparable cases is first warranted to paint a picture and to provide a detailed description of themes within each case prior to cross-case and multiple case analysis. One form of analysis is to gather individual experiences and stories through narrative methods (Creswell, 2013). Gay (2018), Olafson, Salinas-Grady, and Owens (2015) noted that narratives are a legitimate source to gather information about a participants' beliefs and perspectives. Narratives also concentrate on participants' experiences (Merriam \& Associates, 2002; Stake, 2005). Therefore, by analyzing single cases as narratives, the researcher identified themes through LatCrit and presented them for cross-case analysis. The search for themes across multiple cases was then presented in narrative form.

Saldaña (2012) recommended that after the interviews were transcribed, coding should be conducted through alignment with the research questions. Pre-established codes in the study were generated from LatCrit prior to first cycle coding. The study utilized Saldaña's description of In Vivo coding methods by taking words and phrases from the teacher-participants' individual narratives and categorizing them according to themes (Charmaz, 2006; Corbin \& Strauss, 2008; Saldaña, 2013). During the second, third, and subsequent coding cycles of the individual cases, themes were analyzed for recurring beliefs, perspectives, and experiences amongst the teacher-participants through a process called by Saldaña as theming the data. The approach is a search for related emerging themes that are linked and that answer the research questions (Rubin \& Rubin, 
2012). Cross-case analysis followed to identify themes across the individual cases which became assertions and would subsequently become the findings of the study.

The research procedures were as follows:

1. Individual interviews.

2. Transcription of individual interviews.

3. Pre-established codes generated through the theoretical approach to the research questions for In Vivo Coding Methods and theming the data coding of the first, second, and subsequent coding cycles of the individual narratives.

4. Cross-case analysis to generate recurring emergent themes amongst the individual cases of the teacher-participants, which became assertions.

5. Assertions were analyzed to generate findings from multiple cases.

\section{Data Management}

All information regarding interview transcripts and research findings were kept in a locked and stored cabinet in the researcher's home office. Additionally, consent forms and surveys were enclosed in a safe place. Electronic files were kept password protected in the researcher's laptop, USB, and Dropbox, a cloud-based service for storing information. The participants were assigned pseudonyms as protection for their identity. When the present study was completed, some of the interview materials were destroyed. Materials, or any information that may be pertinent to the researcher will be safeguarded on signed approval of the participant.

\section{Integrity Measures}

Trustworthiness, or whether the study was conducted in a rigorous manner (Merriam, 1998), were addressed through credibility, dependability, confirmability, and 
transferability. Bloomberg and Volpe (2012) addressed trustworthiness as an effort in qualitative research to report issues of validity, reliability, generalizability, and ethics. Merriam (1998) added that qualitative studies ask, "whether the study was conducted in a rigorous, systematic, and ethical manner" (p. 24). Trustworthiness in qualitative research design is a process used to enhance the methods by which data collection and analysis are conducted. Creswell (2013) noted that certain characteristics are involved in issues of trustworthiness: (a) the study had detailed methods and rigorous approach to data collection and data analysis; (b) data analysis was conducted from multiple levels of abstractions; (c) the writing was persuasive, clear, and engaging; (d) the researcher expressed their personal experiences, beliefs, culture, and history; and (e) the study addressed all ethical issues.

Credibility, or internal validity, asks whether findings are consistent with reality and are believable (Lincoln \& Guba, 1985; Merriam, 2002). Dependability, or reliability, asks whether findings are consistent with the data collected and make sense to the reader (Lincoln \& Guba, 1985; Merriam, 2002). Credibility issues were addressed through triangulation methods by collecting data through multiple in-depth interviews from each participant. A repetitious gathering of data and critical review of what is being said create redundancy, which is a confirmation of what the researcher believes is the meaning (Denzin \& Lincoln, 2005; Stake, 2006).

In addition, member-checking and peer review were used to enhance credibility. Dependability was improved through an audit trail in the form of a researcher reflective journal where data were collected, and methods explained (Bogdan \& Biklen, 2007; Lincoln \& Guba, 1985; Peshkin, 1988; Stake, 2006). Confirmability asks to what extent 
can others authenticate the study's results (Lincoln \& Guba, 1985; Merriam, 2002). The method used was enhanced through a peer review of the data collected. Transferability, or external validity, asks whether the findings can be applicable in other situations (Lincoln \& Guba, 1985; Merriam, 2002).

In the present study, additional questions pertaining to transferability were: (a) whether the findings were indicative of a situation (Erickson, 1986); (b) the context of a phenomenon (Patton, 1990); (c) a vicarious experience (Stake \& Trumball, 1982); (d) familiar by adding assertions (Stake, 1995). Another method for improving transferability is by providing "enough description and information that readers will be able to determine how closely their situations match, and thus whether findings can be transferred" (Merriam, 2002, p. 29). The current study's rigorous manner in conducting the research was consistent with qualitative research design's considerations for trustworthiness.

\section{Ethical Considerations}

The participant and researcher relationship were enhanced through mechanisms that protect the participants, which is the essence of ethical considerations. Potential illegal activities, mitigating power imbalances between participant and researcher, participant research concerns, stereotyping, and the purposes of the study are all related issues that may hamper the sensitivity of the participants (Creswell, 2013). Creswell identified methods to deal with these issues during the research process. First, the issue of informed consent is presented at the start of the study. This was part of the IRB process at the university. In the process, the purposes of the study are spelled out, voluntary participation provided, and the provisions of undue risk given. In the data collection 
phase, special care was provided in allowing for the least disruptive environment, being sensitive to the power imbalances between participant and researcher, awareness of reciprocity, and avoiding disclosing sensitive information. In data analysis, assigning anonymous names avoids giving out information that would harm participants. The current study followed all the protocols listed above for ethical considerations.

\section{Research Positionality}

In qualitative studies, the researcher plays a personal role in the research process. Peshkin (1988) cautioned that a researcher's subjectivity, biases, views, and limitations are part of the data and should be acknowledged as such throughout the research process of data collection, data analysis, interpretations, and conclusions. Therefore, in the interests to the validity of the research, my personal beliefs and experiences are expressed as they pertain to the study.

Since moving to Miami at the age of twelve, I have self-identified as Colombian. Prior to moving to Miami, I was raised in Pennsylvania where I self-identified as White and American. It was not because I completely felt White American, but because there were only two boxes to check for race in most official forms. Along with my family, at the age of 12, I moved to Hialeah, a city in the Miami metropolis, which has the largest concentration of Cubans in the United States. Subsequently, my sociocultural experience was being around Cubans.

I attended predominantly Cuban-American private schools and all my friends were Cuban-Americans. They were mostly the offspring from the first and second waves of Cuban immigrants (I once danced with the daughter of a former Cuban president). Their parents' Cuban stories fascinated me. I would roll my eyes, just like my Cuban- 
American friends, whenever they spoke of returning to Cuba because I had heard their stories countless times. Within the Cuban-American environment I was raised in, I associated with being Colombian, a self-identity that flourished in the growing Latin American population of Miami. However, in the 1980s being Colombian in Miami was ripe with negative connotations, such as movies like Scarface, which often depicted Colombians as violent drug dealers. Therefore, my cultural and ethnic identity blossomed from feeling American to associating with Colombians and understanding CubanAmerican culture.

I became a high school teacher and taught in various schools throughout the region. My last 11 years were at a school that had over a 90\% Cuban student population. It was a mix between pre-Mariel Cubans and post-Mariel Cubans. The interaction between both groups once more piqued my interests. However, it was not until I chose to teach Cuban history in my American history classes that I realized something was wrong with the curriculum. I began teaching in opposition to the curriculum by ignoring sections that I felt misrepresented certain groups, adding information from my university history classes, and challenging suppositions that I felt would spark debate in the classroom. I did this without knowledge of my pedagogical stance. It was not until I started taking university classes that I realized I was challenging the official curriculum.

Sometimes I would ask the Cuban teachers in that school whether they taught Cuban history, or at least Cuban immigration. Not one teacher said that they did, mostly because it was not part of the official curriculum. What was more shocking was that almost all the Cuban social studies teachers simply followed the textbook without interjecting multiple perspectives into their teaching. As a teacher, I rarely used the 
textbook for instruction in class, instead I attempted to use different resources to make my lessons. I wondered why a Cuban-American social studies teacher would not teach Cuban history to their predominantly Cuban students.

This interest resurfaced in my $\mathrm{PhD}$ program. After reading studies on Latina/o/x teachers and their oppositional stances to pedagogy, I wondered if this was applicable to the Cuban-American social studies teachers in Miami. I felt that something linked cultural identity, educational beliefs, curricular decisions, and teaching for an inclusive pedagogy. After reading studies on Latina/o/x groups, such as Mexicans and Puerto Ricans, I discovered that few studies were on Cuban-American teachers in Miami. I felt that there was something different about Miami and Cuban-Americans social studies teachers and that formed the impetus for the current study.

My research positionality is that of insider/outsider, that is, I have lived in Miami most of my life surrounded by Cuban culture, yet never self-identified as Cuban. I have listened and internalized the stories of my Cuban-American friends about life in Cuba prior to the communist revolution and hatred for Castro and communism. I have shared in many Cuban cultural characteristics, like traditional Cuban ethnic food and festivals. Possibly, that is one reason why the teacher-participants in the current study were open to me with their opinions. They may have seen me as one of them.

If I reflect on my teaching style, I was more in line with an oppositional stance than teacher-centered instruction. I often challenged the facts in social studies textbooks and was not afraid to critique and provide opinions that were controversial. For instance, I would have extensively instructed about Castro's death. I was also critical and wary of any prescribed information that I was forced to follow. I realized the power that teachers 
hold in disseminating information in their classrooms. It was within these perspectives that I conducted the present research study.

\section{Chapter Summary}

The chapter provided the study's methodology and methods. Research design was presented and rationalized as qualitative with multiple and cross-case analysis. The research process involved multiple individual interviews, cross-case analysis, and multiple case analysis in narrative form to present the themes, assertions, and findings for the study. Critical Latino theory was used as the theoretical construct. In addition, the data collection process, selection and setting of the research and participants, issues with trustworthiness, and ethical considerations were presented and remedied.

The next three chapters present the collection, analysis, and discussion of the data. Chapters four presents the teacher-participants individual cases as narrative according to the themes derived after initial analysis. Chapter five presents the assertions and findings. Chapter six discusses the conclusions based on an examination of the findings, practical implications, and recommendations for the future. 


\section{CHAPTER IV}

\section{INDIVIDUAL CASE STUDIES}

The current chapter presents five individual case narratives of self-identified Cuban-American social studies teachers' descriptions of their cultural identities, educational beliefs about learning, teaching, curricular decisions, and perspectives of teaching students of similar and diverse backgrounds. Stake $(1995 ; 2006)$ and Creswell (2013) suggested that an analysis of comparable single cases is first warranted to paint a picture and provide a detailed description of within cases prior to cross-case and multiple case analysis. Each teacher-participant in the study represents a first-person account of the concepts and themes centered around the research questions. Critical Latino theory (LatCrit) was utilized to analyze each case because it provided the conceptual categories of ethnicity, race, culture, language, gender, age, socio-economic status (SES), education, religion, acculturation, immigrant experience, sexuality, and geography that are pertinent to Latina/o/x (Fernandez, 2002; Solorzano \& Delgado, 2001, Valdes, 1996).

The themes involved in the study are strength of ethnic and cultural identity, educational beliefs, instructional practices, and curricular decisions. The themes are presented in narrative form in the teacher participants' own words to reflect their unique ideas, thoughts, and interpretations, so they are authentic to the teacher's voice (Gay, 2018). Cultural identity reflects the strength and characteristics of ethnic, pan-ethnic, racial and cultural affiliation. Cultural identity was presented through favorable or unfavorable immigrant experiences (mode of incorporation) into American and Miami culture. It included social-class mobility and acculturation to Cuban and American culture. It also included instances with racial, ethnic, culture, gender, and linguistic 
discrimination inside and outside of Miami, as well as within their cultural and ethnic group. Educational beliefs refer to the teacher-participants beliefs on learning and teaching through student-centered and teacher-centered approaches to pedagogy.

Curricular decisions were defined as an adherence to the social studies curriculum, state assessment, and the American historical narrative reflected as the official curriculum.

\section{Background to Teacher-Participants}

At the time of the study, each self-identified Cuban-American social studies teacher shared some common characteristics. All teacher-participants were raised, attended schools, and resided in the city of Miami. The city of Miami has the largest concentration of Cuban-Americans, Cuban-born, and of Cuban descent than any other city in the United States (Portes and Armony, 2018; U.S. Census, 2015). Cubans are considered the dominant cultural, and political power in the region (Cortina, 1990; Stepick et al., 2003; Portes \& Armony, 2018). The teacher-participants' ages range from their early 20 s to early 50s and are representative of the different waves of Cuban immigrants to Miami (see Table 1).

All the teacher-participants were currently teachers or had previously taught in the Miami Dade County Public School System (MDCPS), varying in experience from two to 30 years. Miami Dade County Public Schools is the fourth largest school district in the United States and its students and teachers are majority Hispanic, mostly from Cuba, or of Cuban descent (MDCPS Statistical Highlights of 2014-2015). All teacher-participants had taught American history in middle or secondary grades. In addition, some teacherparticipants had taught various disciplines in social studies, such as world history, economics, and government in different academic levels, such as advanced placement, 
honors, gifted, regular, and self-contained English as second language classes (in MDCPS these classes are sometimes referred to as ESOL). All teacher-participants received at least their bachelor's degree $\cdot$ iṇ social studies education from the same large urban university in the region. The university all the teacher-participants attended is regarded as a Hispanic serving institution (HSI) because more than half of its student population are from Spanish-speaking countries of Central America, South America, and Spanish-speaking Caribbean, or are of Hispanic heritage.

Table 1.0

Background to Teacher-Participants

\begin{tabular}{|c|c|c|c|c|}
\hline Teacher & Born & Age & $\begin{array}{l}\text { Immigrant } \\
\text { Wave }\end{array}$ & Self-Identity \\
\hline Jesse & Miami, U.S. & Early $30 \mathrm{~s}$ & $\begin{array}{l}\text { Pre-Mariel } \\
\text { offspring }\end{array}$ & $\begin{array}{l}\text { Cuban Ancestry } \\
\text { and born in } \\
\text { U.S. }\end{array}$ \\
\hline Diana & Miami, U.S. & Early $20 \mathrm{~s}$ & $\begin{array}{l}\text { Pre-Mariel } \\
\text { offspring }\end{array}$ & $\begin{array}{l}\text { Hispanic but } \\
\text { mostly Cuban }\end{array}$ \\
\hline Jose & Cuba & Early 50s & $\begin{array}{l}\text { Pre-Mariel } \\
\text { immigrant }\end{array}$ & $\begin{array}{l}\text { Cuban- } \\
\text { American, but } \\
\text { mostly Cuban }\end{array}$ \\
\hline Lenny & Boston, U.S. & Mid 40s & $\begin{array}{l}\text { Pre-Mariel } \\
\text { offspring }\end{array}$ & $\begin{array}{l}\text { Hispanic, but } \\
\text { feel more } \\
\text { Cuban }\end{array}$ \\
\hline Yaimi & Cuba & Late $20 \mathrm{~s}$ & $\begin{array}{l}\text { Post-Mariel } \\
\text { immigrant }\end{array}$ & $\begin{array}{l}\text { Completely } \\
\text { Cuban } \\
\text { American born } \\
\text { in Cuba but } \\
\text { raised here }\end{array}$ \\
\hline
\end{tabular}




\section{Jesse: The Open-Minded Teacher}

I met Jesse for three interviews at a local Starbucks near the private school where he was currently teaching. Jesse self-identified as a Cuban-American Gay Male. He was in his early 30s at the time of these interviews. Jesse often interjected sarcasm to display his displeasure for an educational theory or administrative directive. However, for the most part Jesse was succinct and forthcoming in his answers to the interview questions.

At the time of the interviews, Jesse was a teacher with nine years' experience who was currently teaching at a private school in an affluent area of South Miami. His students were from diverse countries, such as Brazil and China, as well as students who were Cuban-American, Colombian, and non-Hispanic White European American. His prior teaching assignments included various schools throughout MDCPS, ranging from a predominantly African American charter school to a predominantly Cuban and nonCuban Hispanic high school in a higher- income area. Jesse was enrolled in the $\mathrm{PhD}$ program in social studies education from the same HSI university he received his bachelor's degree.

\section{Description of Jesse's Ethnic and Cultural Identity}

Jesse described how his family emigrated to the United States. He also described how they moved throughout Miami. He said:

My grandparents came to Miami as exiles after Castro took over in 1960. They never saw themselves as immigrants. They had that "I'm going back someday" mentality. They went to Catholic schools here. Both my parents were born in Cuba and came over to Miami in the seventies. My Mom came in 1970 and lived 
in South Miami. My dad came in the late 1970's and lived in Hialeah until he married my mom and moved to Kendall.

Jesse's father first lived in Hialeah, a working-class area with the largest number and concentration of Cubans in the United States (Portes \& Armony, 2018). Jesse's mother lived in South Miami, a middle-class predominantly Cuban area of Miami. Then Jesse moved into Kendall, a middle-to-upper-class area with a large Cuban and South and Central American population. Jesse explained that his family regarded themselves as political exiles rather than economic immigrants. Jesse also alluded to how his grandparent retained the idea of a nostalgic return to Cuba. He pointed out how his parents were raised within a religious environment. Poyo (2002) found that Cubans in the 1960s used the Catholic Church to bind Cuban culture and the Cuban community. Jesse's movement around Miami indicated that he lived in predominantly Cuban places. Jesse spoke about the demographics of the teachers and students in the primary and secondary schools he attended:

First, I went to school in South Miami and then for high school in West Kendall. Most of the teachers I had were Hispanic from different countries. I don't think I had a lot of non-Hispanic teachers. I'm sure I had an Anglo-Saxon teacher, and a Black teacher, but not too many. The students were from different countries in South America, but if I had to generalize, they were mostly Cuban. They were all good schools, at least back then.

Jesse's school experiences were in a predominantly Cuban and Latina/o/x environment. After some reflection, Jesse assumed that most of his teachers and classmates were from 
Latin American. Next, Jesse explained his cultural identity as defined through characteristics of Cuban culture:

I was born here, but I have Cuban ancestry with Cuban cultural influences. But I didn't grow up in Cuba, so my experiences were here in South Florida. Being Cuban are the foods, like croquettas and cafecitos, (traditional Cuban breakfast food and Cuban coffee) the language, subtle religious influences, what was passed down from our grandparents, are all part of Cuban culture.

Jesse's description of Cuban culture emphasized its traditional characteristics. After a little prodding, Jesse described characteristics of his American cultural identity:

I guess the American part is the individual aspect of American culture. When I was little, I used to push away from being Cuban, but, as I got older, I don't find myself being that individualistic. I wanted to go away for college initially, and my family was like, you can't leave your family.

Jesse self-identified as Cuban because of his Cuban descent and being raised in Cuban Miami. However, Jesse stated that being born in the United States, and not having lived in Cuba, made him also American. Jesse understood that a part of mainstream American culture was individualism, an aspect that was different than the familial part of Cuban culture which he later describes.

One important aspect of Cuban culture that Jesse spoke about was the importance of Cuban history passed down from his grandparents' stories. He said:

My grandparents always said that they had to leave Cuba because they had to. They explained all that they had to go through, and how they got here and what happened, but that one day we'll come back. In the beginning the coming back 
was always in the back of their heads, so I guess that's why they passed along all those Cuban stories. But I remember learning a lot from those stories. And even now when I talk to my grandmother, she'll tell a story. And I just love sitting with people hearing their stories.

A nostalgic return to Cuba was one of the common characteristics of the first wave of Cuban exiles (Perez, 1992). Jesse also added how he learned about Castro: "when they spoke about Castro it was something sensitive learned at home, but it was negative learning, a horrible story that you knew there was anger toward the Cuban regime and the revolution". Learning to hate Castro was another characteristic of the pre-Mariel group of Cuban immigrants (Aranda et al., 2014; Portes \& Armony, 2018).

Jesse placed importance on Cuba's historical roots as part of his Cuban identity. It was his grandparents' depictions in their stories of an old Cuba and the traumas of the Cuban communist revolution that allowed Jesse to retain a unique part of Cuban culture. In these stories, Jesse learned the animosity felt toward Castro from Cubans of the older generation.

Jesse also regarded his family dynamics as influential to his cultural and ethnic identity. Jesse depicted his family like the 1970s sitcom Que Pasa USA? The show portrayed a three-generational Cuban family navigating the world of predominantly Anglo-American Miami. He illustrated:

My family was just like Que Pasa U.S.A? Everything was just two languages. I'm fluent in Spanish because I was forced to use it. My dad's first language was Spanish, so he would never speak to us in English, but we wouldn't respond in Spanish. My mom and my grandparents all knew English. I would speak to my 
Mom in English, but with my grandparents it was all in Spanish. It was very interesting and dynamic. It was like this language and cultural thing, but everybody knew what they were saying.

Jesse's depiction of his family dynamic revealed the importance of being bilingual, that is, knowing how to speak both English and Spanish. Jesse's family selectively acculturated English, the dominant language of the United States, and retained Spanish, the language of Miami as part of their Cuban culture (Aranda et al., 2014; Portes \& Armony, 2018).

Jesse was the only teacher-participant who self-identified as gay. Jesse found that being gay was inconsequential during his school years and later to his teaching. He elaborated on both issues:

I was in the closet during most of my school years, but I never felt personally and purposefully discriminated. It wasn't like on TV. with being bullied. It also helped that I was the size of my school, so it's not like people were going to bully me.

Throughout the interviews, Jesse never mentioned being gay until he stated that he married another guy. That was when I asked if he could talk about it, so he elaborated on how it influenced his pedagogical beliefs:

As a teacher, I don't think being gay interferes with the way I approach things, but it definitely changes things. I've always been very open about my sexuality. I've never made it a big political thing. I have colleagues who disagree, who like to keep their lives private. To me it's important to be open about it because there's a lot of kids who need like a positive role model, and I think that it helps. 
Jesse found that being gay was an important part of his cultural identity, which allowed him to be a positive influence on his students. Although he denied it, being gay influenced his worldview.

Jesse stated that he did not feel discriminated within Miami; however, he found the culture outside of Miami as different and representative of another country. He explained:

I don't think anybody singled me out for being Cuban-American in Miami. I don't know if it was because I was the majority, but I never felt discriminated. When I left to the University of Michigan for my PhD, I realized that the culture there was not for me. The people were nice, but it was too cold, and I missed everyone. I was there for three months and came home.

Jesse found himself in a different cultural environment in Michigan. He realized that Miami was a different cultural place. He continued:

I have gone to other places, even in New York, and it always felt like a different country. Everywhere else something was lacking. A certain flavor. I don't know if it's the weather, if it's the people, but something was missing. I mean where else can you wear flip flops all year, eat croquettas [traditional Cuban food], and drink Cuban coffee.

Jesse had a tacit understanding that as a Cuban he belonged to the majority and dominant cultural group in Miami. The understanding of belonging to the dominant cultural group in Miami may be a reason for why he did not report any discriminatory experiences. Outside of Miami, Jesse's depictions of "something lacking" was in relation to Cuban culture. In his words, it was the uniqueness of Cuban culture in Miami that was missing. 
In a final question on his Cuban identity, Jesse added cultural difference between older and younger Cuban generations, or pre-Mariel and post-Mariel Cuban immigrant groups. He simply stated that "there's a Cuban subculture between older Cubans and younger Cubans and those who grew up here and those who grew up in Cuba" without much elaboration. As a second-generation Cuban immigrant from a family that arrived in Miami before 1980, Jesse is regarded as part of the pre-Mariel group (Portes \& Armony, 2018).

Discussion of Jesse's ethnic and cultural affiliation. Jesse affiliated with being both Cuban and American. His affiliation with being Cuban is reflective of his Cuban descent and being raised in a Cuban environment. His identification with being American was by reason of birth. He associated American culture in value-laden terms like individualism. Jesse's grandparents and parent's movement throughout Miami is indicative of upward social mobility in predominately Cuban areas. It appears Jesse was raised in a mostly middle-class predominantly Cuban environment. The schools attended were predominantly Cuban and non-Cuban Hispanic. Jesse's ethnic and cultural identity was reinforced through family dynamics. He learned Cuban norms, traditional ethnic foods, and Cuban history from them. Although Jesse retained and understood Spanish, his main language of choice was English; therefore, Jesse was a fluent bilingual. Jesse also found that being gay did not interfere with his approach to education. In fact, he used his identity as a positive pedagogical tool for students struggling with identity.

Jesse did not report instances of discrimination within and outside of the Cuban enclave of Miami. He understood that in Miami he was part of the majority Cuban culture. Outside of Miami, Jesse realized that Miami's culture was different than 
mainstream American culture. He saw himself as a "cultural other" by missing Miami's unique Cuban culture. Jesse also acknowledged a cultural difference, or bifurcation between the different generations of Cuban immigrants without mentioning in which one he belonged. Jesse exhibited a mixed affiliation between his Cuban cultural identity and being American.

\section{Jesse's Educational Beliefs on Student Learning and Teaching}

Jesse explained his reasons for becoming a teacher, philosophies on learning, teaching, and instructional practices. First, he communicated the unexpected reasons for becoming a social studies teacher:

I fell into teaching by accident. I had no general idea of what I wanted to do. I knew I had to go to college, but I didn't know what I wanted to study so I started taking all these social studies classes. At one time I was an English major, a psychology major, and at one point I was going to law school like everybody else. A friend of mine that was doing education said, have you ever considered teaching? You like tutoring and counseling people. Why don't you try education? So, I took education classes and I didn't hate them, and I loved my internship. Jesse viewed teaching as a career that allowed him to use his expansive knowledge for the benefit of others. In education, Jesse found a way to help people. Jesse continued by expressing his view of education:

Teaching is kind of an art and science. You can know all the content in the world, but you need to know how to deliver it. It is about empowering people to make change and helping them discover that within them. Make well-informed student citizens. Engage in open-minded conversations. Make them aware of how the past 
influenced today, and how today influences tomorrow. Help them to understand how they can get involved, how things directly and indirectly affect them, and how they can make a difference. Make the material matter to the student's lives. Jesse expressed his teaching philosophy in terms of student empowerment, citizen education, open-mindedness, and student relevancy. In this regard, Jesse advocated a philosophy of education based on student-centered principles of learning. Jesse depicted his instructional practices during a typical day in his classroom:

At the start of the day I'll give the students some manipulative activity, like a journal. But, most of the time it's a discussion that covers the material. We then do Socratic circles, or worksheets, or materials where the students work on their own. I'm a big fan of sitting around in a circle and discussing and asking openended, but leading questions, so that it might spark conversations. Then we'll finish with some culminating activity like a project or class activity. I like to do projects in class because it helps the students know that they have a support structure if they need it or get lost. And it is a good time to reflect.

Jesse utilized various instructional activities, ranging from writing to projects and discussions. Jesse then reflected on his style of teaching:

I'm the type of teacher that helps my students to develop things on their own, and to challenge what they know while seeking out information on their own. I don't lecture so that's probably what I do least. Students don't have the attention span to hear a long lecture. If I do lecture, then I'll turn it into a discussion. I'll say here's a question. What do you think? And then I'll interject and ask more questions. 


\section{Discussion on Jesse's educational beliefs and instructional strategies. Jesse}

believed that a teacher is an artist who uses their creativity to develop student empowerment through learning, student engagement in tasks, and open-mindedness to criticism. He found historical learning to be about more than the subject content but about societal change and relevancy. In this belief, Jesse touches on aspects of social justice education.

Jesse's instructional practices rely heavily on student-centered activities, such as open-ended discussions to spark multiple student viewpoints and project-based assignments. Jesse also utilized teacher-centered instruction with worksheets and teacherdirected discussions based on questions and answers. However, Jesse believed these activities were to foster critical thinking, individual learning, and guided instruction. Jesse believed that his teaching allowed students to challenge the status quo and take responsibility for their learning. In this respect, Jesse saw himself as a guide in the learning process, albeit at times with a predetermined outcome in mind. In this respect, Jesse believed in student-centered learning and attempted to practice student-centered instruction.

\section{Jesse's Perspectives on the Official Curriculum}

Jesse accepted the use of the state standards, pacing guides, and state assessments, which make up the official curriculum, as part of the teaching experience. However, he had issues with all of them. He explained:

The state standards are there as a guide, but are not definite, or aren't there to go unchallenged. Sticking to the pacing guides makes it seem like there's a formula to teaching. When I used to work in the district, tests were $35 \%$ of your grade. I 
have free rein now, so I make them $20 \%$, and I'll make projects worth more because it's a more accurate assessment.

Jesse viewed the state standards as a tool for teaching. He expressed concern that they were used by teachers as an exclusive method of instruction. Jesse continued by explaining how student assessment should not be the only measurement of student knowledge:

We are in a test society, so students need to be cognizant of the format, but I don't make it a focal point. How these tests are written it's not the best measurement of how students have done all year.

Jesse described some reluctance to society's reliance on standardized tests. But he found them to be inaccurate in completely assessing his students.

Jesse also held similar positions with the social studies textbook by viewing it as a reference guide for information and not as a resource to be used exclusively in instruction. He expressed this opinion:

The textbook tells what you want to cover, but it doesn't tell you how to teach it. The textbook should be something that people use to give them background and reference information because it makes it condescend and concise, but it shouldn't be used as a crutch that people lean on to teach.

Once more, Jesse believed that the official curriculum's tools were to be used by the teacher as a guide for instruction. In other words, Jesse believed that teaching went beyond what was mandated by the state and district guidelines of the official curriculum. In this respect, Jesse spoke about the American historical narrative found in the social studies textbooks. He said: 
There were no alternative facts in the social studies textbooks, but I challenge the textbook all the time. The facts are static, but that doesn't mean they don't change. Sometimes I'll have the students read something and say, ignore this because it's false. The textbook is not always right! I'll pick and choose what's important from the textbooks depending on what I'm planning to cover.

Jesse accepted some of the facts of the American historical narrative. Yet, he also found that information to be inaccurate at times. Instead, Jesse privileged some information over others. Jesse explained how he did this:

If you're going to teach American history, then you want to cover what happened in this country and get to the core of Americanism. You can't avoid slavery, or how women contributed to American history. You have to find ways to make them central to the story.

It appears that Jesse chose information that was controversial in the American historical narrative. By doing this, Jesse challenged the information in it. He continued to explain why he did this:

Just because the information in the textbooks makes people feel uncomfortable doesn't mean we can't teach it. That's like saying we can't teach the Holocaust because it makes people uncomfortable. I think that we should teach things that make you uncomfortable because that's how you grow outside of your comfort zone. I don't see how that takes away from American unity. It's because we all have different stories to tell that unites us.

Jesse felt American unity is the basis for the American historical narrative. He believes that this requires social studies teachers to challenge the information in the American 
historical narrative by adding alternative stories and embracing controversial topics instead of avoiding them. Peck and Herriot (2015) found that social studies tend to avoid discussing topics that make them feel uncomfortable. Jesse opposes that notion.

As an example, the researcher asked whether Jesse taught his class about Fidel Castro who had died during his teaching duties. Jesse explained why he chose not to teach about this local pertinent event:

Castro dying never came up in class. If it was brought up it was inconsequential because I don't have that many students who care. I can see why people are happy. And I don't think he's a great person. But I don't want people to celebrate death. I don't think that him dying changes anything. I guess it was more symbolic than anything else.

Jesse chose not to teach about Castro's death because he did not believe in its relevancy to his students' lives. He understood the meaning behind his death but decided that the information did not matter to his class.

Discussion of Jesse's adherence to the official curriculum. Jesse's perspectives toward the official curriculum revealed a disruptive stance. He accepted the state standards and understood that they influenced his instruction (Mathews, 2013). That is why he stated that he did not rely on them. Jesse also understood that the state tests were part of the school's and state's policies. Nevertheless, Jesse did not believe in their accuracy for a complete assessment. Jesse believed that assessments should be about student progress and should be conducted in holistic ways utilizing various forms of measurements (Peck \& Herriot, 2015). 
Jesse viewed the social studies textbook as useful only as a reference guide and found it open to interpretation. Jesse challenged aspects of the historical narrative found in social studies textbooks. First, Jesse challenged the authoritative stance of American history textbooks by decrying some of the information in them. Second, Jesse added stories of marginalized groups, such as women and African American groups. Finally, Jesse openly discussed controversial topics like racism and the Holocaust. Only in certain instances did Jesse challenge the dominant ideology of the official curriculum (Davis, 2019).

\section{Jesse's Attitudes on Teaching Culturally, Racially, Linguistically Diverse Students}

Jesse believed in teaching culturally, ethnically, and racially similar and diverse students in ways that promoted their cultures. First, Jesse explained why having the same culture as his students helped with pedagogy:

with ESOL (English Language Learners) you have to teach them differently. It's easier for me because I speak Spanish, and I can manipulate this to help them behave, and make connections with them. You know the population and can make things relevant to them.

Jesse's similar culture and language helped to better communicate with his students. But he also regarded cultural and linguistic similarities as beneficial in making connections with his students of similar cultural backgrounds. Jesse then spoke about how he instructed culturally and racially different students:

I had a large Black population once, and it was a culturally different experience. Things that would have worked with my Hispanic students didn't work with them. There was more apathy. And I was trying to make connections, make the 
material relevant. And I didn't know the pop culture, and what their life was like. It wasn't that I couldn't teach them. I just had to figure out ways to teach them differently.

Jesse was aware of his limitations in teaching racially and culturally different students. He understood that he had to learn about their cultural backgrounds to be an effective instructor. In one culturally conscious moment, Jesse reflected:

I don't know if I would have taught this way if I would have come from a privileged background. I don't know if it's specifically Cuban-American because I come from a minority background. Maybe if you're culturally similar it's a lot easier to make connections. But you have to know the population. So, if you're not comfortable or knowledgeable enough with that population, then how are you going to reach them?

\section{Discussion of Jesse's attitudes toward teaching culturally, racially, and}

linguistically similar and diverse students. It appears that Jesse was culturally aware of how his cultural and ethnic background influenced how he taught both culturally and ethnically similar and racially diverse students. He understood that teaching required an understanding of the student populations' lived experiences. He also acknowledged that his cultural identity helped with students who were culturally and linguistically similar because he spoke the same language and understood their life's situations. On the contrary, Jesse also accepted that with his culturally and racially diverse students he had to learn about their life and environment so that he could teach them differently. However, he admitted that he lacked the pedagogical methods of instruction to teach racially and culturally diverse students. In this respect, Jesse's cultural consciousness 
revealed an incipient desire to affirm cultural diversity and incorporate culturally inclusive pedagogy but lacked the requisite knowledge to conduct it.

\section{Summary of Jesse's Cultural Identity, Educational Beliefs, and Curricular}

\section{Decisions}

Jesse associated with a Cuban-American identity. He identified his Cuban identity through cultural markers, such as traditional ethnic foods, language, and religion. Jesse solidified his Cuban identity through his family's experiences as exiles and with Cuba's pre-Castro and pre-communist historical roots passed down in the family. However, Jesse also incorporated elements of what he saw as American culture, foremost, speaking exclusively in English and adopting American individualism. He reported no discrimination in Miami. He saw Miami's culture as different and unique in comparison to other cultural places. He understood that he belonged to the dominant ethnic and cultural group in Miami. Therefore, Jesse expressed a strong affiliation to both Cuban and American culture.

Jesse expressed his pedagogical beliefs on learning and teaching in studentcentered terms. Jesse believed that learning was to empower students for societal change and to take ownership of the learning process. Jesse's role as a teacher was to guide his students in learning tasks. Jesse promoted students' cooperation and collaboration, multiple perspectives, and individual student learning.

Jesse took a disruptive stance to the official curriculum by utilizing the state standards solely as a guide. He diminished the role of the state and district standardized tests by using other forms of assessments. He also challenged the American historical 
narrative by adding stories of marginalized groups. Although Jesse used the American historical narrative in his pedagogy, he found ways to disrupt the dominant story line.

Jesse used his bicultural identity to better instruct culturally and linguistically similar students. Although Jesse described having trouble with teaching culturally and racially diverse students, he did attempt to make the material relevant to the students' lives. Jesse believed in culturally inclusive pedagogy.

\section{Analysis of Jesse's Cultural Consciousness and Cultural Competency}

Jesse used his cultural identity as an attempt to become a strong culturally competent teacher. Jesse's beliefs on teaching are based on culturally inclusive pedagogy. Jesse's educational beliefs on learning and teaching attempted to instruct according to students' needs in which he acted as a guide. Jesse's perspective on the official curriculum was indicative of a teacher who challenged the status quo in school policy, assessment, and the American historical narrative. Jesse approached the curriculum through a pedagogy of inclusion by adding marginalized groups and openly discussing controversial topics. Jesse exhibited an incipient appreciation for becoming a culturally competent teacher.

It appears Jesse was culturally aware of his strengths and limitations to instructing students of diverse and similar backgrounds. In discussing how he taught culturally and linguistically similar students, he recognized the pedagogical strength of understanding their language and culture. In a culturally conscious moment, Jesse also realized that he lacked an understanding of the culture and skills to effectively instruct students of diverse backgrounds. Jesse demonstrated an affirming attitude and open-mindedness to willingly teach toward cultural competence. 


\section{Diana: The Humanist Teacher}

At 22-years old Diana was the youngest teacher-participant in the study. She was also a previous student of mine in a college social studies methods course. Diana selfidentified as a Christian Cuban-American. She was interviewed three times in different locations around the university where she earned her bachelor's degree, and where she was pursuing her master's in social studies education.

Diana was in her second year of teaching in a predominantly Hispanic, mostly Cuban, middle-school in a lower-income area in west Miami. Her teaching assignments consisted of seventh-grade American History, which was state tested, and sixth-grade World history, which was not state tested. Diana was succinct in her answers, and often described Cuban cultural traditions, foods, and mannerisms in expressive terms.

\section{Description of Diana's Ethnic and Cultural Identity}

Diana described how her family moved from Cuba and ended up in Miami. She also depicted the demographics of the schools she attended. She began:

I was born in Miami. All my grandparents were born in Cuba, so they speak Spanish. They came over as teenagers in the 1960s and were raised here. My parents were born in New York and moved down to Miami. They all lived in Westchester and I still live there now. I attended all Christian private schools in Westchester where my Mom was a teacher, so the tuition was paid. She like followed me around. The students I went to school with were mainly Cuban. If you were something else, then you were something else, and Cuban. 
In Miami, Diana was raised and attended schools in Westchester, which has the second largest concentration of Cuban-Americans in the United States after Hialeah (Portes \& Armony, 2018). This is how Diana described her cultural and ethnic identity:

I am Hispanic, but mostly Cuban. But I am Christian before I am a teacher, before anything else. I consider myself White Hispanic because it is more about culture, or ethnicity. I don't know. I only consider it when I have to check off boxes. If you're Hispanic, there's unity, but if you're Cuban there's more unity. I think I'm Latin, but not Latina. Being Latin means being from [long pause] another country like Venezuela or somewhere else.

In regarding herself foremost as Cuban and then Hispanic, Diana chose a national identity over a pan-ethnic label; however, she did not label herself as a Latina. Instead, she regarded herself as part of a broader Hispanic identity. Diana, in an ambiguous explanation, considered herself racially White but only for governmental purposes. This means she only writes White when she answers for government identification. Yet, Diana pointed out that she valued a religious identity above all other ethnic and cultural identities. Diana continued by explaining which characteristics makes up her Cuban culture:

Cuban culture is growing up and saying hi with kisses on the cheek. If you didn't then it was disrespectful. Foods like croquettas (traditional Cuban cafeteria food) are a big part of our lives. Our belief in God. The parties like Noche Buena (Christmas Eve) and the loud music. So, if somebody doesn't celebrate Noche Buena it's kind of like, what do you celebrate? The way we talk. At times being 
too loud. Putting family first. Speaking Spanish, but I learned it a long time ago so I'm not very good.

Through different cultural characteristics, Diana expressed her Cuban identity in language, mannerisms, foods, religion, and traditional practices and festivals.

Diana saw American culture represented in one's physical attributes. She referenced an uncle who she considered American:

I have an Uncle Ron in the family, but that's because my aunt married someone who was White from California. He's blonde and blue eyes. He's the only Uncle Ron. Other than that, everybody's Tio or Tia (uncle and aunt). I guess I didn't realize that Cuban culture was so different until I started being with people who weren't Cuban when I got older.

Diana associated American culture with physical characteristics, such as being White, blonde, and blue-eyed, which are indicative of attributes in the dominant American mainstream culture. More importantly, Diana viewed these cultural differences in comparison to other non-Cuban cultures. Diana also began to realize differences in her cultural identity when she saw people that were different from her.

In defining Cuban cultural characteristics, Diana held that family remained one of her strongest Cuban cultural traits. She portrayed it like this:

My Mom and sister are very close. They text all the time, “where are you”? My grandparents wanted to keep everything Cuban. If I'm dating someone they would ask, "are they Cuban"? And if they weren't Cuban then my Abuela (grandmother) would say “why not Cuban”? My parents are a little more lenient about it. They didn't really care about that too much. 
Diana also learned about her Cuban roots through family:

I would hear about how my grandparents fled Communism and the Castro regime because they wouldn't join them. They were going to die, or go to prison, and they wanted a better life, so they fled to the United States. Everyone knew about Fidel, and how he was the Hitler of Cuba. It wasn't something taught in school. We were taught this through our parents, yet it was unspoken.

Diana then explained how political awareness was instilled through the family as well: We were all conservative. I remember when elections would come around, they would ask, "who our parents were voting for, Republican or Democrat"? And we were all usually Republican. I think one-person would be Democrat and we were like, "what the heck? That's so different".

Diana's closeness to family was an important factor in shaping her cultural identity. It was within the family unit where Diana maintained Cuban traditions, Cuban stories, enmity toward Castro and communism, and the importance of political participation. As for experiences with discrimination, Diana related two stories when she was mischaracterized as being from another nationality when she traveled outside of Miami: I have never felt discriminated in Miami because I'm Hispanic and I can relate. But, if you were outside of Miami, they would most likely think I'm Mexican. They wouldn't think Cuban. I went on a cruise, and some people who we met were like, “Oh you're Hispanic. You're Mexican”. And we're not Mexican and why are you saying we're Mexican?

Diana recalled another episode: 
I remember when I was in grade school, we went skiing in North Carolina and somebody said, “Oh, so you guys are Mexican”, and I was like, "we're not Mexican, we're Cuban. Who are you to say we're Mexican"? And I'm like, Oh, Ok, because majority of immigrants are Mexican, and I didn't get that until I was older.

Diana reported experiencing no ethnic, racial, or cultural discrimination in Miami because she realized she was part of the dominant cultural group. In places outside of Miami, however, Diana was labeled Mexican and understood that she belonged to a minority group within the United States.

Within Cuban culture, Diana also understood generational differences between older and younger Cubans. She elucidated:

I've seen different generations of Cubans. There was my grandparents' generation, and then there's the newer generation that comes now. They are more like, [pause] the dale, acere. [Cuban slang words] If you speak to my sister that way she will be repulsed. And my grandfather would never say something like that.

Diana understood the Cuban cultural differences between the recently arrived Cubans and post-Mariel group of 1980 with the older Cuban pre-Mariel group of Cuban immigrants. It appears that Diana associated with the older generational group of Cuban immigrants because she disliked the way they spoke Spanish. This could be because Diana was a third-generation offspring of a pre-Mariel group of Cuban immigrants (Aranda et al., 2014; Portes \& Armony, 2018) 
Discussion of Diana's ethnic and cultural affiliation. Diana's parents were the only ones in this study who were both born in the United States. Diana was raised in Westchester, a middle-class suburb of Miami with the second largest concentration of Cubans in the United States (Portes \& Amory, 2018). Diana attested that her environment was predominantly Cuban, where along within her family unit, she learned Cuban cultural beliefs and practices.

Therefore, Diana strongly self-identified ethnically and culturally as Cuban, yet she placed this within the pan-ethnic umbrella label of Hispanic. This was, however, superseded by her Christian unitarian identity. She considered herself racially White, therefore racializing her ethnicity in accordance with dominant mainstream European American culture (Cobas et al., 2009). American culture was described through physical characteristics, such as White, blonde, and blue eyed. In contrast, Diana expressed Cuban cultural characteristics in traditional cultural and ethnic markers of customs, mannerisms, foods, religious beliefs, festivals, music, and language. Although Diana associated Spanish with Cuban culture, she preferred English over her native language. Through her family, Diana learned the exile ideology and Cuban history, such as hostility towards Castro's communist government. She was also inculcated in the preservation of Cuban traditions, norms, and culture and political participation. Thus, Diana selectively acculturated Cuban cultural characteristics while also absorbing American cultural traits like speaking English (Aranda et al., 2014; Portes \& Armony, 2018; Portes \& MacLeod, 1996).

Diana did not experience discrimination in Miami because of its pan-Hispanic culture. She also saw Miami as a different "country" within the United States because of 
its unique Latina/o/x culture. In Miami, Diana expressed comfort for being Cuban, whereas outside of Miami she was called Mexican, a label she did not like. In this regard, Diana recognized she was a minority and acknowledged that she belonged to a Latina/o/xx group, but she self-identified primarily as Cuban. But, by recognizing the “other" through her cultural experiences, Diana's own Cuban identity was reinforced.

Diana also recognized differences between the older and younger generations of Cuban immigrants. She attributed these cultural differences to how the recently arrived younger generation of Cuban immigrants spoke Spanish. In a sense, Diana revealed the cultural and social distancing between the pre-Mariel and post-Mariel groups of Cuban immigrants (Aranda et al., 2014; Portes \& Stepick, 1993). In this respect, Diana associated with the older generation, pre-Mariel group of Cuban immigrants because she is the offspring of them (Aranda et al., 2014; Pedraza, 2007; Portes \& Armony, 2018).

\section{Diana's Educational Beliefs on Student Learning and Teaching}

Diana explained her philosophy on teaching and learning by first describing the characteristics of her best high school teacher. She stated:

I had this one teacher, Mr. Hutchinson, who when I had questions about God, I would talk to him. I really did admire how much he put into the students, how much he cared, and how he communicated with us. He would teach us geography, but would bring in culture, what they ate, and how it's different. It felt like he had conversations with us. All the work had a purpose behind it.

Diana also compared how the rest of her high school history teachers were like:

I remember some of my other history teachers, and all they gave us was busy work, like the questions at the end of the chapter, read the chapter, do the test, and 
I didn't learn anything from them. They didn't do any fun stuff that I hope I do with my students.

Diana's reflection on her best teacher revealed pedagogical attributes, such as caring, communication, and life lessons. These traits were something Diana would attempt to emulate as a teacher. Diana also saw attributes in her worst teachers that consisted of "boring" rote learning, reading and answering questions from textbooks, and frequent summative tests, which are representative of teacher-centered instruction (Sharan, 1990; Weimer, 2013). In this regard, Diana felt that traditional forms of instruction were not appropriate for learning. Therefore, Diana developed an educational philosophy consistent with student engagement. She described it:

Teachers should care about their students and take lessons in class and make them into a life lesson. I could be a teacher that teaches more than the subject. I could teach to be good citizens and have conversations with my students. I would want to make an impact and have relationships with the students. I like that part of teaching history.

Diana's philosophy on education rested on the caring teacher who built lessons around students' lives. Therefore, Diana believed that education was about student relevancy. Diana also believed that teachers need to establish good relations with their students so that they can make an impact in their lives. In instructional practice, Diana depicted a typical day in her classroom:

When students walk into my classroom, they get something called a classy notebook and they'll do a journal, or some CNN student news, on which they'll write a paragraph on. Then I'll most likely lecture on the topic, but my lectures 
are more like storytelling. I do PowerPoints because it's very structured, and because they're tested with the EOC [End of Course Exams]. I tried to make lessons into real life examples, and play "devil's advocate" in discussions to defend the other. I try bringing another perspective.

Diana then explained how she conducted various cooperative activities: In group activities, I put the students according to how good or bad they did on the standards so that the stronger ones can help the weaker ones. I've had them do activities like a magazine on Jamestown where they have an image on the cover, and inside they had to make up two interviews with the first granddaughter and the first person born. I had them do a flip book on the American Revolution, and posters, or comic book strips, and little fun activities that I think they like.

Diana continued by illustrating one of her best lessons:

In one lesson, I began by lecturing about taxation without representation. Then, I broke the students up into groups and gave each student thirteen M\&M's for the thirteen colonies. I was King George and even had a crown made for myself. I had some students go outside and make some laws. If they had blue pants on, they would be taxed two M\&M's, or if they wore braces then it was five M\&M's. I even made some students tax collectors. They started getting really mad. They kept asking, "why are you doing this, and this isn't fair!" And I said, "that's what happens when the King taxes without any representation". Then I showed them all the M\&M's I had taken from them. They got the emotional part.

Diana's instructional methods consisted of teacher-centered instruction, such as lectures, which she depicted as storytelling, and individual free writing activities through journal 
entries and note-taking. Diana also included student-centered instructional activities, such as cooperative and collaborative project-based activities and discussions based on multiple perspectives where Diana countered students' arguments. In her favorite lesson, Diana utilized role-playing to apply her best instructional practices. It is noteworthy to note that Diana described these last activities in an enthusiastic manner.

Discussion on Diana's educational beliefs and instructional practices. Diana strived to be a teacher who taught more than the subject matter. She wanted to have meaningful conversations and communications with her students. Diana wanted her lessons to incorporate student relevancy and "life lessons" just like her favorite high school teachers had done earlier. Diana's purpose in social studies education was aligned with democratic citizenship education. Diana felt that education should have an impact on students' lives. From her experiences as a student, Diana found teacher-centered instruction, such as reading and answering questions from the textbook, lectures, and note-taking as dull and tedious. In educational beliefs, Diana appears to believe in student-centered instruction.

Diana's approaches to teaching did encompass multiple student-centered activities. Diana incorporated cooperative task-orientated activities, such as project-based group activities and role playing. However, her student groups were selected according to her perceptions of academic performance. Diana's discussions were used as a method to develop multiple perspectives and spark debate, yet Diana remained at the center of discussion. However, it was Diana's most utilized instructional method in the lecture, which inclined her toward a teacher-centered approach. Diana even attempted to frame her lectures as 'storytelling' as to align herself to her beliefs of active student 
engagement. Regardless, most lectures are an instructional activity of learning where the teacher, acting as an authoritative voice, imparts knowledge to their students (Mascolo, 2009). Without personal observation of Diana's lectures, it is difficult for the researcher to draw a sound conclusion to her "storytelling" techniques. Weimer (2013) acknowledged that lectures can be student-centered; however, it is contingent on the teacher to allow students' control of discussion.

\section{Diana's Perspectives on the Official Curriculum}

Diana viewed the official curriculum as a requirement imposed by the state that she was supposed to follow. This was apparent in how Diana compared her state tested seventh-grade classes and her sixth-grade non-tested classes. She explained the different approaches taken for both classes:

For my seventh graders, I have to use the state standards and pacing guides because I have to be accountable to the district, and we are assessed with them. This is between you and me, I hardly looked at the pacing guide for sixth grade because it isn't going to be tested.

Apparently, Diana approached both classes quite differently dependent on whether she was required to do so or not. Diana continued by stating her views toward state assessment:

I have a love/hate relationship with the EOC [End of Course Exams] because I love how it's structured, and I know exactly what I need to teach, and where I can get it, and what exactly I need to do, but I don't like all the testing. Honestly, after testing nobody bothers me. 
Once again Diana took different approaches to her classes with regards to testing. Since Diana was only a second-year teacher, she appreciated how the EOC helped organize her lessons, but she also revealed that all the testing impeded her teaching.

Diana explained her perspectives toward the information inside the social studies textbooks, or the American historical narrative:

Personally, I don't like the social studies textbook. It's not aligned to the standards. I didn't find any information in the historical narrative that was bogus, or that was wrong. I found information that they placed so much emphasis on, and not enough emphasis on something else. It gives a lot of information that was not easy to convey, so, I added more information to it because I know this information is more valuable.

Diana then justified how she used the information found in the social studies textbooks: I try to connect this information to my students. For the sixth-graders, I go in the order of the textbook as a guideline. I choose what I think is important. For seventh grade, I don't use it because there's this gateway book that the school wanted me to use.

Diana demonstrated an ambivalent attitude toward social studies textbooks and the information found in them. She seemed to agree with the factual knowledge yet felt that it placed too much emphasis on some parts and disregarded others. Therefore, Diana at times, added outside information to make it clearer for her students. Also, Diana chose information that connected to her students' lives.

The researcher asked the teacher-participant about the relevancy of Fidel Castro's death, which occurred during these interviews. Diana only slightly taught about the death 
of Fidel Castro, even though her classes were made up of predominately Cuban students. She explained why:

My students were very happy when Fidel Castro died, so, I asked, Well, isn't he a person? or How did he get into power? or How can we compare this to other things? and Why is this important? Then we talked about it a little bit. A lot of them are just happy that he died, and so I try to bring another perspective, and then they were like, oh, okay, yeah, he's a person, but he was really mean, and we left. And I was like, okay, yes, let's move on.

Diana took a humanistic approach to teaching by portraying Castro as a human being, rather than a ruthless leader that her students may not have liked. It could be ascertained that this was in part because of her Christian identity. She believed that Castro was a human being and should not be demonized upon his death.

Discussion on Diana's adherence to the official curriculum. Diana appeared to oppose the state standards because she acknowledged not using them in her state-tested classes. But, by her own admission, she followed the state standards because it was a requirement by the state and district and never challenged the dominant ideology found in them that has been known to influence instruction (Davis, 2019; Mathews, 2013). Also, Diana's dislike for state exams was framed around the number of tests administered and not the purposes for assessments. Diana accepted the accountability measurements of the state exams as an accurate measure of student knowledge (Peck \& Herriot, 2015).

Diana stated that she did not find any information wrong in the American historical narrative. Therefore, Diana followed the tenets of the official curriculum. The only time Diana disrupted the American story was when she added materials, chose 
which information to privilege, or discarded information she deemed unimportant. However, the information chosen from the social studies textbooks has been found to follow a dominant American ideology (Cruz, 2002; Urrieta, 2005). Diana never added her own culture or her students of diverse backgrounds' cultures and histories. This is even more troubling because most of her students shared the same Cuban and Latina/o/x cultural identity. Diana did not teach for a culturally inclusive pedagogy because she did not oppose, disrupt, or challenge the official curriculum.

\section{Diana's Attitudes on Teaching Culturally, Racially, Linguistically Diverse Students}

Diana explained the differences between teaching students from her same culture and racially diverse students. She first elaborated about how she taught students who were culturally and linguistically similar:

With my ESOL (English Language Learners) students, I try to make the material connect to their lives. It's the same content, but I expect different results. I might give them solely multiple choice while I expect the regular students to give me a written answer. I might give them extra time, or, I'll let them work in groups. I give them tablets that has translators on it. But, overall, it's the same information. They're just getting it in a different way, or form, or with extra time.

Since her students were mostly Cuban or from other Latin American countries, Diana acknowledged that she had not taught many non-Hispanic Black students, so she provided an example of when she interacted with one non-Hispanic Black student. She said:

I taught this one African American student and I remember him getting very upset and agitated when we talked about slavery. I ended up bonding with him over 
what he liked, football. I made an effort to learn about football or ask him

questions about it. And, I used examples of football teams in class. I even went to go see him at one of his games. Ever since then he didn't give me any problems because he saw that I was trying to make an effort to go and support something that he was passionate about.

Diana made a connection by finding a hobby for her racially diverse student. However, Diana did not use slavery to teach for the students' culture. In other words, Diana ignored the issue and found another way to interact. Therefore, it cannot be said that Diana used culturally relevant and responsive pedagogy on this one student.

\section{Discussion of Diana's attitudes toward teaching culturally, racially, and}

linguistically similar and diverse students. Diana believed that linguistically, ethnically and racially diverse students should be taught the same content as every other student, although utilizing various resources. In this regard, Diana held a color-blind perspective (Logan, 2017). For English Language Learners (ESOL in Miami) she used the same information as her regular students but allowed for group help, tablets, while assessing them in a different fashion. Diana did not acknowledge the culture of her racially diverse student. Diana used one of his hobbies to make a personal connection with his cultural background. But, was this one critical incident enough to draw a conclusion on her cultural competence?

\section{Summary of Diana's Cultural Identity, Educational Beliefs, and Curricular}

\section{Decisions}

Despite Diana and both her parents being born in the United States, she still selfidentified foremost as Cuban. Diana's association to Cuban culture was formed in part 
through her primarily Cuban environment where she was raised. She characterized Cuban culture through traditional cultural markers and American culture through physical characteristics. Diana's educational beliefs were student-centered, and she utilized multiple student-centered activities for instruction. However, Diana's most utilized instructional method was the teacher-centered lecture. Diana advocated for a pedagogy that was the same for all students, yet, she used her cultural background to aid culturally and linguistically similar students. When Diana taught culturally and racially diverse students, she attempted to make personal connections. Diana accepted the official curriculum as a state and district requirement. She only demonstrated instances of disruption to the official curriculum by adding materials to the American historical narrative and privileging information. However, she did not incorporate her own culture and the cultures of her predominately Cuban and Latina/o/x students into the curriculum. In this regard, Diana accepted the tenets of the official curriculum. Her only instance of opposition was when she chose not to follow the state standards in her classes that were not state tested. But Diana did not challenge the state assessment measures or the information in the tests.

\section{Analysis of Diana's Cultural Consciousness and Cultural Competence}

Diana did not appear to be aware of her beliefs, biases, and prejudices toward her pedagogical beliefs, practices, and curricular decisions. In describing her cultural identity, Diana defined her social and cultural differences between the pre-Mariel group and the post-Mariel group of Cuban immigrants. In this regard, Diana seemed to believe that she was culturally superior to the post-Mariel group (Aranda et al., 2014). In fact, Diana was aware that she belonged to the dominant ethnic and cultural group in Miami. Yet, her 
derision for being labeled Mexican outside of Miami made her realize that she was a minority in the United States.

In her educational beliefs, Diana spoke about building relationships with her students and applying student-instruction. However, Diana mostly utilized teachercentered instruction in her pedagogy. Weimer (2013) posited that teachers used mostly teacher-centered instruction when they wanted to control the learning process. Diana appeared to want to direct the information the students learned, rather than allowing them to construct their own knowledge. Nevertheless, Diana attempted to frame her lectures in what Mascolo (2009) called active learning by attempting to engage students in conversations which she believed to be student-centered.

Diana did not oppose, disrupt, or challenge the official curriculum. In fact, Diana stated she accepted the information found in the American historical narrative, agreed with state assessments, and used the state standards for guidance. Researchers have pointed out that most teachers lacked adequate pedagogical training, had little multicultural knowledge, or demonstrated an unwillingness to teach for cultural competence (Busey \& Russell, 2016; Mathews, 2013; Shares, 2017; Yilmaz, 2008). Yet, Diana showed some cultural competence when instructing students who had similar cultural backgrounds. Regardless, Diana appeared to be a teacher who taught mostly from a dominant ideological perspective, although in a few instances she demonstrated some cultural competence.

\section{Jose: The Political Teacher}

I met Jose for three interviews at the high school where he was currently teaching American government, economics, American history, and world history. At the time, Jose 
was in his early 50s with close to 30 years of teaching and administrative experience in MDCPS. This made him the oldest and most experienced teacher-participant in the current study.

Jose had taught in various schools throughout MDCPS including a predominantly Haitian urban high school, a suburban predominantly Cuban and Hispanic school, and in various charter schools. Jose was teaching at a suburban charter high school in a middleclass to upper-class area of west Mami. The school's demographics were predominately Cuban with a large population of recently immigrated Latina/o/x students from South America. Jose was the most opinionated of all the teacher-participants, especially on topics such as Cuban history, politics, and Cuban identity. I observed that he would raise his voice to emphasize a belief or point. Jose also is one of two teacher-participants in the study who were born and attended schools in Cuba during the Cuban revolution. Jose strongly self-identified with his Cuban identity with a strong political inclination.

\section{Description of Jose's Ethnic and Cultural Identity}

Jose described his family's arrival to Miami, how he lived under Castro, and about growing up in a communist country. He first described why his parents emigrated from Cuba:

My parents came over to Miami in 1979, six months before Mariel. My father worked in a labor camp in Cuba, and the reason he left was because Jimmy Carter wanted to extend a hand to Castro, so he allowed a lot of ex-prisoners and men who had been in labor camps to reunify with their families in the United States. I came at an early age and I remember everything in Cuba. 
Jose and his parents were part of the pre-Mariel older generation Cuban immigrants. Before arriving in Miami, Jose had lived and attended schools in Cuba under the Castro regime. Jose recalled one aspect of his life under Castro as a child:

We would go down to the river and throw flowers for Cienfuegos, who Castro probably had killed, and all the martyrs of the revolution. They are probably martyrs because Castro went ahead and killed them. Everything in Cuba is politicized. Everything is about the cult of Fidel Castro.

Jose remembered the Cuban revolutionary figures, like Cienfuegos, who as a child he was forced to honor. Jose came to realize the politicization of his Cuban education. This was part of the reason why Jose held a strong animosity toward Castro and the Cuban revolution.

Jose continued his life story by illustrating his life and the schools attended in the Little Havana neighborhood of Miami, which is considered the heart of the Cuban enclave (Grenier \& Moebius, 2015). He recalled:

I was ten when I arrived in Miami and I lived right in the heart of Little Havana. My first school was Twin Lakes Elementary, where most of the people were Anglo. I was then moved to Coral Terrace Elementary, which had the only curriculum that was bilingual. Then I went to Shenandoah Middle in Little Havana.

He especially recalled Miami High, which at the time instructed the largest number of Cubans immigrants. He vividly described life there:

Then I went to Miami High, the Cuban of all schools in Miami. I had a great time in Miami High, and it was unusual in the sense that it was not only full of Cubans 
at that time, but we were following school traditions from before, like clubs and fraternities. It was like a brotherhood. Now as an administrator I can't believe that they actually allowed that, but back then it was what made Miami High strong. Jose was raised in the Little Havana neighborhood of Miami and attended schools that were predominately Cuban. Most of the students in the area were the children of the first two waves of the pre-Mariel Cuban immigrants. However, Jose recalled Miami High as the school where he learned some American traditions. It is no surprise that Jose strongly identified with being Cuban. Jose explained the uniqueness of being Cuban:

I'm Cuban American, absolutely [loud voice], but mostly Cuban. [laughs]. We are a little ethnocentric. I am very much a Yuca [young upscale Cuban American] in that sense. Our identity is different than anybody else. Our Cuban history is different. You look at a guy like Marco Rubio, great guy, his politics are OK with me, but he never lived in Cuba. He doesn't understand what it means to be a pioneer.

Jose envisioned himself a pioneer because he was one of the first Cubans to emigrate from Cuba as a child to a new cultural environment. Therefore, Jose felt he understood the Cuban experience more than Marco Rubio, who was born in the United States, and was one of the two U.S. Senators of Florida. But Jose also felt American and called himself a young upscale Cuban-American (YUCA). This means that Jose saw himself as a Cuban-American success story because he was educated in a United States university, was an accomplished professional, and in his opinion was living the American dream (Vidal de Hymes, 1997). 
When asked whether he preferred the pan-ethnic labels Hispanic or Latino, Jose chose the latter. He explained why:

I prefer the word Latino better than Hispanic. It's like we Cubans say, somos [we are] Latino. I was born in Cuba, so my ear was first Spanish, so that's why I don't like the word Hispanic. I think it's made up.

Jose found that being Latino better exemplified his shared cultural roots with other Latin American countries, like the Spanish language, rather than being labeled Hispanic. Jose inherently realized that Hispanic was a term made to bring together South American and Central American Latin countries, as well as Spanish-speaking Caribbean countries under one umbrella label (Fergus et al., 2010; Gimenez, 2014). Latina/o/x was a reactionary label to Hispanic which united shared cultural characteristics, like language under one label (Padilla, 1984).

Jose went on to explain the characteristics of being Cuban in political and historical language. He portrayed it as follows:

Cuban culture is for me [long pause] understanding who you are, where you come from, the struggles of your parents, the struggles of your grandparents. I tell my kids all the time that my grandfather didn't take up communism, and we fought in the mountains against it. I tell them your great grandfather started out with nothing, and he became a wealthy milkman until the revolution came and took everything away. It's just being able to understand that we are very unique. Jose depicted being Cuban through the struggles of the family, the history passed down through the family, the hatred his family felt toward Castro and communism, and the uniqueness of being Cuban. These characteristics tighten the bonds of the Cuban 
community (Aranda et al., 2014; Pedraza, 2007; Portes \& Armony, 2018). Jose continued by describing the characteristics of being American:

I believe in American culture. I see the need to keep your roots to a certain extent, but also that you have to integrate. If you look at the most successful immigrant groups that have made it here, Little Italy in Boston, Chinatown in New York, Calle Ocho in Miami, they have integrated but they were able to keep their authenticity. There has to be a degree where you keep the old American values. In describing American culture, Jose acknowledged that Cubans and other successful immigrants were able to selectively acculturate into the United States. The successful immigrant groups were able to keep aspects of their native culture while integrating useful characteristics of American culture (Aranda et al., 2014; Pedraza, 2007; Portes \& Armony, 2018; Portes \& Rumbaut, 2014). Clearly, Jose views Cuban-Americans as a successful immigrant group.

Jose did not recall any instances with discrimination in Miami. He did reflect on cultural and linguistic differences while visiting outside of Miami. Jose remembered:

When I was a student, I may have experienced some discrimination in Twin Lakes [a predominately Anglo school]. The other students might have said something, but I don't remember. In my other schools, we were the majority there. The only other time was when I thought I was being treated unfairly was as an administrator. The new superintendent got rid of a lot of Cubans that opposed him. He's not Cuban but that's not an excuse. 
Jose understood that he belonged to the majority group in Miami. Therefore, he did not recall many experiences with discrimination; however, when he traveled outside of Miami he explained:

When I've gone up to Georgia, or North Carolina, or DC, I never felt discriminated, but then again, I don't try to look for it. In other words, if I'm in Georgia I try not to speak Spanish. It's like respect. But, if I'm with my cousin who doesn't speak English then I don't have a problem speaking Spanish, but I don't make it sound too loud.

In stating that he wanted to "respect" other cultures by not speaking Spanish, Jose acknowledged that he considered himself the "other" and part of a minority group relative to a broader dominant American mainstream culture. Also, he did not wish to make evident his Cuban-American culture because he was outside of his Cuban cultural domain. Jose reflected on why Miami was a unique place in the United States:

In Miami we Cubans have been able to keep everything Cuban. It's like Little Italy up in New York. You have to stay true to your roots because you're surrounded by your own people. If I was in the middle of Idaho, I probably wouldn't be saying I'm Cuban American. I would just say I'm American.

Jose continued:

There's a Miami culture that's unique and authentic in a sense. I've been to Boston, New York, and I don't think there's anything like Miami. It's an extension of Latin America. There's something very unusual about us and I don't know what it is. 
Jose found Miami to be a unique place because it was majority Cuban. He also found Miami to have Latin American cultural characteristics. In Miami, Jose was able to express his Cuban cultural identity without fear of discrimination from the dominant American mainstream culture. As Portes and Armony (2018) surmised, Miami is an extension of Latin America with a strong Cuban cultural influence where the Spanish language and immigrants are not rejected (Aranda et al., 2014).

Jose also saw differences between the older and younger Cuban generations. He explained the dichotomy between these two groups:

You can ask someone about politics who just came from Cuba and they're completely off base because the education in Cuba is for brainwashing. There's a lot of miscommunication, because they're bred that way to think and take it. Every time they say that people in Miami are extremists, but ask who's responsible? Listen, on this side we think we have all the answers, and on the other side they have the answers. And the problem is there's never been any type of communication and we're not allowed to speak to each other.

Jose felt that the younger Cuban generation did not have the exile experience of the older Cubans in Miami like himself. Instead, Jose saw the younger Cubans as an extension of Castro's Cuba. Jose felt that miscommunication between both Cuban immigrant groups did not allow both sides to talk with each other. Therefore, Jose felt that the bifurcation between the pre-Mariel and post-Mariel groups of Cuban immigrants was mostly the result of political differences.

Discussion of Jose's ethnic and cultural affiliation. Jose strongly affiliated with the Cuban part of his Cuban-American self-identity. Jose considered himself a "pioneer" 
because he lived under Castro and communism and fled to a new country; whereas, some Cubans in Miami never lived the communist experience and were raised in Miami. Jose was raised primarily in Little Havana, the first large Cuban-American community in Miami (Grenier \& Moebius, 2015), attended predominately Cuban schools in the city, and was enveloped in a Cuban sociocultural and political environment. Therefore, Jose described his Cuban cultural identity as different from other ethnic and cultural groups because of Cuba's unique historical and political experiences. He associated Cuban cultural characteristics within the framework of Spanish and Cuban history and enmity toward Castro and communism. He associated Americanness with the English language and American values. By holding on to Cuban cultural characteristics and embracing American ones, Jose exhibited a selective acculturation process while developing a strong sense of Cuban exceptionalism.

Jose did not recall many experiences with discrimination in Miami. He attributed this to Miami being largely a Cuban and Latin American cultural place. In Miami, Jose's Cuban cultural identity was the majority one. Outside of Miami, however, Jose realized the cultural and linguistic differences he had with other regions in the United States. By revealing that he did not speak Spanish in these culturally different regions, Jose tacitly understood that his ethnic and cultural identity was different to the dominant American mainstream culture. By stating that he did not speak Spanish, Jose acquiesced to his minority status in the United States. Jose also found that the more recent arrivals of Cuban immigrants were politically misguided because of Castro, thus, he exhibited a sense of cultural and political superiority over them. 


\section{Jose's Educational Beliefs on Student Learning and Teaching}

Jose began describing his educational beliefs and pedagogical practices by describing his best teachers. First, he described how he learned English from his elementary school teacher:

My favorite teacher of all time was Miss S. She was Jewish Ecuadorian. She was the one who pushed me hard to learn English. She would say, "Jose do me a favor and when you get home start watching English TV. and not novelas" [Spanish soap operas]. I started to develop an ear for English and understand things better. But of course, that may have been the age. You pick up things quicker at ten or eleven.

In looking back at his past schooling experience, Jose found that teachers should make personal connections with their students. Jose also spoke about another characteristic of his best teachers depicted in his high school teacher:

I never really had any great social studies teachers, but I had one good one, a Mr. $\mathrm{B}$, who was truly a genius when it came to giving lectures. He could get up there and talk without notes. That's really the only person that meant something to me. Jose believed that the best social studies teachers would give lectures and be knowledgeable in the subject matter. Jose continued by portraying the type of student he was. He stated:

I was very confrontational when it came to politics with my senior economics teacher who was super liberal, a Democrat. He was very sarcastic and would always jab at the Cubans by saying, "you guys are minorities, so why don't you vote Democrat”. But I would argue with him and give him a run for his money. 
Jose portrayed himself as an argumentative student. Considering how he was as a student and the best characteristics of his social studies teachers, Jose believed in the viability of teacher-centered instruction for the transmission of knowledge. In his view, the teacher is the expert and relays his knowledge to a passive student (Mascolo, 2009). Jose then justified why he became a social studies teacher:

I became a social studies teacher because it was my natural love of history and a unique way to make money. I took one of those ancient surveys in school and it said first to go into the army and second to be a social studies teacher. I should've gone into the army. [laughs] But, when I got my bachelor's I got an offer to be a teacher in the army. The teaching aspect initially didn't grab me, but history did. Now, once I started teaching history that really brought out my passions.

Jose's desire to become a social studies teacher is based on his love of the subject matter. Jose believes that along with expert knowledge of the subject matter, social studies teachers need to be passionate about history. Jose continued by describing his approach to social studies education:

In order to have a civil society that understands its responsibilities, you need to not only learn history but understand history and be able to talk about history. I like to have a longitudinal approach to history. You need to know what happened before you can get into any part of history. My biggest fear is that history teachers give students too much disjointed information. One thing is to memorize things. But you need to be able to use your critical thinking skills, by thinking about what happened before, the reasons for that moment in history, and compare/contrast. Jose portrayed the attributes of a great social studies teacher in these terms: 
A great social studies teacher is someone who engages the students, allow the students to give their opinions, be project-orientated, and allow the kids to be their own learners. If the kids like the material and you challenge them then it can be rewarding to them.

Jose believes in a linear historical approach to teaching history as opposed to thematic. His beliefs about social studies education is based on developing critical thinking skills like in compare/contrast activities. Jose also believes in engaging students in multiple perspectives and individualized learning, which he believes helps build enthusiasm for the subject.

As a teacher, Jose described his instructional practices by depicting a typical day in his class:

The kids come into class and they have their agenda on the board that they copy in their notebook. If the class is economics, I put them into groups, give them specific scenarios about the economy, give them notes, or a lecture. I let them pick their stocks and allow them to change them. For history class I put them into groups, give them notes and lecture. But we discuss things like the second amendment and look at the pros and cons of having weapons today. Jose's typical day consisted of note-taking, lectures, and working in groups. Jose continued to describe some more of his instructional activities:

When we review for tests the students come up with their own questions, and basically compete against each other for extra points on the test. The kids love competition, so I try to incorporate it as much as possible. I use four or five 
activities a day, such as lectures, group activities, projects, and scenarios on a daily basis.

Jose utilized a variety of activities each day and believed that instructional activities are best conducted through competition. Jose spoke about his use of scenarios as one of his best activities:

Scenarios are the one I use the most. For instance, if you're George Washington, how would you deal with a situation knowing what you know about George Washington and the revolutionary war. It's a way to get them motivated and to think outside the box.

Jose felt that motivation, enthusiasm, and critical thought were positive outcomes of his instructional activities. However, Jose's most utilized instructional activity was the lecture. Jose elaborated on how he utilized it in class:

I lecture about 33 percent. I have kids copy about three to four slides from Power Points in their notebooks. Then I like talking about it, breaking it down, and depending on the issue they may get it. But sometimes I may have to explain it sixty times. I use application, synthesis, evaluation, but obviously we have some recall because history to a certain extent is recall.

Jose used a variety of instructional activities, such as lectures, note-taking, group work, and discussion. Except for scenarios, Jose remained at the center of the learning process. Therefore, Jose appeared to follow a mostly teacher-centered approach to learning and teaching.

Discussion on Jose's educational beliefs and instructional practices. Jose's educational beliefs on learning, teaching, and historical education were mostly teacher- 
directed and teacher-centered. Jose did utilize a variety of student-centered activities like his project-based scenario activity. By allowing different opinions in discussions, Jose was engaging in multiple perspectives through active learning (Mascolo, 2009).

However, Jose clearly favored teacher-centered instruction. These included lectures and discussions with right and wrong answers, competition, and recall, which comprised some of the attributes of his past and best social studies teachers. Jose's objectives for social studies seems to be in developing critical thinking skills in his students as in compare/contrast and multiple perspectives by garnering different opinions in discussion. However, both instructional methods rely on supporting evidence from the textbooks, notes, or lectures. In his own words, Jose stated that history was "mostly recall." Jose epitomizes a teacher-centered philosophy to education where he is the authoritative source of knowledge. Jose's purpose is to transmit that knowledge to the students through various methods directed and controlled by the teacher. These characteristics are part of teacher-centered instruction (Mascolo, 2009; Weimer, 2013).

\section{Jose's Perspectives on the Official Curriculum}

Jose agreed with the requirements of the state-imposed official curriculum;

however, he had issues with restrictions placed on teachers' ability to think freely and the fairness of evaluation. He expressed his opinions on these accountability measures:

You have to follow the state standards, but it doesn't necessarily mean that I'm going to cover exactly what's in it. I like the district pacing guides because they're useful and they keep me on pace, but they're an instrument of accountability with so much information. There has to be a certain extent of academic freedom for teachers. Good teachers can't be thinking outside the box 
because then they're outside the pacing guide, and that's a problem. It's like we're being boxed in.

Jose elaborated on the fairness of the state accountability measures:

I don't see a problem with the EOC [End of Course Exams]. What I do see is that we cannot read the results through the same prism for everybody. For instance, if I'm at Tesla High School, who has a failing grade, and you're going to base my paycheck on their test results with someone in my current school, then there's a problem. I don't have a problem with standardized testing, but it has to be even handed.

Jose believed in the state standards and the state accountability measures. For the state standards, Jose felt that it helped guide his instruction, but he found that they contained too much information, which prevented his academic freedom. For state assessments, Jose felt that they too were warranted for evaluating student progress, but he did not agree that the state exams were used to evaluate his teaching, which he found unfair. Jose then explained how he utilized the history textbooks in class:

I use the history textbook, but I don't rely on it. It's there to reinforce the parts I choose from it. There is too much volume and it's boring to read. I found a couple of things that I thought were questionable in the textbooks. You're always going to find information that is questionable because the authors are college professors, and they make mistakes, and they're skewed politically.

Jose found the history textbooks useful for information. He chose the information he wanted to teach from them. However, Jose also found that the social textbooks were full of too much information and he found them boring. Jose also found the information in the 
American historical narrative as questionable and politically biased. Jose, nevertheless still used the information in the American history textbooks for instruction.

Jose spoke about how he taught about Castro's death to his predominately Cuban students. He said:

When Castro died I kind of just went over it with one of my classes. I always give them enough information, so they understand my point of view. I know enough Cuban history to know what's happening inside Cuba and that him dying wasn't going to make a difference. Those people are unwilling to change.

Jose added that non-Cuban teachers did not know how to instruct about Cuba:

A buddy of mine, he's a teacher from Iowa, and he didn't get it. I think it's hard for Anglos to understand Cuba and explain it. Maybe if you're from Venezuela you can get a feeling of what we're feeling. Even Fox News they can't explain it. They mess it up royally. We call CNN the Castro News Network [laughs].

Jose elaborated on Castro through his Cuban cultural identity as a pre-Mariel immigrant. It did not appear that he dedicated much time to this event. The controversial local issue would have allowed him to garner multiple perspectives from his students.

Discussion on Jose's adherence to the official curriculum. Jose accepted the official curriculum as an instrument of accountability, which he found both necessary yet restrictive. Yet, Jose did not acknowledge that the state standards and state assessments are highly influential in guiding teachers' instructional practices and curricular decisions (Davis, 2019; Hilburn et al., 2016; Mathews, 2013). Jose accepted the dominant American historical narrative found in the social studies textbooks yet at times opposed it because he realized inherent biases in the narratives. This could be viewed as disrupting 
the dominant American historical narrative by choosing and privileging which information he taught in class. However, the information Jose chose had to fit into his worldview. Nevertheless, Jose did not outright oppose the official curriculum; instead, he only challenged certain parts to it.

\section{Jose's Attitudes on Teaching Culturally Similar and Diverse Students}

Jose first taught in a school with predominately Haitian students of varying English learning levels (ESOL 1 and 2 were the lowest English proficiency levels). He explained how he connected with his linguistically diverse students:

At the first school I taught the students were Haitian kids and that was tough [laughs]. The ones that knew English they really enjoyed being with me because for whatever reason I clicked with them. I enjoyed their sense of humor and they enjoyed mine. They tried to teach me Creole and I found that rewarding. But the ESOL "ones" and "twos" they were challenging. By the time I got to my thirdyear things simplified. I started to joke around more.

Jose explained why teaching culturally and linguistically similar students helped with instruction:

It's easier with Spanish speaking ESOL students because you know the language. It's usually gratifying for them. I use a lot of humor to get them motivated. I try to engage them as much as possible. I pair them up with a mentor buddy, and I'll walk around to them and ask how they're doing. I have this kid recently arrived from Cuba. He's a blue-chip baseball player (one of the highest rated baseball players in the United States). I joke with him and say, oye, dale, los millones (hey, come on, the millions) [laughs]. 


\section{Discussion of Jose's attitudes toward teaching culturally, racially, and}

linguistically similar and diverse students. Jose demonstrated a personal

communicative approach to teaching culturally and linguistically diverse students. For his Haitian students, who spoke Creole, a language he did not understand, Jose attempted to make connections by learning their native language and joking with them. For his Spanish-speaking students, he developed different learning activities while relating with their culture. In both instances, Jose used different instructional methods and acknowledged the students' culture and language, demonstrating a level of cultural awareness. However, Jose did not use a culturally inclusive pedagogy for his culturally, racially, linguistically diverse and similar students.

\section{Summary of Jose's Cultural Identity, Educational Beliefs, and Curricular Decisions}

Jose self-identified as a "true" Cuban because he had lived and understood communism, was raised in the heart of Miami's Cuban enclave, attended a majority Cuban high school, and wholeheartedly embraced Cuban culture. Jose did not recall many experiences with discrimination while in Miami because he felt it was a Cuban dominant place where he was part of the dominant cultural group. However, he was cognizant of his cultural and linguistic differences and minority status relative to the dominant American mainstream culture in places outside of Miami. Jose viewed himself as an older Cuban and disparaged recently arrived Cuban immigrants for being brainwashed under communism.

Jose utilized multiple activities, which were mostly teacher-centered and teacherdirected. He felt that the official curriculum was both needed and a hindrance to education and pedagogy. He accepted the dominant American historical narrative, yet he 
also chose which information to present to the class according to his political and worldviews. Thus, Jose demonstrated some modicum of disruption to the official curriculum. Jose attempted to validate and communicate with his culturally, racially, and linguistically similar and diverse students utilizing his culture and language for the former and attempting to speak their language with the latter.

\section{Analysis of Jose's Cultural Consciousness and Cultural Competency}

Jose periodically expressed his beliefs, biases, and perspectives, although they were limited to his political views. Jose's cultural identity revealed a strong inclination toward his Cuban affiliation. He strongly believed in the uniqueness of Cuban history. Also, because Jose lived during the early years of the Cuban enclave in Little Havana, he developed a strong sense of bonded solidarity through an anti-communist and anti-Castro in an almost exclusive Cuban sociocultural environment in which he resided (Aranda et al., 2014; Pedraza, 2007; Perez, 1992; Portes \& Armony, 2018). Jose did not report many instances of discrimination in Miami because he found it to be a Cuban place in which he represented the dominant culture (Portes \& Armony, 2018). His experiences with speaking Spanish outside of Miami revealed to him that he belonged to a Latina/o/x minority relative to the dominant American mainstream culture.

Jose's educational beliefs and instructional practices were heavily teachercentered. Jose allowed for multiple perspectives in discussion by allowing different student opinions and utilized a variety of group activities; however, the information discussed, and the activities used were teacher-directed and teacher-controlled. This type of pedagogical practice is indicative of teacher-centered instruction (Mascolo, 2009;

Weimer, 2013). 
Jose accepted most of the official curriculum. Jose believed in the saliency and effectives of the state standards and state assessment without challenging the information in them and the influence it has on his pedagogical practices. At times, Jose interjected his personal views on the American historical narrative, which was not reflective of the information in the social studies textbooks. Regardless, not once did Jose add voices of marginalized groups or discuss opposing views in the dominant American historical narrative. It can be inferred that Jose agreed with the tenants of the official curriculum.

Jose did make personal connections with his students of diverse backgrounds. In teaching culturally and linguistically similar students, Jose utilized part of his cultural knowledge to validate their culture, ethnicity, and language. Yet, Jose did not add students of diverse backgrounds' histories and cultures into the curriculum, therefore, exhibiting a lack of cultural inclusive pedagogy. In this respect, Jose exhibited some nascent skills at becoming a culturally competent teacher.

\section{Leonardo "aka" Lenny: The Funny Teacher}

I met Lenny for four interviews at the school he was teaching, a local Starbucks, and a neighborhood restaurant. Lenny was 42 years old and had been teaching in MDCPS for 15 years at the time of these interviews. He first taught three years of self-contained ESOL (English language learners) and regular academic students at a school with a significant migrant and seasonal student population. At the time of these interviews, Lenny's teaching assignment was at a predominately Hispanic, mostly Cuban middle school in an upper-income area in northwest Miami. He was also performing part-time counseling duties. Lenny was the only teacher-participant who was born in the United States in a city outside of Miami. He was also the only teacher-participant with a non- 
Cuban parent. I observed that he often answered heartedly with laughter and made jokes over some cultural or educational topics.

\section{Description of Lenny's Ethnic and Cultural Identity}

Lenny arrived in Miami from Boston with his Cuban father at an early age;

however, his mother was born in Guatemala. He described how he was raised through his father's Cuban family in Miami:

I was born in Boston but came to Miami when I was five before I started Kindergarten. My father is Cuban, and he came over here in the 1970s. He left us when I was little, so I don't remember much about him. My mother is Guatemalan, but she came here when she was young and doesn't remember much about it except for some Guatemalan foods [laughs]. She never talked to me about Guatemala. We lived in Little Havana. Most of my dad's family would visit us all the time and they were all Cuban.

In Little Havana, the traditional heart of the first wave of Cuban immigrants (Grenier \& Moebius, 2015), Lenny adopted a Cuban identity through the Cuban sociocultural environment that surrounded him. The areas Lenny lived, and the schools he attended, were predominately Cuban. Lenny did not meet any other significant numbers of nonCuban ethnic groups until he reached high school. He explained:

First, I went to Wilderness elementary in Little Havana. The school was very Hispanic and lower class. The teachers were mostly White American, and they were not nice to the Hispanic kids because they were mostly Marielitos. Then we moved to Westchester and I went to Sawgrass Elementary. It was mostly Hispanic Cuban, but there were more White Americans. 
Lenny's description of the schools he attended in Little Havana epitomized the transition from the pre-Mariel to post-Mariel group of Cuban immigrants. Lenny's observation of how negatively the latter group was treated in school demonstrates the negative impact they had on the community. Additionally, even though Lenny does not detail his social class, he does state that he attended school with lower-class students. It was in high school where Lenny began to see other groups of Latina/o/x students. He described: I was sent to Reef High School and it was awesome. I met my wife there and she was also Guatemalan Cuban [laughs]. It was there that I started seeing kids from other places. It was still mostly Cuban, but there was a lot of Nicaraguans, and very little Whites and African Americans. The Nicaraguans had just got there, and they only spoke Spanish, and they were darker, so there was a lot of tension with the Cubans, and the non-Nicaraguans. The Nicaraguans had a hard time.

Lenny depicted his Cuban and non-Cuban high school friends in cultural terms:

Most of my friends were Cuban, but I had a Chilean friend. We made fun of him because of the food he ate and the way he danced. I had a Puerto Rican friend who drowned, and a Colombian one. My Cuban friend was really Cuban. He was very proud of being Cuban. I had been to his house and it was always oye, oye, [Cuban slang words] like a hard-core Cuban house. [laughs] Lenny's description of his high school experiences shows the tensions between the Cuban-American majority group and other Latina/o/x and non-Latina/o/x groups. It also shows that Lenny's world up this point was an almost exclusive Cuban environment. Lenny's friends demonstrate the different Central and South American nationalities that were present. Therefore, it is unsurprising that Lenny proceeded to describe his cultural 
and ethnic identity in ambiguous terms. Lenny stated this ambiguity in three separate interviews:

I consider myself first Hispanic American because I was born here and have a U.S. passport, but my first language was Spanish. I'm proud of the Hispanic side even though I'm a mix (first interview). I consider myself more Cuban because I was surrounded by Cuban culture. I grew up around Cuban food, the Catholic Church, everything Cuban (second interview). I feel more Cuban. When I was in school, I would tell people I was half Guatemalan, but they would say you don't look Guatemalan, you look more Cuban (fourth interview).

In Lenny's first interview he revealed that his identity was related to a pan-ethnic Latina/o/x culture. In his second interview, Lenny surmised that he was Cuban because he was brought up in a Cuban environment. In his fourth interview, Lenny said he felt Cuban because that is how other students saw him. And, when asked if he preferred being labeled Hispanic or Latino, Lenny answered, 'I'm Hispanic man. I'm fine if they call me Latino. Yeah, I'm Latino. Aren't they the same thing?" In each of Lenny's responses to his cultural and ethnic identity, Lenny appeared to waver between both pan-ethnic labels of Hispanic and Latina/o/x and his national Cuban identity. In a sense, Lenny appeared to prefer being labeled "mixed" instead. Nevertheless, Lenny did consistently state that he was Cuban.

Lenny described the characteristics of Cuban and Hispanic culture in traditional cultural markers. Again, he was ambiguous about both labels, depicting them through shared cultural characteristics. He said: 
Man, Cuban culture is something that's unique, like the food, music, language, attire, how you treat your parents, the elderly, a way of living, a whole medley of things. We did a lot of salsa dancing on Noche Buena [Christmas Eve party].

Lenny described his Cuban culture as different from other cultures. His descriptions were in terms of traditional ethnic food, dancing, music, and language. Yet, the issue of speaking Spanish or English was recounted through how his mother reacted when he began to speak English. He said:

When I came to Miami, I spoke Spanish all the time and the English I learned was from watching Sesame Street. One day someone started speaking English to me, and my Mom thought I wasn't going to answer, but I did, and she was shocked. Lenny's depiction of his mother's shock over English demonstrates the selective acculturation process. By retaining Spanish and learning English, Lenny incorporated American culture into his cultural identity. Lenny went on to compare Hispanic, Cuban, and American culture by depicting each as:

Hispanic culture is primarily that they're Spanish, the romantic language, but there's going to be a lot of beans there [laughs]. My mom is coming down from New York and she wants croquettas [traditional Cuban breakfast food], pan con bistec [steak on Cuban bread] from Vicky Bakery because they don't sell it up there. American culture is turkey and chicken wings. My mom doesn't know how to make them [laughs]. This is a complicated question. There's something that separates and binds each culture.

Lenny viewed Latina/o/x, Cuban, and American culture as having characteristics that are both shared and unique. He associated each cultural label with distinctive foods. Yet, 
Lenny found himself confused over defining each label. Once again Lenny demonstrated his ambiguity in identifying cultural characteristics.

Lenny did not describe any moments with discrimination in Miami. He attributed this to the predominately Cuban neighborhoods he lived in, as well as his "Cuban features", in that he felt he looked Cuban. Yet, he was mischaracterized as Mexican while visiting outside of Miami. First, Lenny described why he never felt any discrimination in Miami:

In Miami, I haven't felt discriminated because I've lived in mostly Cuban Hispanic neighborhoods. I never felt discriminated against in school by other kids even though I'm half Guatemalan. Even when I've gone where it's more mixed, and you have Brazilians, Jewish Americans, Whites, I've never felt discriminated. Lenny's reasons for not feeling discriminated in Miami may be because he felt accepted or comfortable with other ethnic and cultural groups. He spoke about this:

I think Miami is a kaleidoscope of different cultures, different voices, different accents, different looks. When I sit with different Hispanic nationalities, or countries, and we kind of all look the same, we rip on each other (tell jokes) about where we're from, and it's all fun.

In Miami, Lenny believed that he belonged to a broader culture that encompassed a multitude of nationalities. Lenny felt he was a part of a pan-ethnic Miami culture. He inferred that similar physical features between Latina/o/x groups was one reason for comradery. Yet, in multicultural places outside of Miami, Lenny did not have those same feelings. Lenny retold a story about this: 
Once when I was in Chicago, they thought I was Mexican, and I was uncomfortable, not because I was being called Mexican, but, because it was not accurate. So, I told them, no, I'm from Cuba and Guatemala. And you could tell they had no idea what that meant. They looked like fraternity types, like bluecollar guys. They were like, if you speak Spanish then you're Mexican. They were generalizing.

Lenny had a sense of familiarity in Miami because of its Cuban and Hispanic cultural environment. He viewed Miami as a meeting place of different cultures. Outside of Miami, however, Lenny experienced this loss of familiarity and understood the generalization made on Latinx groups from the dominant American mainstream cultural group.

When asked if he saw differences between Cuban generations, Lenny began by describing his Cuban friend: "my Cuban friend was really Cuban. He was very proud of being Cuban. In his house, it was always oye, oye [Cuban slang], like a hard-core Cuban house [laughs]." He explained being Cuban as emphasizing Cuban cultural traits. In this case, Lenny was probably portraying a post-Mariel Cuban immigrant because of the Cuban slang words he used. If this is true, then Lenny felt he belonged to the pre-Mariel group of Cuban immigrants. But Lenny never mentioned social and cultural distancing between older pre-Mariel and post-Mariel groups of Cuban immigrants in any interview.

Discussion of Lenny's ethnic and cultural affiliation. Lenny's father arrived from Cuba during the 1970s and settled in Boston before moving his family into Little Havana in Miami. Lenny did not speak much about him but did mention that his childhood and sociocultural environment was filled with his father's Cuban relatives. 
Lenny was raised by his Guatemalan-born mother who had lived most of her life in the United States. The schools Lenny attended were predominately Cuban, mostly in Little Havana (Grenier \& Moebius, 2015). He later moved to Westchester (Portes \& Armony, 2018). Lenny was raised in this predominately Cuban environment.

Throughout his interviews, Lenny expressed his ethnic affiliation and cultural identity ambiguously. He saw himself as American by reason of birth in the United States. Lenny first self-identified with the pan-ethnic label of Hispanic because he spoke Spanish, a cultural characteristic shared by South, Central, and some Caribbean countries (Gimenez, 2014; Padilla, 1984). In the second interview, Lenny self-identified as Cuban because of his cultural affiliation through his father's relatives. In his fourth interview, Lenny self-identified strongly as Cuban which was reinforced by his peers in school. It is telling that Lenny used words, such as "I consider myself" and "I feel more" as ethnic and cultural monikers for his self-identify. Lenny understood he was a mix of Cuban, American, and Hispanic consciousness, which may attribute to his ambiguity in choosing one self-identity.

Lenny expressed uncertainty in describing the differences among Cuban, Hispanic and American culture. He conveyed that Cuban culture consisted of unique traditional cultural and ethnic markers, such as traditional Cuban food, music, language, familial obligations, and festivals. Yet, he articulated that Hispanic culture shared these characteristics. Similarly, he associated American culture with non-Cuban and nonHispanic staples. Lenny admitted bewilderment about the pan-ethnic labels of Hispanic and Latina/o/x. The juxtaposition of Lenny's predominately Cuban sociocultural 
environment and having a non-Cuban Hispanic mother in his household influenced the strength and ambiguity of his ethnic affiliation and cultural identity.

Lenny's experiences in Miami were devoid of any cultural, ethnic, racial, or linguistic discrimination because he shared common cultural and linguistic characteristics with Miami's majority Cuban and Hispanic culture. Lenny believed that he was accepted by this Cuban culture despite acknowledging that he was mixed. He felt uncomfortable being labeled Mexican outside of Miami as a misrepresentation of his identity. Interestingly, he stated that the non-Hispanic White Americans who labeled him Mexican would not understand the variety of Hispanic identities. He never mentioned any social and cultural conflict with other Cuban co-ethnics. Lenny viewed Miami as a multicultural place with different ethnicities living together.

\section{Lenny's Educational Beliefs on Student Learning and Teaching}

Lenny began describing his pedagogical beliefs by portraying some of the best and worse teachers he had in high school. First, he illustrated his unconventional American history teacher:

Mr. M was fantastic! He taught American history and brought comedy into history. He was bald and always wore crazy ties. He would ask questions and you had to be prepared because he would quickly have a smart remark back at you. The class was like a mixture of lecture and trying to get you involved.

Then, Lenny described the characteristics of his worst history teachers:

I had Ms. C, who was a horrible history teacher. She was dull and if you said anything off the mark, she would put her glasses down and just look at you. She didn't get out of her chair and during lectures she would stand by the podium. She 
never added excerpts or any additional information to the reading. She just followed the textbook. In hindsight she was just there to collect a paycheck. The majority of the social studies teachers I had were mostly lecture.

Lenny felt that the best social studies teachers were engaging in their lectures. He also felt that the worst characteristics of a bad teacher was that they were boring and only followed the textbooks. Both of these pedagogical practices are teacher-centered (Mascolo, 2009; Weimer, 2013). Lenny continued by providing reasons for why he became a teacher:

I became a teacher because I wanted summers off. I remember telling my Mom that it would be cool to be a teacher because I had good ones. I would look in the teachers' parking lot and they all seemed to have nice cars. When I was in college, I observed a class in a private school and the teacher asked me to read to the class. When I did, the students started asking me questions and I really liked it.

Lenny was drawn into teaching because of the money, the amount of days off, and the interaction with students. As a counselor in high school Lenny was able to observe some teachers. This is how he characterized some of the most effective teachers:

The good teachers are dynamic, energetic, and creative. There's this one teacher who has stimulus everywhere, like bubbles to remember things, and is always smiling. There's this other teacher who tells dry jokes, but he knows his facts. like an encyclopedia. He brings music and makes everyone laugh. Another teacher uses textbooks and tablets, but she is compassionate. She'll revisit the lesson if the kids don't get it. 
Then Lenny depicted the bad teachers, "the bad teachers who are boring and unmotivated. Teachers need to be funny but know their facts. They need to make things more interesting, instead of just following the boring textbooks and old ways of learning." Once more, Lenny's observations of the more effective teachers were characterized by student engagement, knowledgeable of the subject, and awareness of student needs.

As a teacher, Lenny described his instructional activities through a typical day in his classroom:

A typical day in my class began with me having a little handout, or a journal prompt for the students as soon as they came in. I would have notes on the board and the kids would copy them in their notebooks. I gave them a lot of notes because they didn't know how to take them. I would go over it with them while walking around the class. I would ask them questions, and I would add information to them. I would have discussions, but sometimes the kids started jumping in, so I would stop it. I would ask the kids to come up to the front of the class and read. They didn't like that at first, but they got used to it. I would let them study with each other before tests.

Lenny's instructional activities included directed journal writing, note-taking, questions and answers, discussion with right/wrong answers, and reading in front of the class. These instructional activities are mostly teacher-centered and teacher-directed (Mascolo, 2009; Weimer, 2013). It is apparent that Lenny believed in keeping control of the classroom and the learning process (Weimer, 2013). Lenny described one activity where he took the class outside: 
I'd like to take my students outside as much as I could. I remember when I taught at a school in Miami where we had this sunflower garden outside, so I would take my class to it with our clipboards and do educational things. I could tell they really enjoyed that. It was still learning.

Lenny approached teaching through activities that were mostly teacher-centered, such as lectures, note-taking, questions and answers, and reading from the textbook. The only activity that Lenny described as student-centered was when he took his classes outside to learn, but this could also be construed as teacher-centered because he still directed the learning. He just changed the scenery.

Discussion on Lenny's educational beliefs and instructional practices. Lenny believed that student learning took place through the energy, knowledge, compassion, and creativity that the teacher brought to the lessons, rather than the materials and resources. His teaching practices, however, included a multitude of instructional methods ranging from teacher-centered activities, such as lectures, reading from the textbook, and note-taking to outdoor classroom activities. Yet, these outdoor activities were still teacher-directed. It appears that Lenny seemed to want to control and direct the learning process. Not once did he mention using student-centered instruction, such as group and project-based activities. In this respect, Lenny exhibited instructional practices which were teacher-centered.

\section{Lenny's Perspectives on the Official Curriculum}

Lenny accepted the state standards, state assessments, and American history textbooks, which make up the official curriculum (Davis, 2019; Salinas \& Castro, 2010; 
Spring, 2011), with only a few reservations. Lenny started his discussion on the state of education and his opinions on the state standards and accountability measures:

The way education is now is good because of accountability, so now teachers can't just slack off. They're going to have to teach something. The state standards and district pacing guides are okay, but it doesn't fit everybody and there's too much information to learn. Kids with limited language, or with learning disabilities, or struggle to learn are going to be left behind because they can't keep up and that's not fair.

Lenny's concerns with the state assessments were with the number of tests, although he believed they forced teachers to do their jobs. He also found the state standards adequate but filled with too much information. In this case, Lenny felt that the state standards did not effectively measure students with learning difficulties or English language learners. Lenny conveyed his concerns because he felt these students would be left behind using such measures of assessment. Lenny continued by discussing what the state tests do to education:

I don't understand why we have so many tests. I understand that we need some kind of snapshot of where the kids are but some of these kids it's just months and months of information. It's a little extreme. There are too many tests now and kids are going to have to leave school or go to alternative schools because of them. They are not seeing the whole child. I think if you chunk it up, you're better off. Lenny predicted that high number of state tests would force certain students out of regular schools and into special schools. He also found that the state assessment did not provide an accurate measure of students' academic progress. If Lenny felt that the state 
measurements did not provide an accurate assessment, then possibly he would advocate for some alternative form of measurement. Could this be regarded as some form of resistance ideology?

Lenny provided his perspectives on the social studies textbooks and how he pursued them in pedagogy. Mostly, Lenny had some reservations with them. He explained:

As a teacher the social studies textbooks I've used were boring. They're more exciting now, but there's very little work to do in it. There's a lot of pictures and snippets. I just skip through them and just focus on the information and facts.

It appears that Lenny found that the social studies textbooks provided too much extraneous information, like pictures. What Lenny looked for in the social studies textbooks was the information in them. Thus, Lenny admitted that he followed the dominant American historical narrative found in social studies textbooks. He elaborated: I followed the history textbook and didn't really challenge it. I did elaborate and add more information that I knew about or researched. You have to come up with different information while you're reading the textbooks with the kids. I would think about a good question to ask, like a basic information one, and a question that you had to synthesize, and analyze, or put more thought into it while going over it with them. I don't know if that's challenging it.

Lenny was a little puzzled over whether he challenged the dominant American historical narrative. First, he admitted that he believed in the dominant American historical narrative. But then Lenny said that he questioned and added information when he was knowledgeable about it. Lenny also said that that he would use this information to build 
students' critical thinking skills by asking synthesis and analysis questions. Finally, Lenny was ambiguous on whether he challenged the official curriculum.

When asked whether he taught about Castro's death or about Cuban or other Latin American history, Lenny simply stated:

I never taught about Cuba or Latin America because that really wasn't in the history textbook. The only time I did was when we had some type of multicultural activity and the students had to find a country to talk about.

Lenny's statement that he did not teach about Cuba because it was not in the textbooks means that he only taught information found in the American history textbooks. This means that Lenny only taught to the dominant American historical narrative.

Discussion on Lenny's adherence to the official curriculum. Lenny accepted the state standards but had issues with the amount of information. Similarly, Lenny accepted the state assessments but felt the number of tests caused many educational problems. Lenny believed that social studies textbooks held too much information and were boring, yet he also used them almost exclusively for instruction. He also appeared to agree with the American historical narrative found in them. When Lenny was knowledgeable on the information being taught, he added "different" information. The problem is that he did not appear that he had enough multicultural knowledge to challenge it. Also, this implies that Lenny privileged certain information. However, as he stated for the reasons for not teaching about Cuba, "because that really wasn't in the history textbooks." Lenny admits that he did not challenge the official curriculum. 


\section{Lenny's Attitudes on Teaching Culturally Similar and Diverse Students}

Lenny admitted that knowing Spanish and having familiarity with linguistically and culturally similar students helped him to better communicate and make connections with them. He explained:

The first school I taught in I was the only bilingual teacher. Some of the students were transient and these kids didn't know any English, and they were low level. I would use some ESOL strategies I learned in college. But I also cheated because I spoke Spanish to them just to get them back on track, and it also helped me work with them. So, I think it helped that I knew Spanish and their culture.

Lenny described teaching culturally and racially diverse students through the prism of one student and the attitudes of some of their parents. He explained:

I only taught a few African American students at that school. I had some that were great, and others who didn't trust you to teach them. I remember one was very guarded. She would look at me as if I was picking on her whenever she didn't do her assignments. I didn't want to make it a racial thing, so I would just let it go. Lenny appeared to misunderstand the cultural backgrounds of his racially and culturally diverse students that he taught. In this one instance, Lenny took a "guarded" attitude by one of his students to mean that she did not care about education and was being "picked on" by the teacher. He did not try to understand the needs of this student. Lenny compared this experience to the current students in his present school:

Where I teach now, I have more African American kids. Some of them have professional parents, and then there are other parents who when they talk to you, they are already on the defensive, or on the attack. You let them talk, and then 
say, what can I do to help you, and this kind of eases up the tension for some of them.

Lenny utilized two different pedagogical strategies with his culturally, racially, and linguistically similar and different students. On the former, speaking the same language helped him to better instruct and communicate with them. On the latter, Lenny made little attempt to understand their culture, which inhibited his ability to better communicate and provide a pedagogy conducive to their cultural needs. Interestingly, Lenny expressed his beliefs on teaching all types of students. He explained:

All students should have an equal education, but the difference is how do you approach the tougher students. It's not racial because you have Hispanic kids who are also street, and they're going to read through your BS. So, you have to figure out how to tailor the delivery of your curriculum to them. It's not a matter of race but it's a matter to what level they're at. You might have to reintroduce the lesson in another manner, but not in a racial construct.

Lenny believed that all students should be taught in the same fashion. He also believed that race or color should not matter in instruction. However, Lenny did insinuate that certain students require a different type of instruction.

\section{Discussion of Lenny's attitude toward teaching culturally, racially, and}

linguistically similar and diverse students. Lenny's belief in teaching culturally, linguistically, ethnically, and racially diverse students hints at a color-blind approach. He believes in teaching all students the same regardless of differences in race, culture, ethnicity, or language. However, Lenny's instructional methods were not the same for all students. For ESOL students, he used his knowledge of Spanish to better communicate 
with them. For African American students, he spoke to parents to build better relationships. He even stated that for certain "at risk" students a different type of curriculum was needed. He demonstrated some awareness of the differences between culturally, racially, linguistically and ethnically diverse students; however, he did not provide a meaningful inclusive pedagogy.

\section{Summary of Lenny's Cultural Identity, Educational Beliefs, and Curricular}

\section{Decisions}

Despite being born in the United States and raised by a non-Cuban Latina/o/x mother, Lenny ambiguously self-identified as mostly Cuban. He lived in a predominately Cuban sociocultural environment and attended predominately Cuban schools, which shaped his association to Cuban culture. Nevertheless, Lenny found similarities with a broader Hispanic identity. He selectively acculturated to English while maintaining Cuban and Hispanic cultural traits. He also found Miami to be a multicultural place and did not experience any instances of discrimination within it. Outside of Miami he recalled being labeled Mexican as a generalization of his identity by the dominant American culture.

Lenny stated that teachers should be "dynamic, energetic, and creative." His educational beliefs rested on the notion that teachers are experts and knowledgeable in their subject matter but also engaging and compassionate. Therefore, Lenny’s pedagogy was mostly teacher-centered. The use of lectures, note-taking, reading from textbooks, and having discussions with right/wrong answers are all teacher-centered activities (Mascolo, 2009). It may be that Lenny did not want to lose control of the learning process and the classroom (Weimer, 2013). Possibly, Lenny's past schooling experiences with his 
high school history teachers, who used teacher-centered instruction, may have influenced the way he instructed as a teacher (Windschitl, 2015). It is noteworthy that Lenny did not adequately attempt to use student-centered instruction. It appears that Lenny was not aware of or understood on how to instruct with it.

Lenny accepted the state standards and state assessments as appropriate for guiding instruction and measuring academic progress. Yet, he believed that the state standards provided too much information. He also believed that the state assessments were too numerous and did not fully evaluate academic progress, especially on English language learners and learning disadvantaged students. Lenny accepted the dominant American historical narrative stating that he only taught what was in the textbooks. However, he did mention adding information when he was knowledgeable on the topic and did attempt to teach critical thinking skills. Regardless, Lenny mostly followed the dominant ideology of the official curriculum (Urrieta, 2005).

Lenny somewhat used his cultural identity to better instruct his culturally and linguistically similar students by speaking Spanish to them. He did not use his students' cultural background to instruct his culturally and racially diverse students. Yet, Lenny stated that he believed in an equal education for all students regardless of color or culture. This is a type of color-blindness in which teachers profess an equal education for all students without considering the students' unique cultural backgrounds (Logan, 2017). In this regard, Lenny did not provide a culturally inclusive pedagogy.

\section{Analysis of Lenny's Cultural Consciousness and Cultural Competency}

Lenny exhibited a low level of cultural competence. Lenny utilized mostly teacher-centered pedagogy, which adhered strongly to the official curriculum and the 
American historical narrative. His protests of the state and district assessment measures were a positive, but Lenny only lamented the amount of testing and not the test themselves. Lenny also followed the American historical narrative without much to challenge it. In other words, Lenny did not add information for a culturally inclusive pedagogy.

\section{Yaimirylis, a.k.a. Yaimi: The Expressive Teacher}

Yaimi was 27-years old at the time of these interviews. I met her for three interviews at three different locations throughout the same university where she received her bachelor's and master's degree in education and where she was pursuing a doctorate in social studies education. Yaimi had been teaching for four years. Her first teaching assignment was at a middle school of mostly recently arrived Cuban immigrants with a large African American student population in a lower-income area. During these interviews Yaimi was teaching at a predominately Hispanic, mostly Cuban, charter high school in a higher-income area. Her classes included advanced placement American history and regular world history and American history.

Yaimi was one of two teacher-participants who was born and attended schools in Cuba during the Cuban revolution. She was the only teacher-participant to emigrate from Cuba during the 1990s. This made her one of the more interesting cases to study. Yaimi was extremely opinionated and at times emotional, especially about Cuban culture, Cuban history, politics, and her educational beliefs. She often used Cuban colloquialisms in her answers. 


\section{Description of Yaimi's Ethnic and Cultural Identity}

Yaimi arrived in Miami from Cuba as a young girl. She described how her family emigrated:

I was born in 1986 in Havana, Cuba. My parents and grandparents were all born in Cuba. My Dad did metallurgy in Cuba in the 80s. He didn't feel comfortable working for that government, so he left for Panama and asked for political asylum. When he got to Miami, his brother, who was a Marielito, kind of paved the way. We were very fortunate to have family on my Mom's side that came in the 60s that could send remittances to us in Cuba. So, when we got here my Dad had a little apartment for us, and we had clothes, we had what we needed.

Yaimi's arrival to Miami involved family reunification. Some of her family members were already living in Miami, which helped financially for her family to immigrate from Cuba and settle in Miami. Her uncle arrived during the Mariel boatlift in 1980 and her father arrived soon afterward. This makes Yaimi and her family part of the post-Mariel group of Cuban immigrants, however, she did have family in the pre-Mariel group of Cuban immigrants. Once in Miami, Yaimi's family moved into higher income areas. She described this process:

We lived in Hialeah for about two or three months, and then we went to Westchester that we pronounce Weschesser. And then eventually we got fancy, like Cubans say, and in 1996 we moved to Kendall. My parents became homeowners pretty quickly, and they wanted me to go to good schools, and a neighborhood that was more residential. 
The movement of Yaimi's parents exhibited upward social mobility. First, Yaimi lived in Hialeah, a heavily populated Cuban working-class city in the Miami metropolis (Portes \& Armony, 2018). Then Yaimi's parents moved to Westchester, a west Miami middle-class area with the second largest number of Cubans in the United States (Portes \& Armony, 2018). Yaimi ended up in Kendall, a middle-to-upper class area in the southwestern suburbs of Miami. Yaimi described the demographics of the schools she attended:

All the schools I went to were mostly Cuban Hispanic schools. In Kendall we saw a change in the 90s as it went to Central American and South American and from what I understand it became more and more Colombian.

Yaimi's school environment was composed largely of Cuban and Latin and Central American students. She described the nationalities of some of her school friends: I was very cosmopolitan. One of my friends was Venezuelan. The other one was American. One of my best friends was from Trinidad and Tobago and Venezuelan and I would go over and had tea and crumpets. And I'm like, I eat croquettas, (Cuban breakfast food made of breaded ham). I think I did a pretty decent job of being all over the place.

By stating that she was "cosmopolitan" Yaimi implies that she was a multicultural person. She compared her Cuban cultural traits, as represented in foods, to other cultural foods. Yaimi continued by describing her cultural and ethnic identity: I consider myself completely Cuban-American. I was born in Cuba and raised here. I didn't have an identity crisis. I'm Hispanic, but I may not look Hispanic enough, or White enough either. I feel weird because I have the European, but I don't have the indigenous, or the Black, or Mestizo. 
Yaimi left no doubt that she self-identified as both Cuban and American by being born in Cuba and being raised in the United States. Yet, she explained Hispanic in racialized terms of White, Black, and Indigenous. Using race as a self-identity seemed to trouble her.

Yaimi explained why she preferred being labeled Hispanic instead of Latina: "I feel more comfortable with Hispanic than Latina because I've seen Latina being associated with Mexican women more than Cuban ones. When someone calls me Latina, I think it's hypersexualized, so I don't get positive connotations." Yaimi also described her identity in gendered terms. She elaborated:

Maybe one day I feel more Hispanic. But then another day I feel more as a woman. Sometimes it's both. So, you live a cultural experience based on your gender, but also gendered, plus your ethnicity. I liked America. I liked what I saw on T.V. I wanted to be blonde and blue eyes, and I liked how some of the blonde boys looked.

Yaimi depicted her cultural and ethnic identity in different ways related to how she feels. She stated that one day she may feel part of broader Hispanic culture. On some other days she might feel like a woman rather than ethnicity. Yaimi described the term American through physical characteristics, such as blonde and blue eyes. Yaimi viewed Americans through a mainstream American cultural lens, which saw on television. Regardless, Yaimi primarily self-identified as Cuban-American.

Yaimi's description of her family dynamics revealed an intergenerational clash between older Cuban cultural norms and American progressive ones. First, Yaimi described her household: 
I grew up in a household that is very machista. It's from my grandfather. God forbid if my father cleans the dishes or does any kind of house chores. He's changed over the years, but that's not his role.

Machismo refers to the idea of male superiority in the family household. The role of the older male in a traditional Cuban and Latina/o/x family is usually as an authority figure with designated roles for men and women. Yaimi described that most men do not participate in household chores. But machismo goes beyond kitchen chores. Yaimi depicted a moment when her opinions clashed with her father's political views:

When we discuss politics in my household my father would say, you can't think like that, and I'm just like, what do you mean I can't think that way. I don't have to think like you. I kind of have a difference of opinion in how we think that can create conflict at times.

This exchange of views between Yaimi and her father exemplifies the intergenerational clashes that are common in immigrant families. Yaimi also expressed how her family attempted to maintain Cuban cultural norms: "I knew that dating somebody that was too outside of my ethnicity might be controversial. And if they were White, it's like, avansando la raza [advancing the race]. That's terrible. My sister only dates Cuban men." Yaimi shows how racial mentality is formed within the family unit. The idiom of "advancing the race" means that her family places more prestige on being White rather than being darker skin. By "whitening” through intermarriage, the children's' status may improve. 
When asked about any experiences with discrimination, Yaimi at first did not recall any moments. She attributed this to being both Hispanic and Cuban in Miami. She explained:

I don't feel discrimination in Miami for being Cuban because I live in a Hispanic bubble. I mean birds of a feather flock together, right? Cubans have this position of power to help other Cubans, and that makes you confident, so maybe that's why we don't think discrimination is such a big deal.

Yaimi's statements like, "Hispanic bubble" and "birds of a feather flock together", suggest that Yaimi associates with a Cuban culture. Yaimi understood that this Cuban culture holds the political power and cultural capital in the Miami (Pedraza, 2007; Portes, \& Armony, 2018). Yaimi felt this helped her excel in Miami. She also viewed Miami as a place that accepted different peoples and cultures. She explained:

My dad says we Cubans made Miami. We didn't discover and make Miami, dad, but we have been a group that, because of what happened in Cuba, we have always been go getters. Honestly, I have to give it to our city. I think most people are pretty inclusive. I feel more discrimination in this city by I would say powerful people, for being young, for being a woman than I do because of my ethnicity.

Yaimi used the Cuban experience to describe a type of Cuban exceptionalism in Miami. She saw Miami as a multicultural place, where discrimination may occur in other areas, like being a woman, rather than just ethnicity or culture. As the interviews continued, Yaimi recalled an episode in school where she felt discriminated by her non-Hispanic White teacher. She recalled: 
There was this White European teacher who taught math and one day she made a comment that got me very upset, I don't understand why you, Hispanic people, you kids, put a dash on your seven. I don't know what's wrong with you people! She made it obvious that we're Hispanic, and we don't know how to write a seven, and that the way she writes a seven is correct [laughs].

This episode revealed that she saw herself as a minority in the eyes of dominant nonHispanic White culture because of her customs. In another story, Yaimi spoke about when she perceived herself as different outside of Miami:

I went to a conference in Orlando and stopped at Cracker Barrel where there were a bunch of you know [paused], Americans in these little rocking chairs. We walked in and everyone is looking at us like, who are these folks. And, for a second, I was scared. And I was like, people in Miami don't look at me like this. It appeared that Yaimi attributed being different from Americans in physical characteristics. As she previously stated many Americans have blonde hair and blue eyes. When Yaimi went outside of Miami she felt a certain discomfort over this. Yaimi also described a moment of social and cultural distancing between the pre-Mariel and postMariel groups of Cuban immigrants:

In school I did experience discrimination subtly because the way I said jello [Cuban accentuated English for the word yellow] when I had just come from Cuban. I always felt bad about my name. I'm Y generation, Yaimirylis, and it happened to me the other day in class [lowers voice] by accident. I was called Yenniseee. Really? I always tried to see if the teacher butchered my name the first day of school. 
Yaimi continued by recalling another story where her mannerisms were perceived as informal by an older Cuban teacher:

Once, I needed something from the teacher, so I knocked on her desk and was like, oye I need something. The teacher, who was an old Cuban, was like, you can't do that. You can't just go [laughs] oye on my desk. I was used to the whole oye thing in Cuba because it was not a formal environment.

Yaimi was the only teacher-participant who recounted episodes of social and cultural distancing. Since she belongs to the post-Mariel group of Cuban immigrants, this was quite revealing. In her stories, the manner of speaking Spanish, the cultural norms, and her name were looked down upon by the older Cuban generation. What makes this more interesting is that Yaimi spoke about it as if she was in the pre-Mariel group.

Discussion of Yaimi's ethnic and cultural affiliation. Yaimi immigrated to Miami through family reunification. Each family member, starting with her grandparents in the 1960s sustained the other family members until their arrival in Miami. Her parents demonstrated class mobility by moving from the working-class city of Hialeah to the middle-class area of Westchester and eventually to the higher-income region of Kendall. Thus, Yaimi was raised in a middle to upper class environment. She also attended predominately Cuban and non-Cuban Hispanic schools. This sociocultural environment influenced Yaimi's cultural identity.

Yaimi self-identified primarily as Cuban-American, yet she spoke of herself in pan-ethnic Hispanic and gendered terms. She associated American identity with American mainstream physical features, such as blonde hair and blue eyes. She characterized being Hispanic as a blending of different races, cultures, ethnicities, and 
regions. However, Yaimi found that the pan-ethnic label of Latina hypersexualizes and is indicative of Mexican heritage. Yaimi chose to self-identify through multiple selfidentities, such as national origin, country of residence, race, and gender.

Through the centrality of the family unit, Yaimi developed an appreciation for political awareness, retainment of Cuban cultural norms, and preservation of Cuban cultural traditions. It was in machismo, the idea of male superiority over the family where intergenerational conflict occurred between her parents' old Cuban norms and her progressive American ideals. Yaimi also expressed how her family wished to preserve Cuban racial practices by having her date only White Cuban men.

Yaimi understood she belonged to the majority culture in Miami, which she labeled an "Hispanic bubble." She also revealed instances of a type of Cuban exceptionalism. Thus, Yaimi did not recall experiencing many moments of discrimination in Miami because she was Cuban and spoke Spanish. Her only moments were during her schooling experiences, where she realized that her cultural norms were different than American culture. Yet, she expressed discomfort outside of Miami mostly because of her different physical features relative to non-Hispanic White European Americans. Regardless, Yaimi labeled Miami as an inclusive place.

Yaimi was the only teacher-participant who experienced social and cultural distancing from the older pre-Mariel group of Cuban immigrants. Her first name started with a $Y$, indicating that she belonged to the Generation $\mathrm{Y}$ of Cubans after the revolution. This identified her to the pre-Mariel group of Cuban immigrants as a recently arrived Cuban immigrant who had lived under Castro and communism. Also, Yaimi realized that the way she used Cuban slang and her informal manners displayed cultural inferiority to 
the older pre-Mariel generation. Yaimi exemplifies a case where a post-Mariel generational Cuban aligned with the sociocultural beliefs of the pre-Mariel generation. Regardless, Yaimi exhibited a strong affiliation to her Cuban cultural identity.

\section{Yaimi's Educational Beliefs on Student Learning and Teaching}

Yaimi spoke about her educational beliefs by depicting the characteristics of her former high school teachers. She recalled:

My high school teachers really had an impact on me. Mr. H was dynamic. He knew his stuff. He would tell us interesting things. I would mention something, and if he read it in a book, he would highlight it for me and say, I read this last night, this quote. When you were talking about communism in class, I remember you said, what do you think about this? He validated our opinion. If you had a curiosity about something, he'd encourage it. He taught us a little bit of everything. Of course, if he had some information to cover, he would lecture. And some of the stuff I learned in his class I never forgot.

Yaimi then spoke about the characteristics of another high school teacher:

Mr. G was more satirical around the kids. As much as I love Mr. $\mathrm{H}$ as a teacher, and his topics, the class that made me think I was a human being with ideas was Mr. G's AP European history. Rene Descartes, I think therefore I am. My world just changed because of him.

Yaimi's best teachers made connections with their students through validation of their opinions. They also demonstrated knowledge and enthusiasm for the subject. They asked insightful questions to spur deep thinking. In this light, Yaimi approached student 
learning in an interdisciplinary manner with an emotional component. She described this belief:

I think historians are the smartest people because you know a little of everything making it interdisciplinary. There's a lot of emotional investment, not just cognitive, or academic rigor by both students and teachers. I believe in the civic component of education and the academic growth mindset. Teach academics, but also teach about life's decisions and about students' future jobs and lives.

Yaimi felt that the subject of history allowed teachers to incorporate multiple disciplines of knowledge and connect this knowledge to students' lives. In this respect, Yaimi explained why teachers can be powerful in their classrooms:

Teachers are powerful because they can teach students what they think within those four walls. If you're going to be a teacher, then you should be a constant learner because a lot of teachers don't have the content knowledge. I definitely understand the political impact, the social impact of education, and the power of teaching people what you think.

Yaimi felt that teachers should constantly learn about their academic subjects. She also felt that teachers should not evade political discussion and instead embrace social issues in the classroom. In some fashion Yaimi exhibited a social justice perspective to her educational beliefs. Yaimi described her instructional practices by first depicting a typical day in her class:

I quiet down the students and go over the material for the day. I may show videos or pictures. I get to the vocabulary and then have a discussion or question and answer session. Then I would get to an activity with them but I'm lecturing 
majority of the year. The students can interrupt me, ask me questions, and then it becomes a conversation.

Yaimi utilized mostly teacher-centered instruction, such as lectures, questions and answers, and discussions as part of her everyday instructional activates. However, she regarded herself as a different type of lecturer. She explained:

I'm traditional but with a twist, because we have discussion, so the students are fed information, transferring information, and making connections. I think you really have to be a hands-on facilitator to have the students understand the basics and then go to the complexities, especially in a topic like social studies.

Yaimi delved deeper into the reasons for lectures. She stated:

I'm not against lecture. I have to lecture. Lecture is good. I think if you have a teacher that comes from behind the podium and walks around the class, and initiates conversations, that will work, especially when you have such a rigid curriculum which I find myself in.

Once more Yaimi attempted to legitimize her reasons for using lectures:

I like to be complex and complicate what we learn. I ask myself, am I being critical enough, or inserting too much of my opinion. But this is how we start discourse. I wish I could try all those different things other teachers do, but sadly I have to teach content while we engage in discourse because you have a pacing guide.

Yaimi felt she was a teacher who "facilitated" the transmission of knowledge through lectures by engaging students in conversation and making connections. However, Yaimi 
also acknowledged that the "rigid" curriculum was an imposition to her teaching. Yaimi described the instructional approaches she used for some of her best lessons:

In one of my lessons I had my students create boards on human geography. They had to use another group's board to help them answer the question. So that's good for maybe a visual learner. I had a vocabulary panel and vocabulary theorists. I asked the kids questions about their board. It was an interactive type of thing. And it was cool to have the kids do that because on the test, on the real test, they would be an expert. And I tried that this year and I really liked it.

Yaimi described her best lesson in enthusiastic tones. In fact, she retold this lesson a couple of times throughout the interviews. She stated:

My favorite lesson was a day when I brought in Cuban coffee to class, and different teas from around the world. The kids just drank coffee and tea in little pillows like it's a café. I lectured about joint stock companies, about global trade, and about our American revolution. I try to make it dynamic. I love that day because we get to eat, and we get to learn at the same time.

Yaimi utilized cooperative and collaborative learning activities to engage students in the learning process.

Yaimi provided the most interesting account of teaching about Fidel Castro's death, which occurred during her tenure as a teacher. She described it:

For example, being Cuban-American I know Castro is terrible and bad. But I can see how other people would have a different viewpoint. I wouldn't dispute that. He did bring certain things. But I've had students glorify certain leaders because they don't know or understand socialism and communism. It can get awkward 
when I disagree with them because you have a lot more knowledge than they do, so you don't want to belittle them. But just sometimes the stuff the kids say in error and I have to make a decision about how intense I want to be about it. It's very complex.

Yaimi was the only teacher-participant in the study to elaborate on her instructional activities regarding Castro's death. She allowed for students' opinions, but as she stated, "you have more knowledge than them." Yaimi saw herself as the authority on the issue.

Discussion on Yaimi's educational beliefs and instructional strategies. Yaimi believed that teachers need to develop the capacity to make connections with the lives of their students through content and interdisciplinary knowledge in a quest to build political and societal change. She understood what Hilburn et al. (2016) advised, that teachers are the gatekeepers in the classroom and can present the information any way they like. Yaimi also saw herself as a "hands-on facilitator" because she guided learning using the language of student-centered instruction (Yilmaz, 2008).

However, Yaimi utilized mostly teacher-centered activities, such as questions with right/wrong answers, teacher-directed discussions, and lectures. Yet, it was lectures that she utilized the most to transfer information. Yaimi considered herself a different type of lecturer because she walked around the class, eliciting and engaging students in the learning process through active learning (Mascolo, 20009). Despite framing lectures as student-centered, Yaimi said that she still "fed the students information." This is a teacher-centered instructional practice (Weimer, 2013). At times, it appeared that Yaimi was defending her use of the lecture saying that she needed to lecture because of the "rigid" curriculum. 
Yaimi did use student-centered instruction like cooperative group projects and role-playing. Yet, her project-based activities were in response to the test items. That is, Yaimi asked students questions that she privileged, rather than allowing her students to discover answers for themselves. Even in her best lesson where she role-played, Yaimi still transmitted the information through lectures of the information she wanted her students to learn. When she taught about Castro, Yaimi implied that her opinions on the issue were the correct ones, therefore, downplaying the multiple perspectives of her students. In every aspect of the learning process, Yaimi remained in control.

\section{Yaimi's Perspectives on the Official Curriculum}

Yaimi followed the state standards, state assessments, district pacing guides, and the American historical narrative without much opposition. However, at times she hinted that she wishes to challenge them. Yaimi first explained her perspectives on the state standards and accountability measures and the effects they had on her teaching:

I follow the state standards, so I won't get fired. I believe in accountability, but you also miss the big picture. I don't think I'm a bad teacher, but these accountability measures make me one because it's just rote learning, and hinders discussion, and prevents me from being a natural teacher.

Yaimi was required to follow the state standards. Yet, she believed that the state and district forced her to use teacher-centered instruction because the accountability measures were tied to the state standards. Interestingly, she also said that accountability prevented her from becoming a "natural" teacher. In other words, the state standards inhibited her from teaching in the fashion she would have liked. Similarly, Yaimi had some issues with the state assessments. She explained: 
I don't like the pressure the EOC (End of Course Exams) puts on the students. I don't think somebody should be throwing up over a test. I don't want my passing rate to be the only thing that defines who I am as a teacher. But I do what I'm told.

Yaimi found that the official curriculum's assessment placed too much pressure on students. Yaimi also found them too restrictive as a teacher. Yaimi then discussed her views on the history textbooks:

I use the history textbook as an additional tool for information. They're like a giant highlighter. The textbook will say this is important, but then you have to look beyond that, and get thematic. Honestly, I think we can do away with a lot of them. I see the history textbooks more as a prep for my lecture.

Yaimi found the American history textbooks useful only as a tool for her lectures but felt that they were not needed for instruction. She accepted the American historical narrative found in the American history textbooks. She explained:

I've never found anything completely wrong with the information in the history textbooks, but I found things I don't agree with, or understand the depths of it. These textbooks are tied to the standards or have professors as a part of the board that looked at them, so, they are not made irresponsibly.

Yaimi admitted that the information in the history textbook was not completely wrong. She stated that they were made by experts, implying that the information in them was correct. But Yaimi qualified that assertion by saying that she did not agree with some of the information in them. She explained: 
A part of teaching is challenging the master narrative, but I only challenge the information that I know, like when I challenge the notion of Columbus as a savior. The historical story told by the dominant group, that we've been taught for a long time, is hard to challenge.

Yaimi continued:

All this makes me think about how I'm a cog in the machine that keeps people ignorant because I teach American exceptionalism. I buy into it a little bit, because how dare I acknowledge there's negative things there, but not have a level of respect and admiration for this country who took me in.

Yaimi displayed a nascent understanding that the American historical narrative was constructed by the dominant American culture. She also added that she challenged portions of it when she felt knowledgeable on the topic, like in the Christopher Columbus' story of being a savior to America. She also seemed to admit to teaching to American exceptionalism, despite keeping her students “ignorant." However, Yaimi admitted that she did not find it necessary to oppose the official American story because it was the country that accepted her as an immigrant.

Yaimi's acceptance of the official curriculum and American story was tested when Castro died. She provided details on which perspective she took:

When Castro died, not only did I show my students my two-minute video of going down to La Carreta [a famous Cuban restaurant in Little Havana] at three in the morning to celebrate, but I also showed them a newspaper clipping where three of my relatives died in the thirteenth of March tugboat massacre by the 
Cuban government. Yeah, I got emotional, but I don't care. I tell them you don't have to agree with me, but this is why I feel the way I do.

In teaching about Castro's death, Yaimi appeared to validate the culture of her Cuban students. In this regard, she taught a subject outside of the mainstream American story. However, as pointed out in the discussion on her instructional practices, Yaimi taught about Castro through only one perspective and did not encourage other points of view. In this example, she demonstrated a passion for Cuba and did teach about a historical event pertinent to the students in her class. This can be viewed as a type of disruption (Davis, 2019). But, Yaimi did not oppose the official curriculum.

Discussion on Yaimi's adherence to the official curriculum. Yaimi complained about parts of the official curriculum but accepted it at face value because of job security. She found that the state standards lacked cohesiveness. She viewed the state and district assessments measures as obstacles to her teaching. She saw the EOC (End of Course Exams) as providing too much pressure on students. Yaimi looked at the social studies textbooks as a guide and tool to be incorporated into her other resources. Yaimi accepted the official American historical narrative because of its professional construction and because it was part of mainstream American beliefs. However, at times Yaimi also viewed the American historical narrative as biased, which she challenged when she was knowledgeable about the information. It was in these moments, like when she used a counter-story to discuss Columbus, that Yaimi displayed opposition to the official curriculum. However, whether because she felt she lacked enough knowledge on the topic, or was hesitant to do so, Yaimi rarely disrupted the official curriculum. 


\section{Yaimi's Attitudes on Teaching Culturally Similar and Diverse Students}

Yaimi's experience with culturally similar students was reflective of her own experiences as an immigrant student when she had arrived from Cuban. She told a story about a former student in her class who had emigrated from Cuba and how she handled the situation: She illustrated:

I had this student who had just come from Cuba who didn't speak a speck of English and I was giving him the same assignment as everyone else, so he became inattentive. I called home and his Dad said, aye miss we just came from Cuba and my wife is doing everything she can. And I felt my own experience reflected in that since I started the same way. I got him a translator and spoke Spanish to him because it made him feel comfortable.

Yaimi's similar cultural experiences with a student who had recently arrived from Cuba in her class allowed her to make cultural and linguistic connections. However, this was not the case when it came to teach culturally and racially different students. She said: Where I've had issues of culture shock was when I taught in a school that was predominately African American. The perception is that they didn't want to learn and didn't value education. I would get upset that they would have expensive sneakers but have no school supplies. I was flabbergasted that they were throwing chairs and couldn't put two sentences together in the eighth grade. And they wouldn't even let me speak. I don't know how long I could've lasted there if I hadn't changed jobs. But I also realized that some of these kids, they didn't know any better. 
Yaimi acknowledged her cultural shortcomings when she taught culturally and racially different students. Her own sociocultural background did not match with these students and left her pedagogically bereft. This opened a culturally conscious moment in our interview. She said:

And I would judge, and that's wrong. I have felt that I have had a prejudice toward the attitudes that African Americans have in that school to education because education was serious in my house. Maybe it's because we came from a different culture, a different environment.

Yaimi continued to reflect on her cultural and racial biases by making comparisons with her own cultural background:

I had some African American students who were wonderful, but I made generalizations because that's what I was dealing with every day. They had issues that I didn't have to deal with like not having money in a substantial way. I felt that the Hispanic community somewhere, somehow, did something right versus some other neighborhoods.

Yaimi's reflections on teaching culturally similar and racially and culturally diverse students revealed an understanding of her own pedagogical shortcomings. She used her own culture and language to connect to a recently arrived Cuban student. Even though Yaimi felt that she could not teach her non-Hispanic Black students, her cultural consciousness revealed that it may have been in part because she did understand their culture. She continued to instruct in the same fashion without regard for their cultural needs. 


\section{Discussion of Yaimi's attitudes toward teaching culturally, racially, and}

linguistically similar and diverse students. Yaimi utilized her cultural identity to make connections with her Spanish-speaking and culturally similar ESOL students through shared language and cultural experiences. She stated, "I felt my own experiences reflected there". However, Yaimi exhibited a mismatch with her racially different students. She acknowledged a lack of cultural understanding and instructional methods for teaching non-Hispanic Black students. She allowed her beliefs, perceptions, and differences to inhibit a pedagogy based on cultural inclusiveness. Yet, Yaimi did reflect on her own cultural shortcomings. In other words, Yaimi admitted that she was not fully prepared to teach students of diverse backgrounds.

\section{Summary of Yaimi's Cultural Identity, Educational Beliefs, and Curricular}

\section{Decisions}

Yaimi demonstrated a strong ethnic and cultural affiliation to her Cuban identity. She was raised in Cuba and Cuban Miami and attended schools that were predominately Cuban and non-Hispanic Cuban. Therefore, Yaimi's sociocultural environment was primarily Cuban influenced. She retained Cuban cultural norms, traditions, and characteristics through the family unit. It was within the family where intergenerational cultural clashes occurred involving older Cuban worldviews and her American ideals. Yaimi selectively acculturated English and successfully preserved Spanish and Cuban culture (Grenier \& Perez, 2003; Perez, 1992).

In Miami, Yaimi understood she belonged to the majority Cuban and non-Cuban Hispanic culture; thus, she experienced very little discrimination. She did feel as an outsider in places outside of Miami, reflecting her minority status relative to the dominant 
American mainstream culture. Yaimi did experience cultural and social distancing from older Cubans when she first arrived from Cuba. Yet, it appears that now she has embraced a hybrid pre-Mariel Cuban immigrant mentality.

Yaimi's pedagogy was mostly teacher-centered because she believed in the transmission of knowledge from an authoritative and expert source to a receiving student (Mascolo, 2009; Weimer, 2013). Yaimi also utilized lectures as her main instructional method and discussions that were teacher-directed. She attempted to frame her lectures as student-centered by calling herself a hands-on facilitator, yet, both instructional practices are central to teacher-centered instruction. Yaimi also used a variety of student-centered collaborative and role-playing activities. However, she guided and controlled these activities with teacher-directed questions. Although Yaimi attempted student-centered instruction, the ubiquitous use of lectures made it seem that she did not allow for enough activities for students' construction of their own knowledge.

Yaimi followed the requirements of the official curriculum, although she felt they inhibited her teaching and placed too much pressure on students. Yaimi challenged the American historical narrative as far as her content knowledge allowed her. She also revealed that some of the information about the mainstream American story was biased and disagreeable, yet she rarely challenged it. She stated that she had respect for the United States because the country had accepted her as an immigrant. In this respect, Yaimi accepted the premise of the American story.

Yaimi used her cultural identity to provide culturally inclusive pedagogy for her culturally similar students. She spoke their language and made connections with their lives. However, Yaimi's cultural biases and prejudices about culturally and racially 
diverse students inhibited a cultural inclusive pedagogy. It is telling that Yaimi understood that she lacked the needed skills to enact a pedagogy of cultural inclusivity.

\section{Analysis of Yaimi's Cultural Consciousness and Cultural Competence}

Yaimi, at times, appeared to be aware of her biases and prejudices. However, she was also ambivalent in some situations. Regardless, Yaimi exhibited the most cultural consciousness of any of the other teacher-participants. She described her ethnicity and other groups in racialized terms. When she spoke about her own cultural and ethnicity, Yaimi stated that she was not White, Black, or Indigenous. She associated ethnicity and culture with skin color.

Additionally, Yaimi described American culture in physical characteristics like hair and eye color. She also attributed negative attributes to Mexican females, calling them hypersexualized in the public discourse. Yet, Yaimi seemed unaware that she used these descriptions to identify herself and others. In this regard, Yaimi placed her CubanAmerican cultural identity into the United States racial system with Whites on top and Blacks on the bottom (Cobas et al., 2009). However, Yaimi understood that her Cuban cultural identity was the dominant culture in Miami. Although part of the post-Mariel group of Cuban immigrants, Yaimi later saw herself associating with the pre-Mariel group.

Yet, Yaimi is not a pre-Mariel immigrant. Her father and Uncle both arrived during and after Mariel. The only connection she has with the pre-Mariel Cuban immigrant group is one group of grandparents who arrived during the 1960s. One reason for associating with the pre-Mariel group can be that Yaimi is highly educated and understands the differences between both Cuban immigrant waves. After all, she did live 
in both worlds and initially experienced discrimination by the pre-Mariel group of Cuban immigrants. Being in between both worlds and developing a dominant cultural perspective in Miami influenced how Yaimi approached her educational beliefs, instructional practices, and curricular decisions.

Ladson-Billings (1995) advised that teachers need to provide a pedagogy that is attuned to students of diverse backgrounds' cultural needs to enact a culturally relevant pedagogy. Yaimi's attempts at culturally inclusive pedagogy were deficient in this regard. She seemed to be lacking an understanding on how to proceed with enacting instructional activities that legitimized the cultures of students of diverse backgrounds in her classes. Instead, Yaimi taught mainly through teacher-centered instruction. She used lectures in almost every activity, including student-centered ones, such as group projects and interactive activities. Busey and Russell (2016) attributed teacher-centered pedagogy to teachers who taught from a lack of cultural diversity. Yaimi used teacher-directed lectures, teacher-guided cooperative activities, and teacher-controlled discussions because she did not how to construct a culturally inclusive pedagogy.

Researchers have stipulated the addition of students of diverse backgrounds' histories and cultures into the curriculum legitimizes their identities (Busey \& Russell, 2016; Gay, 2018; Ladson-Billings, 1995). Yaimi taught mostly from the perspective of the official curriculum, which is reflective of the dominant culture (Davis, 2019; Mathews, 2013; Salinas \& Castro, 2010). There was no indication that Yaimi added marginalized voices or substantially challenged the American historical narrative. She did bring in some Cuban history, but this occurred in the context of a recent event that was personal to her. Yaimi stated that she would not oppose the official curriculum out of 
respect for the United States, despite having reservations about the information in it. Therefore, Yaimi proceeded to teach one version of history that of the dominant American historical narrative.

In some culturally conscious instances, Yaimi admitted her lack of cultural competence. She said, "I have a prejudice toward the attitudes of African Americans" and "I made generalizations" indicating her cultural misunderstandings and shortcomings. This realization, however, did nothing to change her pedagogical beliefs and practices. For instance, she did not attempt to alter her style of teaching. One possibility was because she did not have knowledge or skills to accomplish this. Another possibility was her belief that students should learn in the same fashion. 


\section{CHAPTER V}

\section{CROSS-CASE ANALYSIS: ASSUMPTIONS AND FINDINGS}

The chapter presents the findings of the current qualitative cross-case analysis of how five self-identified Cuban-American social studies teachers in Miami, a city where they are viewed as the dominant culture, demonstrated their ethnic and cultural identity, expressed educational beliefs on teaching and learning, approached the official curriculum, and promoted culturally inclusive pedagogy relative to their cultural consciousness. The data were collected primarily through interviews to describe each teacher participant's intentions, attempts, and actions of their beliefs (Pajares, 1992). The main research questions and sub questions guided the themes and sub-themes to this study. The research questions are as follows:

1. How did each teacher-participant describe his or her ethnic and cultural identity?

a. How did each teacher-participant describe his or her immigrant experience?

b. How did each teacher-participant define and characterize his or her cultural and ethnic identity?

c. What encounters and perceptions with ethnic, racial, linguistic or cultural discrimination did each teacher-participant experience inside or outside of Miami and within their ethnic and cultural group?

2. What was each teacher-participant's educational and epistemic beliefs on learning, teaching, and social studies?

3. What was each teacher-participant's view toward the official curriculum? 
4. What was each teacher-participant's perspective on teaching linguistically, racially, and ethnically diverse students?

Critical Latino theory (LatCrit) was the theoretical framework used for analysis to prioritize categories pertinent to Latina/o/x groups. The theoretical framework formed the foundation for the themes and sub themes in the study. Critical Latino theory drew special attention to: (a) ethnic, cultural, racial, and linguistic self-identification; (b) experiences with ethnic, cultural, racial, and linguistic discrimination; (c) teaching culturally, ethically, racially, and linguistically diverse students; and (d) questioning or challenging the official curriculum used by state and district schools (Davis, 2019; Cruz, 2002; Fernandez, 2002; Gay, 2010; 2018; Mathews, 2013; Salinas \& Castro, 2010;

Solorzano \& Delgado-Bernal, 2001). The main themes and sub themes in the analysis are as follows:

(1) Strength of ethnic and cultural affiliation.

(a) Favorable, hostile, prejudiced, or neutral immigrant experiences.

(b) Pan-ethnic, foreign national, hyphenated American, or American selfidentification.

(c) Issues of race, gender, sexual orientation, religious identities.

(d) Assimilation or acculturation into White European American mainstream culture.

(e) Personal experiences with discrimination within and outside of Miami, and cultural and social distancing within own ethnic group. 
(2) Teachers' educational beliefs on learning, subjectivist epistemic beliefs on teaching social studies, and student-centered or teacher-centered principles to pedagogy.

(3) Opposition, acceptance, or partial acceptance of the official curriculum.

(a) Challenging, accepting, or partially accepting the state sanctioned standards and assessments.

(b) Challenging, accepting, or disrupting the American historical narrative found in the social studies textbooks and curricular resources.

(4) Cultural competence relative to culturally inclusive pedagogy in teaching culturally, racially, ethnically, linguistically diverse students.

After cross-case analysis was completed, assertions were determined for each theme and presented as inferences for each of the findings. The chapter also presents a discussion of the findings. A note on how the findings are expressed. The teacher-participants are unique individuals with different beliefs and perspectives, which were expressed in the previous chapter. In order to examine them as a group, generalizations were made approximating their beliefs and perspectives as a group. This is the essence of multiple case studies (Creswell, 2013; Stake, 2006).

\section{Theme \#1: Strength of Ethnic and Cultural Identity}

Ethnic and cultural identity refers to the strength of each teacher-participant's ethnic and cultural affiliation (Gay, 2018). They include on which Cuban immigration wave did the teacher-participants and their families arrived in the United States and Miami (see below for an explanation). It also includes socioeconomic status and mobility. It involves strength of ethnic and cultural affiliation to national, pan-ethnic, racial, 
gender, religion, and sexual orientation labels. The theme also pertains to cultural characteristics, such as familism, attachment to ethnic and cultural roots, and traditional cultural markers, such as language and food. Strength of ethnic and cultural affiliation also pertains to acculturation into American cultural norms and beliefs, as well as experiences with discrimination within and outside of Miami. Strength of ethnic and cultural identity may be viewed as the teacher participants' attachment toward their own cultural group and identity.

The Cuban immigrant experience in Miami pertains to the five Cuban immigration waves, which each teacher-participant or their family arrived in the United States. The Cuban immigrant experience includes the process of family reunification, social-class mobility, ethnic and cultural makeup of their residential neighborhoods, and demographics of the schools attended. The bifurcation of the five Cuban immigration waves before and after 1980 was utilized to draw a distinction between the pre-Mariel Cuban immigrants, which included the first two waves and their second-and-third generation children, with post-Mariel Cuban immigrants starting in 1980 until the most recently arrived Cuban immigrants (Aranda et al., 2014; Pedraza, 2007; Portes \& Armony, 2018). Generally, the pre-Mariel group has been attributed positive and favorable governmental and societal ratings, while the post-Mariel group has been attributed negative and hostile ones (Portes \& Armony, 2018; Portes \& Rumbaut, 2001; 2014). The distinction is determined because of differences in racial, class, educational, and political ideologies (Eckstein, 2009; Garcia, 1996; Pedraza, 2007; Perez, 1992). It is also a major reason for cultural and social distancing between both immigrant waves. 


\section{Finding \#1:}

\section{Teacher-Participants Developed a Dominant Cuban-American Cultural Ideology in Miami}

All the teacher-participants in the current study demonstrated a dominant CubanAmerican cultural ideology because they believed, understood, and accepted that they belonged to the dominant ethnic and cultural group in Miami. The assertions revealed that each-teacher-participants: (a) had favorable immigration status and positive immigration experiences by associating with the pre-Mariel immigrant group; (b) strongly selfidentified as Cuban-American and positioning themselves at the top of Miami's hierarchical racial classification system; (c) lived in a primarily Cuban sociocultural environment; (d) showed upward social mobility, which allowed them be raised as middleclass; (e) shared Cuban cultural characteristics, such as norms, traditions, histories, and language, which bonded them to other Cubans in Miami with similar experiences; (f) reported experiencing little or no discrimination in Miami; (g) selectively acculturated to the English language and other American traits, which associated them to the broader American mainstream culture. Through the appropriation of these mixed cultural characteristics, the Cuban-American social studies teachers in the study developed a dominant cultural perspective within Miami.

\section{Assertion \#1: The Teacher-Participants Had Favorable Immigration Experiences}

To assess whether the teacher-participants had favorable or unfavorable immigrant experiences, three areas were studied: (a) each teacher-participant's family time of arrival; (b) each teacher-participant's time of arrival; (c) each teacherparticipant's sociocultural environment. It is important to note that Cuban researchers 
view the pre-Mariel group as having favorable immigration experiences because of the financial and legal privileges they received from the United States government and charitable agencies (Duany, 2011; Perez, 1992). These first two waves of Cuban immigrants and their offspring also adopted Miami as their city and created a highly successful politically, economically, socially, and culturally Cuban enclave (Eckstein, 2009; Garcia, 1996; Pedraza, 2007; Perez, 1992; Portes \& Armony, 2018).

First, each teacher-participant reported that their grandparents emigrated to Miami during the early 1960s as part of the Golden Exiles, the first wave of Cuban immigrants. Except for Yaimi and Diana, each teacher-participant's parent arrived in the second wave of Cuban immigrants prior to Mariel. Diana's parents were born in the United States and Yaimi's parents arrived during Mariel. Therefore, most of the teacher-participants' grandparents and parents were part of the pre-Mariel group of Cuban immigrants.

Second, each teacher-participant strongly associated with the pre-Mariel group of Cuban immigrants (more will be said about the characteristics of Cuban culture in later sections). Jose represented the strongest affiliation to the pre-Mariel group because his time of arrival was in 1978 before Mariel. Jesse and Lenny represented the second generation of Cuban migrants, both born in the United States but having parents who arrived in the pre-Mariel group during the 1970s. Diana and her parents were born in the United States; however, they associated with the pre-Mariel group because their family arrived as pre-Mariel immigrants and kept many of their ideologies (Portes \& Armony, 2018). Only Yaimi represented the post-Mariel group having arrived in the 1990s as part of the fourth wave of Cuban immigrants. Yaimi's parents and family members arrived during or immediately after Mariel. Although Yaimi may be regarded as a post-Mariel 
Cuban immigrant, she tended to have cultural characteristics of both the pre-Mariel and post-Mariel groups of Cuban immigrants.

Third, the neighborhoods where each teacher-participant and their families resided demonstrated upward social mobility within a predominately Cuban sociocultural environment. Jose and Lenny both lived in Little Havana, a lower-to-working-class predominately Cuban neighborhood where the initial Cuban enclave was established (Grenier \& Moebius, 2015). Jose's family would subsequently move into Kendall, a higher-income area in suburban Miami with demographics of Cuban, non-Cuban Hispanic, and non-Hispanic White European American (Portes \& Armony, 2018). Lenny would move to Westchester for high school, a middle-class area with the second largest concentration of Cubans in the United States (Portes \& Armony, 2018; U.S. Census, 2010). Yaimi first resided in Hialeah, a lower-income area with the highest concentration of Cubans in the United States and second in the world next to Havana in Cuba (Portes \& Armony, 2018; U.S. Census, 2010). Yaimi's family would also eventually move into Kendall. Jesse and Diana were raised in the predominately Cuban middle-class areas of South Miami and Westchester respectively. Jesse would move into Kendall and Diana would remain in Westchester. It can be surmised that each teacher-participant's upbringing was in a middle-to upper-middle class setting within a predominately Cuban sociocultural environment.

In addition, each teacher-participant also attended public and private schools, which were predominately Cuban with a large non-Cuban Hispanic population in the Miami area. Diana, Jose, and Lenny attested that the schools they attended were almost exclusively Cuban. Jesse described his schools as mostly Cuban and non-Cuban 
Hispanic. In all cases, the teacher-participants' schooling was in a mostly Cuban environment.

Summary. The teacher-participants in the current study had favorable immigrant experiences relative to their families and their own time of arrival and the Cuban sociocultural environment they were raised. The teacher-participants and their families belonged or associated with the pre-Mariel group of Cuban immigrants tracing their family roots to the Golden Exiles, the first and highly successful Cuban immigrant wave. Therefore, it can be inferred that the teacher-participants received family and government support to successfully manage the immigrant experience. The teacher-participants' families demonstrated upward social-class mobility moving from lower-income areas, such as Little Havana and Hialeah, to higher-income areas, such as Westchester and West Kendall. It can be inferred from the upward social movement of the teacher-participants' families that they experienced a middle-class lifestyle prior to college. The schools the teacher-participants attended were predominately Cuban, which helped shape, maintain, and reinforce their Cuban cultural identity.

\section{Assertion \#2: The Teacher-Participants Strongly Affiliated with A Cuban-American Cultural Identity}

The strength of each teacher's cultural affiliation was determined by the extent to which the teacher-participants associated with a Cuban, American, or Hispanic and /Latina/o/x self-identity. A determination was made by the researcher to ascertain the strength of each teacher-participant's self-identity in part utilizing the intensity of their descriptions, words, and phrases. To begin with, each teacher-participant self-identified foremost as Cuban, in various intensities, and then identified as American, thus choosing 
the hyphenated label of Cuban-American, which is consistent with previous research of Cubans in Miami (Portes \& Rumbaut, 2014). Three of the teacher-participants ambiguously accepted Hispanic as a secondary self-identity. Three of the teacherparticipants held negative connotations toward the Latina/o/x label. Only one of the teacher-participants preferred being labeled Latina/o/x over Hispanic, while another teacher-participant was ambiguous over any pan-ethnic label. Not one teacher-participant self-identified solely as American.

Jose, the oldest of the teacher-participants was born in Cuba, strongly selfidentified as Cuban and then American by stating, "I'm Cuban-American, absolutely, but mostly Cuban" (first interview, September 2017). Yaimi, who was also born in Cuba, acknowledged that she was Cuban-American, clarifying, "I consider myself completely Cuban-American. I was born in Cuba and raised here" (first interview, April 2017). Jesse, Lenny, and Diana were all born in the United States, yet they primarily self-identified as Cuban. Jesse associated his self-identity to his Cuban heritage saying, "I have Cuban ancestry with Cuban cultural influences" (first interview, August 2017). Diana also selfidentified as Cuban despite having been born to American parents, although she did add a pan-ethnic qualifier: "I am Hispanic but mostly Cuban" (first interview, April 2017). Only Lenny demonstrated ambiguity to his self- identity, shifting from Hispanic to mostly Cuban. First, he stated he was "Hispanic Cuban" and then he said, "I consider myself more Cuban." Lenny eventually clarified himself during the fourth interview, "I feel more Cuban. People would say you look more Cuban" (fourth interview, February 2018). All the teacher-participants described their cultural identity as primarily Cuban. 
The question of self-identifying with a pan-ethnic label of Hispanic or Latina/o/x was to determine each teacher-participants' affiliation with a broader shared Hispanic or Latina/o/x culture. When asked whether each teacher-participant associated with the panethnic labels of Hispanic or Latina/o/x, four of the five reported Hispanic. Two of the teacher-participants found Latina/o/x derogatory, whereas two were ambiguous. Only one teacher-participant preferred to be labeled Latina/o/x.

Jesse, Diana, Yaimi, and Lenny chose a Hispanic self-identity because they viewed it as an umbrella label of shared pan-ethnic and Cuban cultural characteristics, such as speaking Spanish, listening to the same music, and celebrating the same festivals. However, all four of the teacher-participants derided the Latina/o/x label. Diana stated, "being Latin means being from another country like Venezuela or somewhere else" (first interview, April 2017). Jesse added, "I've heard Latinos being used negatively. That's what I heard" (first interview, August 2017).

Yaimi found being Latina related to being Mexican, avowing, "I've seen Latina being associated with Mexican women more than Cuban ones. I think it's hypersexualized, so I don't get positive connotations" (first interview, April 2017). Lenny simply declared, “aren't they the same thing?" (first interview, October 2017). Only Jose preferred Latino because of its association to the Spanish language, expressing, "It's like we Cubans say, somos [we are] Latino" (first interview, September 20170. The teacher-participants mostly chose the pan-ethnic labels of Hispanic or Latina/o/x as a secondary or as a derogatory cultural identity.

One surprising finding of the study was the paucity of race references to the teacher-participants' description of their cultural identity. Only Diana and Yaimi alluded 
to race when describing being Cuban and describing Cuban cultural traits. Diana only identified as White when she "checked off boxes" on government forms. Yaimi said that she was not "White enough" or "Black enough" when she described her Cuban cultural characteristics. No other teacher-participant mentioned skin color as an ethnic or cultural descriptor for their identity. A possibility is that the teacher-participants all believed that they were White and did not need to describe it. As the researcher noticed, all the teacherparticipants were light-skinned. However, the study found that the dominant American mainstream culture outside of Miami did not see the teacher-participants as themselves (see below for discussion with experiences outside of Miami).

Summary. The teacher-participants preferred being self-identified foremost as Cuban through being Cuban born, of Cuban descent, or having a Cuban identity. The findings in the study are consistent with prior research, which found that Latina/o/x groups tend to favor national identities over pan-ethnic ones (Duany, 2003; Portes \& MacLeod, 1996; Portes \& Rumbaut, 2014). However, the teacher-participants in the study all added the American hyphen to their identity. When forced to choose a panethnic label, however, most of the teacher-participants chose being called Hispanic over Latina/o/x. Some of the teacher-participants found Latina/o/x to be representative of a Mexican heritage or other South and Central American countries.

What can also be determined from the study is that Cuban-Americans in Miami felt that their experiences are unique, thus exemplifying Cuban exceptionalism (Aranda et al., 2014; Portes \& Armony, 2018). Although most of the teacher-participants did not identify a race, Perez (2009) found that almost $90 \%$ of Cubans see themselves as White. 
Nevertheless, the teacher- participants almost exclusively chose a mostly Cuban selfidentity, despite differences in ages and places of birth.

\section{Assertion \#3: The Teacher-Participants Developed a Bicultural Identity}

The strength of each teacher-participant's Cuban identity was expressed in the belief in the uniqueness in being Cuban. The teacher-participants viewed being American in individual and value-orient characteristics. Being Cuban was expressed through traditional cultural markers, such as language, food, traditions and values. Another cultural characteristic expressed was familism (German, Gonzalez \& Dumka, 2009), the normative beliefs of the centrality of family obligations, in which Cuban history, norms, enmity towards Castro and communism, and political awareness were passed down through generations.

First, Jesse related that Cuban culture encompassed "foods, like croquetas and cafecitos, (traditional Cuban food and coffee), Spanish language, subtle religious influences, what was passed down from our grandparents, are all part of Cuban culture" (first interview, August 2017). Diana associated Cuban culture as "saying hi with kisses on the cheek, foods like croquetas (traditional Cuban cafeteria food), belief in God, parties like Noche Buena (Christmas Eve), loud music, the way we talk too loud, putting family first, and speaking Spanish" (first interview, April 2017). Likewise, Lenny explained Cuban culture as comprising "unique foods, a lot of Salsa, Spanish language, dancing on Noche Buena [Christmas Eve party] Catholic Church, how you treat your parents and the elderly, a way of living, a whole medley of things" (first interview, October 2017). Jose underlined the importance of Cuban history to Cuban culture, expressing it as "understanding who you are, where you come from, the struggles of your 
parents, the struggles of your grandparents, being able to understand that we are very unique" (first interview, September 2017). Yaimi's view of being Cuban was politically orient, maintaining that "Cubans have always been politically involved. There were two Cuban-Americans running for President of the United States. It makes you think we get things done faster than say Mexicans, or other groups" (first interview, April 2017). In each response the teacher-participants expressed the uniqueness of Cuban cultural characteristics.

The importance of family was a consistent theme in all the teacher-participants' descriptions of Cuban culture. In familism each teacher-participant received, maintained, and passed on the exile ideology of enmity towards Castro and communism, retention of the Spanish language, and maintenance of Cuban cultural traditions and practices (Pedraza, 2007; Perez, 1992). Additionally, some of the teacher-participants expressed machismo, the idea of male superiority in the family unit, political ideologies, and intergenerational conflict.

Jesse described the maintenance of Spanish and English through his family's dynamics: "I'm fluent in Spanish because I was forced to use it with my family" (first interview, August 2017). Lenny explained how Cuban culture enveloped his life: "I was surrounded by everything Cuban" (first interview, October 2017; second interview, December 2017). Yaimi expressed how machismo was part of her family household: "I grew up in a household that is very machista. It's from my grandfather. God forbid if my father cleans the dishes or does any kind of house chores" (first interview, April 2017). Diana shared her family's desire to maintain Cuban traditional practices: "my grandparents wanted to keep everything Cuban. If I'm dating someone they would ask, 
are they Cuban?" (first interview, April 2017). Yaimi added how her family maintained racial norms: "I knew that dating somebody that was too outside of my ethnicity might be controversial. And if they were White, it's like, avansando la raza [advancing the race] (first interview, April 2017)".

Additionally, through familism, Cuban stories, enmity toward Castro, and political awareness were passed down through the generations. Jose explained: "I tell my kids that my grandfather fought in the mountains against communism" (first interview, September 2017). Similarly, Jesse shared how his grandparents held a nostalgic view of Cuba: "my grandparents said they had to leave Cuba because of what happened, but that one day they'll come back" (first interview, August 2017). Diana added some similar stories: "I would hear about how my grandparents fled communism and Castro because they wouldn't join them, so they fled to the United States" (first interview, April 2017). Yaimi described her intergenerational conflict with her family: "when we discussed politics my father would say, you can't think like that, and I'm just like, what do you mean I can't think that way. I don't have to think like you" (first interview, April 2017).

Each teacher-participant also viewed being American through personal values and traditional cultural attributes. Jesse said, "I guess the American part of me is the individual aspect of American culture" (first interview, August 2017). Jose affirmed, "I believe in American culture. You have to integrate the old American values, but also keep your roots" (first interview, September 2017). Lenny added, "sometimes I crave American foods like chicken wings and turkey. My Mom can't make those" (second interview, December 2017). 
Both Diana and Yaimi expressed being American through physical features. Diana characterized her American uncle as "someone who was White from California. He's blonde and blue eyes" (first interview, April 2017). Yaimi mentioned American mainstream media: "I liked America. I liked what I saw on TV. I wanted to be blonde and blue eyes, and I liked how some of the blonde boys looked" (first interview, April 2017). The teacher-participants saw American characteristics as distinct from Cuban ones. In other words, American identity was defined as what Cuban culture was not. Therefore, the teacher-participants did not see themselves as solely American.

Summary. The teacher-participants selectively acculturated to parts of American culture and retained parts of their Cuban culture (Portes \& MacLeod, 1996; Stepick et al., 2003). Each one of them spoke and understood Spanish, the home language of Cuba, and appropriated English from American culture as their language of choice, thus becoming fluently bilingual (Portes \& Armony, 2018). Through familism, Cuban cultural characteristics, such as norms, traditions, the exile experience, and Cuban history were passed down through each generation, bounding them to the Cuban enclave in Miami and safeguarding them from mainstream American culture (Grenier \& Perez, 2003; Perez, 1992; Portes \& Stepick, 1993). For the teacher-participants, selective acculturation created a type of biculturalism where Cuban roots, ties, and identity were maintained within Miami alongside mainstream American culture (Portes \& Armony, 2018; Portes \& Stepick, 1993). 


\section{Assertion \#4: The Teacher-Participants Viewed Themselves as Belonging to Miami's Dominant Culture}

Portes and Armony (2018) described Cubans in Miami's acculturation process as acculturation in reverse. The authors found that Miami is a city where Spanish, Cuban and pan- Hispanic cultural characteristics, and toleration for Spanish-speaking immigrants, redefined what it means to be American. In Miami, Cubans are the most populous, have the most political power, are the dominant linguistic presence, and have the security to be the dominant culture (Cortina, 1990; Portes \& Armony, 2018; Stepick et al., 2003; U.S. Census, 2015). Consequently, Cubans in Miami have reported less discrimination than any other Latina/o/x group (Aranda et al., 2014; Portes \& Rumbaut, 2014). Aranda et al. (2014) found that the pre-Mariel Cuban immigrant group discriminated against the recently arrived co-ethnic Cubans. Friction between both groups of Cuban immigrants is referred to as cultural and social distancing (Aranda et al., 2014; Grenier \& Perez, 2003; Portes \& Stepick,1993).

Each teacher-participant noted few experiences with ethnic, racial, cultural, and linguistic discrimination within Miami, although they viewed themselves as different outside of Miami. Also, each teacher-participant saw themselves as belonging to the preMariel wave of Cuban immigrants; thus, they demonstrated cultural and social distancing with the post-Mariel group of Cuban immigrants. These few experiences with discrimination implied that Cuban-Americans in Miami realized that they belonged to the dominant Cuban cultural group.

All the teacher-participants, except perhaps Yaimi, did not report any instances with discrimination in Miami. They each provided reasons why they did not feel 
discriminated. Jesse stated, "I don't know if it was because I was the majority" (first interview, August 2017). Diana asserted, "I'm Hispanic and I can relate" (first interview, April 2017). Jose affirmed, "in Miami we Cubans have been able to keep everything Cuban" (first interview, September 2017). Yaimi found Miami to be a Cuban place declaring, "Cubans have this position of power to help other Cubans, so maybe that's why we don't think discrimination is such a big deal “(first interview, April 2017). Lenny called Miami a multicultural place saying, "I've lived in mostly Cuban Hispanic neighborhoods. Miami is a kaleidoscope of different cultures, different voices, different accents, different looks" (second interview, December 2017). All the teacher-participants saw Miami as a Cuban sociocultural place in which they represented the dominant culture.

In places outside of Miami, each teacher-participant did not report instances of overt discrimination but mentioned that they felt as "outsiders" or were "mischaracterized" as belonging to another culture or nationality. Jesse said, "in other places it always felt like a different country" (first interview, August 2017). Yaimi felt some discomfort: "people in Miami don't look at me like that" (first interview, April 2017). Jose noted, "I try and not speak Spanish. It's respect" (first interview, September 2017). Diana shared, "we went skiing and somebody said, so you guys are Mexican" (first interview, April 2017). Similarly, Lenny stated this mischaracterization: "in Chicago they thought I was Mexican" (second interview, December 2017).

Each teacher-participant elaborated on the cultural and social distancing between the pre-Mariel and post-Mariel waves of Cuban immigrants. Jesse acknowledged a separation: "there's a Cuban subculture between older Cubans and younger Cubans and 
those who grew up here and those who grew up in Cuba" (first interview, August 2017). Diana noted the cultural and linguistic differences: "if you speak like dale and oye (Cuban slang) my sister will be repulsed. My grandfather would never say something like that" (first interview, April 2017). Jose disparaged the post-Mariel group: "you can ask someone about politics who just came from Cuba and they're completely off base because the education in Cuba is for brainwashing" (first interview, October 2017).

Yaimi was a special case in that she arrived in Miami after the Mariel exodus, but her grandparents came in the pre-Mariel group. She retold a story: "I did experience discrimination subtly because the way I said jello (Cuban accentuated English for the word yellow) when I had just come from Cuba" (first interview, April 2017). Then Yaimi recalled this one instance as a student: "the teacher was an old Cuban who said you can't just go oye and knock on my desk" (first interview, April 2017). Most of the teacherparticipants in the study admitted to cultural and social distancing between the pre- and post-Mariel groups of Cuban immigrants. Mostly, they perceived themselves as belonging to the pre-Mariel group of Cuban immigrants.

Summary. In each of these cases outside of Miami, the teacher-participants realized that they did not belong to the dominant cultural group in the United States. By not speaking Spanish, observing physical differences, and being labeled Mexican, they reflected a minority status relative to the dominant mainstream White European American culture. This was why each teacher-participant could say that they viewed Miami as a different culture. Miami represented a place where Cuban culture and demographics were the majority. 
Likewise, the teacher-participants in the present study associated with the preMariel group of Cuban immigrants. Portes and Armony (2018) reported that pre-Mariel Cuban immigrants and their offspring in Miami often hold positions of economic, political, and social power. The dominant cultural perspective was expressed in how the teacher-participants negatively viewed the post-Mariel group of Cuban immigrants. The dominant cultural perspective also reinforces the supposition that the teacher-participants felt comfortable and accepted in Miami because they were part of the dominant Cuban culture.

\section{Summary of Finding \#1}

Aranda et al. (2014) alluded that Cubans have made Miami their place where spaces are culturally meaningful. The teacher-participants in the current study were a part, or their family belonged to, the pre-Mariel group of Cuban immigrants, experienced upward social-mobility, which encased them in the middle-class, and lived and attended predominately Cuban neighborhoods and schools. In other words, the teacher-participants lived in a Cuban sociocultural environment which offered them economic, cultural, and social advantages over other groups in Miami. The favorable immigrant experience allowed the teacher-participants to develop and maintain their pre-Mariel Cuban culture.

The teacher-participants primarily self-identified as Cuban, disassociated from being labeled Latina/o/x, and sometimes accepted Hispanic as a secondary label despite differences in ages, gender, and generation. This implies that the teacher-participants developed a strong ethnic and cultural affiliation to Cuban culture within Miami. For instance, the strength of cultural and ethnic affiliation was evident when Jose, the oldest 
teacher-participant at age fifty, and Diana, at age twenty-two, both strongly self-identified as Cuban.

The teacher-participants described Cuban characteristics as unique and mostly separate from other Latina/o/x groups and American culture. Cuban cultural characteristics were consistently stated as ethnic foods, retention of Spanish, Cuban historical stories, and political awareness. However, the teacher-participants felt that familism was an integral part of Cuban cultural characteristics. Through familism, Cuban cultural norms, practices, traditions, and more importantly what it means to be Cuban, were passed down from generation to generation. Diana, a third-generation CubanAmerican with both parents born in the United States, and Lenny with a non-Cuban Hispanic mother and a Cuban family network, both expressed similar Cuban cultural traits.

The teacher-participants selectively acculturated to parts of American culture and retained parts of their Cuban culture, such as being fluent in both Spanish and English (Portes \& MacLeod, 1996; Stepick et al., 2003). Researchers note that Cuban-Americans in Miami developed biculturalism through selective acculturation that safeguarded Cuban culture from being fully assimilated into American culture (Grenier \& Perez, 2003; Perez, 1992; Portes \& Armony, 2018; Portes \& Stepick, 1993). Instead, the teacher-participants in the study were able to retain Cuban cultural characteristics, while acquiring selective American cultural norms, which helped them attain success in Miami by associating with both cultures.

All the teacher-participants in the current study viewed Miami as a Cuban place where they felt they were dominant group (Aranda et al., 2014). At times, the teacher- 
participants described themselves as culturally superior over the post-Mariel group of Cuban migrants, they experienced little or no discrimination inside of Miami, yet saw themselves as a minority in other places in the United States. They found that Miami is a city where Spanish, Cuban and pan-Hispanic cultural characteristics, and toleration for Spanish-speaking immigrants, have redefined American culture (Portes \& Armony, 2018). This allowed for Jose to state that "in Miami we Cubans have managed to keep everything Cuban" and Yaimi's father to say that "Cubans made Miami." The findings indicate that the Cuban-American social studies teachers in the present study developed a dominant cultural mindset in Miami, closely associated to the dominant American mainstream culture.

\section{Theme \#2:}

\section{Educational Beliefs on Student Learning and Teaching}

Teachers' beliefs help shape their pedagogical ideas, instructional style, and curricular decisions (Barton \& Levstik, 2014; Pajares, 1992; Salinas \& Castro, 2010). Pedagogy is often dominated by the dichotomy between student-centered pedagogy and teacher-centered pedagogy (Fives et al., 2015). Student-centered pedagogy involves the belief that students are actively engaged in their own meaningful learning where the teacher is a facilitator in this process (Mascolo, 2009; Weimer, 2012; Windschitl, 2002; Yilmaz, 2008). Student-centered instruction includes collaborative task-orientated and problem-solving activities, engagement in multiple perspectives, evidence-based argument and open-ended discussions (Fostnot, 2005; Windschitl, 2015). Teachercentered pedagogy is centered around the teacher as an expert who transmits knowledge to a novice student learner (Mascolo, 2009). Teacher-centered instruction involves mostly 
lectures, textbook reading, and standard-based worksheets (Mascolo, 2009). In the following section, each Cuban-American teacher's educational and pedagogical beliefs were examined on how closely they aligned to student-centered or teacher-centered pedagogy to teaching and learning.

\section{Finding \#2:}

\section{Teacher-Participants Believed in Student-Centered Pedagogy, but Provided Examples of Teacher-Centered Instruction}

Each teacher-participant provided different philosophies for student learning. Apart from learning the subject matter, it also involved student acquisition of life lessons, empowerment, critical thinking, emotion, and relevance to students' lives. Educational researchers believe that student-centered pedagogies to learning are beneficial to students of diverse backgrounds (Busey \& Russell, 2016; Gay, 2018; Kagan, 1985; LadsonBillings, 1995; Nieto, 2014). Each teacher-participant also depicted their instructional practices as student-centered; however, they largely described teacher-centered or teacher-controlled instructional activities as part of their typical instructional practices.

Educational researchers have found that student-centered instructional practices were enjoyable, engaging, and motivational for students and teachers; whereas teachercentered instructional practices were found to be mostly rote-learning, boring, and contributing to social distancing between students (Busey \& Russell, 2016; Cuban, 1991; Sharan, 1990; Weimer, 2013; Yilmaz, 2008). Finally, each teacher-participant advocated for democratic principles and citizenship as the purposes of social studies education, yet their pedagogy was mostly subject-centered. Researchers noted that social studies 
teachers used mostly teacher-centered instruction in their day to day activities in the classroom (Busey \& Russell, 2016; Weimer, 2013; Windschitl, 2002; Yilmaz, 2008). Assertion \#5: The Teacher-Participants Believed in Student-Centered Pedagogies to

\section{Learning}

Each teacher-participant felt student learning involved more than learning the subject matter. They also believed that teaching social studies was about the growth of the individual through student engagement, student relevance, life lessons, critical thinking skills, and emotional investments. Each teacher-participant believed that student learning was best approached by providing more than the subject content. Jesse called it “empowering students to make change and matter to student's lives" (second interview, September 2017). Diana aspired to "make life lessons to make an impact with students" (second interview, September 2017). Yaimi also believed in student relevancy in life, explaining "teach about student's life decisions and future jobs" (second interview, May 2017). Jose strongly endorsed critical thinking skills, stating that "you need to not only learn history, but understand history, be able to talk about history, and be able to use your critical thinking skills" (second interview, October 2017). Lenny depicted learning as "the compassion, energy, creativity, and intelligence that teachers bring into the lesson" (third interview, February 2018). Each teacher-participant's belief in student-learning is closely associated with student-centered pedagogy because it involves students actively constructing their meanings in life and the teacher acting as a facilitator in the process (Ashman \& Gillies, 2003; Fostnot, 2005; Mascolo, 2009; Weimer, 2013; Yilmaz, 2008). 


\section{Assertion \#6: The Teacher-Participants Consistently Used Teacher-Centered Instruction}

First, each teacher-participant in the study believed they utilized mostly studentcentered activities for instruction. Jesse named his instructional activities as "discussions, sitting around in a circle, asking open ended, but leading questions, have conversations, and projects. (second interview, September 2017). Diana's instructional practices included multiple student-centered activities through "discussions to bring another perspective, Jamestown magazine, American revolution flip book, and role playing as King George" (second interview, September 2017). Jose also implemented multiple student-centered activities like "group activities, projects, and scenarios where you deal with a situation based on what you know about that person in history" (second interview, October 2017). Lenny only mentioned one student-centered activity: “I'd take my students outside with clipboards and do educational things" (third interview, February 2018). Yaimi utilized a variety of student-centered instructional methods, such as creating academic boards for display and bringing "Cuban coffee to class, and teas from around the world where the kids drank like it's a café" (second interview May 2017).

However, each teacher-participant also consistently used teacher-centered instruction in their everyday instructional activities. Jesse utilized lectures the least of the teacher-participants as he stated, "I don't lecture but when I do then I turn them into discussion" (second interview, September 2017). However, Diana said, "I lecture most of the time, but it's like storytelling" (second interview, September 2017). Jose promoted "lectures, notes, competition for extra points on tests, and a lot of recall" (second interview, October 2017). Lenny used "handouts, journal prompts, notes on board, 
reading in front of the class, and questions" (third interview, February 2018). Yaimi affirmed, "I'm lecturing the majority of the year, but students can ask me questions" (second interview, May 2017). In just about every instructional activity the teacherparticipants were utilizing teacher-centered instruction.

\section{Assertion \#7: The Teacher-Participants Felt Social Studies Involved Academic Knowledge and Critical Components to Learning}

For social studies education, each teacher-participant regarded democratic principles and citizenship education as the main goals for historical education. However, each teacher-participant in the study added other components for learning social studies. Jesse advocated to "help students become aware and understand how they can get involved and make a difference" (second interview, September 2017). Diana explained: "I could be a teacher that teaches more than the subject to have a purpose behind it through conversations" (second interview, September 2017). Jose sought multiple perspectives to "engage students, allow opinions, challenge and let them be their own learners" (second interview, October 2017). Lenny found that social studies teachers should "know the facts like an encyclopedia, but make everyone laugh" (third interview, February 2017). Yaimi believed that "history teachers know a little of everything, making it interdisciplinary, be a constant learner, understand the political and social impact of education" (second interview, May 2017).

\section{Summary of Finding \#2}

The teacher-participants in the current study believed that they used studentcentered pedagogies in their teaching and learning, such as student empowerment and social change (Jesse), relevancy to student's lives (Diana and Yaimi), and critical 
thinking (Jose). Sometimes the teacher-participants promoted student-centered activities, such as group projects, collaborative task-orientated activities, and role playing. Although the teacher-participants believed they used student-centered pedagogy to their instructional practices, the findings suggest that they were mostly teacher-centered instruction. That is, students did not choose what they wished to learn, or which activities best fit their interests and talents.

The most used teacher-centered instructional activity by the teacher-participants was the lecture. They also used note-taking, reading from the textbook, and competition. The issue was that the teacher-participants attempted to explain the teacher-centered activities in language associated with student-centered instruction. For example, Yaimi expressed lectures as engagement with her students. Diana and Jose implied that their lectures provided for multiple perspectives and critical thinking skills. The teacherparticipants also described their collaborative task-orientated projects and group activities as student-centered, but in most cases the teacher-participants maintained control of the learning environment. They directed the discussions, controlled the group assignments, and interspersed lectures with right/wrong answers in their interactive activities.

The type of educational beliefs about teaching and learning used by the teacherparticipants cannot be considered entirely student-centered because students are not completely engaged in their own construction of knowledge. Also, the teacherparticipants mostly directed the learning process, instead of acting as facilitators. Therefore, the teacher-participants' educational beliefs in the study are closely aligned with teacher-centered pedagogy, rather than student-centered instruction. 
Apart from teaching the content knowledge of social studies and history, the teacher-participants in the present study believed in civic engagement, open-mindedness, purposeful learning, creativity, and holistic education. Along with the twin pillars of social studies education, citizenship education and democratic principles, the teacherparticipants promoted student-centered learning and engagement of social studies principles. Nevertheless, the teacher-participants agreed that content was a critical component to social studies education. They all seemed to take a mostly teacher-centered approach to teaching social studies.

\section{Theme \#3:}

\section{Perceptions of the Official Curriculum}

The official curriculum are the state sanctioned standards, district pacing guides, state and district assessments, social studies textbooks, and the dominant American historical narrative that teachers use as guidelines for their ideological and pedagogical practices (Davis, 2019; Evans, 1989; Salinas \& Castro, 2010; Spring, 2011). They are considered representative of American mainstream culture and are shown to exclude Latina/o/x and other marginalized groups (Acuna, 1988; Apple, 2000; 2004; Cruz, 2002; Davis, 2019; Foster, 1999: Journell, 2009; Loewen, 1995; Mathews, 2013; Noboa, 2012; Sleeter \& Stillman, 2005; Stanley \& Longwell, 2004; Spring, 2011; Urrieta, 2005; Zinn, 2003). Teacher-participants' acceptance of the official curriculum is seen as promoting a pedagogy from the dominant American cultural perspective (Cruz, 2002; Davis, 2019; Mathews, 2013; Salinas \& Castro, 2010). The teacher-participants who disrupted or challenged parts of the official curriculum had issues, reservations, or disagreements with some of the information, requirements, or implementation of them. Teacher-participants 
who opposed the official curriculum showed that the information, state requirements, and implementation were wasteful, unfair, and misrepresentative of their cultural group.

\section{Finding \#3:}

\section{Teacher-Participants Accepted the Official Curriculum with Some Reservations}

The teacher-participants mostly accepted the validity of the official curriculum but often did this with some reservations. However, each teacher-participant had individual issues with the implementation and construction of the state standards, social studies textbooks, and the American historical narrative that make up the official curriculum. For purposes of the study, the official curriculum involves the Florida state standards called the Next Generation Sunshine State Standards (NGSSS), MDCPS pacing guides, and Florida's End of Course exams (EOC). The official curriculum also includes the middle and high school's American history textbooks and the historical narrative found in them.

\section{Assertion \#8: The Teacher-Participants Accepted the Requirements of the State Standards with Reservations}

The state standards are the guidelines that teachers use for instruction (Davis, 2019; Mathews, 2013). Each teacher-participant in the study accepted the Florida state standards as a requirement, although they had different perceptions about its usefulness. Diana stated, "I use the Florida standards and pacing guides because I am accountable to the district, and we are assessed with them" (third interview, October 2017). Jose similarly said, “you have to follow the Florida standards, but it doesn't necessarily mean that I'm going to cover exactly what's in it" (third interview, November 2017). Lenny bemoaned the copious amount of information saying, "the Florida standards and pacing 
guides are OK, but there's too much information for the kids to know" (third interview, February 2017). Jesse noted that the "Florida standards are there as a guide but are not to go unchallenged or make it seem there's a formula for teaching" (third interview, October 2017). Yaimi succinctly said, "I follow the state standards, so I won't get fired" (third interview, July 2017).

Summary. Each teacher-participant accepted the NGSSS and district pacing guides mostly because they were a requirement imposed by the state and district. The responses showed that teachers feared losing their jobs for not adhering to them. Other studies have found that teachers tend to follow the state standards because it tells them what to teach, are used as a source and guide for knowledge and instruction, or are a requirement (Busey \& Russell, 2016; Hilburn et al., 2016; Mathews, 2013) Nevertheless, the teacher-participants held some reservations with the state standards and district pacing guides because there was too much information in them and they did not allow for instructional creativity. However, not one of the teacher-participants spoke about the lack of multicultural education in NGSSS, or that they presented a biased portrait of the United States. The teacher-participants in the current study simply accepted the NGSSS at face value while holding some individual reservations about them.

\section{Assertion \#9: The Teacher-Participants Believed in Accountability Measures of the State Assessments with Reservations}

Teachers' beliefs on state assessment, as part of the official curriculum, fall along a binary between pedagogical and accountability measures (Barnes et al., 2015). On one extreme, the pedagogical group felt that assessments were useful for both the teacher and student to improve instruction. On the other extreme, the accountability group felt that 
assessments were worthwhile because they make students and schools accountable through evaluation and student performance. Teachers who accept the state assessments usually believe in accountability and viability of high-stakes testing. Teachers who oppose the official curriculum usually support the belief that they are irrelevant and biased toward education. The data suggest that most of the teacher-participants in the study accepted the state assessments as accountability measure, but they tended to oppose the amount and reliance of the tests for accurate and holistic assessment.

Each teacher-participant in the current study found the Florida End of Course Exams (EOC) acceptable as an accountability measure to a certain extent. Jesse explained that "tests are needed because of our test society, but I don't make it a focal point" (third interview, October 2017). Diana declared that "I love the EOC because it's structured, but I don't like all the testing” (third interview, October 2017). Similarly, Lenny found the amount of testing counterproductive to education noting that "there are too many tests now and kids are going to be left behind. They are not seeing the whole child" (third interview, February 2018). Yaimi concurred and added that "I believe in accountability but there's too much pressure and you miss the big picture. These accountability measures shouldn't be the only thing that defines or prevents me from being a natural teacher" (third interview, July 2017). Jose framed it in this fashion: "I have no problems with the EOC and testing. But it must be even handed and fair for all teachers" (third interview, November 2017).

Summary. All the teacher-participants in the present study accepted Florida's state assessments and the EOC, yet they had some reservations about them. Most of the teacher-participants agreed that state testing was needed as an accountability measure for 
students and teachers. Some of the problems that the teacher-participants took issue with included too much testing, not addressing the whole child, obstructing teaching, and fairness. Nevertheless, the teacher-participants accepted state assessments at face value without much in the way of disruption or opposition.

\section{Assertion \#10: The Teacher-Participants Used the American History Textbook as a}

\section{Resource for Instruction}

Studies have revealed that American history textbooks are the most used resource by social studies teachers (Barton et al., 1996; Cornbleth, 2001; Cruz, 2002; Davis, 2019;). Social studies textbooks are considered a part of the official curriculum and influence social studies teachers' decision-making (Busey \& Russell, 2016; Cruz, 2002; Davis, 2019; Evans, 1988; 1989). Each teacher-participant in the present study had used the American history textbook for instruction and planning. The teacher-participants held strong opinions and perspectives for the purpose and utility of the social studies textbook.

Jesse found social studies textbooks useful but cautioned that "it's a loose guidebook that gives background and reference but shouldn't be used for teachers to lean on" (third interview, October 2017). Diana expressed, "I don't like the textbooks. It is not aligned to the standards. It leaves out important information and spends time on irrelevant things" (third interview, October 2017). Jose added, "I use the social studies textbooks to reinforce the topics I teach, but I pick out parts. There's way too much volume" (third interview, November 2017). Lenny maintained that "the textbooks are boring. I have to come up with different information to synthesize, analyze, and put more thought into it" (third interview, February 2018). Yaimi said, "I use the textbooks as a tool for 
information. They're like a giant highlighter as a prep for my lecture. You need to look beyond them and get thematic" (third interview, July 2017).

Summary. All the teacher-participants in the current study used the social studies textbook as a guide, reference, tool, or to reinforce information. The issues the teacherparticipants had with them was that they were boring, contained copious and irrelevant information, and were relied on heavily by other teachers. The shortcomings of the social studies textbooks forced some of the teacher-participants to add information from outside sources or to pick and choose information from it. Only Jesse mentioned that it was open to interpretation. The teacher-participants accepted the social studies textbook as a legitimate informational resource. They all stated that they utilized them quite often.

\section{Assertion \#11: The Teacher-Participants Accepted the American Historical Narrative with Partial Disruption}

Researchers found that the American historical narrative in social studies textbooks excludes marginalized groups, fails to provide multiple perspectives of American history, and reflects the dominant culture (Acuna, 1988; An, 2016; Apple, 2004; Busey, 2017; Busey \& Russell, 2016; Cruz, 2002; Davis, 2019; Epstein, 2009; Foster, 1999; Hilburn et al., 2016; Loewen, 1995; Shear et al., 2015; Spring, 2011; Zinn, 2003). The dominant American cultural perspective is representative of a White, Western European, Male, Middle-Class, Protestant view of history (Acuna, 1988; An, 2916; Cruz, 2002; Davis, 2019; Hilburn et al., 2016; Mathews, 2013; Salinas \& Castro, 2010; Spring, 2011). Each teacher-participant in the study mostly accepted the American historical narrative, yet at times demonstrated some disruption without fully opposing it. 
Jesse affirmed, "there were no alternative facts, but the textbook is not always right so you have to challenge it and ignore some of it. Teach information in the textbooks that makes you feel uncomfortable because our different stories unite us" (third interview, October 2017). Diana noted, "I didn't find any information that was wrong. It gives a lot of information that was not easy to convey. I pick and choose information that I think is more valuable that I try to connect to my students" (third interview, October 2017). Jose added, "I found information that was questionable because it is written by authors who are skewed politically, and they make mistakes" (third interview, November 2017). Lenny explained that "I follow the history textbook and didn't really challenge it. I did elaborate and add more information that I knew about or researched. I don't know if that's challenging it" (third interview, February 2018). Yaimi expressed that "I've never found anything completely wrong, but I found information that I don't agree or understand. I only challenge the parts of the textbook that I know, like Columbus being a savior" (third interview, July 2017).

Summary. Each teacher-participant accepted the story of the dominant American historical narrative found in the social studies and history textbooks. They appeared to disrupt information that they found inaccurate, irrelevant, questionable, or disagreeable. At times, some of the teacher-participants added information from marginalized groups. At other times, the teacher-participants simply disregarded the information. The teacherparticipants added information when they were knowledgeable of the subject matter. Rarely did the teacher-participants inform that the information in American history textbooks were misleading or outright wrong. The use of partial disruption may be considered opposing the American historical narrative because it challenged the official 
storyline. However, the teacher-participants in the study mostly stated that they accepted the validity of the information in the American historical narrative.

\section{Summary of Findings \#3}

The teacher-participants accepted the validity of the state standards, district pacing guides, state and district assessments, and the American historical narrative with some reservations. All the teacher-participants followed the state standards and district pacing guides without opposing them. They felt that it was a state requirement for teaching. The issues they had with the state standards and district pacing guides ranged from that there was too much information and that the information for the students was difficult to understand. Not one of the teacher-participants stated that they would oppose the state standards and district pacing guides in any constructive fashion.

Similarly, the teacher-participants also accepted the state and district assessment measures, although with some reservations. The teacher-participants in the study took an accountability perspective to the state and district assessment believing state testing was needed to assess and evaluate students. In a sense, the teacher-participants in the study believed in formal assessment of their students, which included tests and quizzes, to measure progress through data. However, the teacher-participants did speak about the sheer number of administered tests. They also felt the state assessment measures allowed for inaccurate student assessment, obstruction of teaching time, and unfair use of teacher and school evaluation. In this regard, there is some evidence that the teacher-participants would oppose the state assessment if they were not required to administer them and push them toward a more holistic form of assessment. 
At times, the teacher-participants appeared to partially disrupt the American historical narrative by deeming it inaccurate, irrelevant, questionable, or disagreeable. They acted upon it by privileging information from marginalized groups, connecting information to students' lives, and researching for outside information not found in the social studies textbooks. Despite the teacher-participants demonstrating some disruption to the American historical, they all believed that the information was mostly accurate. In this regard, the teacher-participants in the current study approached the American historical narrative from a dominant American mainstream cultural perspective without much opposition.

\section{Finding \#4}

\section{Each Teacher-Participant Lacked Sufficient Skills and Dispositions for Cultural Consciousness and Cultural Competence}

Geneva Gay (2018) in Culturally Responsive Teaching noted that teachers often hold prejudices toward their students because of their cultural, ethnic, and racial backgrounds. The section's purpose is to answer the question on whether the teacherparticipants in the study were aware of their cultural, racial, and linguistic biases, that is, whether they indicate cultural consciousness and teach for cultural competence. The analysis involves the attitudes and approaches that the teacher-participants took for instructing culturally, racially, linguistically similar students and diverse students. The current section presents each teacher-participant's view on teaching ethnically, culturally, racially, and linguistically similar and diverse students. They are presented as individual portraits to better understand the nuances of their responses. The individual responses provide for a more detailed examination of each teacher-participants' cultural 
consciousness. In the next chapter, an in-depth discussion on the teacher-participants' cultural consciousness will be made.

Jesse

Jesse found that his cultural and linguistic similarities helped with teaching students who were linguistically similar. He said, "with ESOL (English Language Learners)] you teach them differently. I speak Spanish, and it can help them behave, make connections, and make things relevant" (third interview, October 2017). However, Jesse found that teaching racially diverse students was more problematic. He stated, "it was culturally different. There was more apathy. I tried making connections, make the material relevant, but I didn't know what their life was like" (third interview, October 2017). Jesse explained that knowing the culture of racially diverse students is essential in an inclusive pedagogy: “maybe if you're culturally similar it's easier to make connections. But you must know the population to reach them" (third interview, October 2017).

Jesse was aware that his cultural and ethnic background helped foster better pedagogy with culturally similar students. He also understood that the lack of cultural and racial similarities inhibited an inclusive pedagogy. Therefore, Jesse believed learning about students' culture and language helped with pedagogy. In this regard, Jesse exhibited some degree of cultural consciousness by being aware of his limitations in teaching for cultural competence.

\section{Diana}

Diana helped her culturally similar ESOL students by providing them with extra time, translators, or help buddies. Yet, Diana believed in teaching culturally and 
linguistically similar students in the same fashion as her regular students. She mentioned, "it's the same information but in a different way" (third interview, October 2017). Diana admitted she did not have many racially diverse students in her classes, but she did share an experience with an African American student where she made connections with him over his favorite sport of football. She explained her interaction: "I would use examples of football teams in class and even went to see one of his games. He saw that I was supporting something he was passionate about" (third interview, October 2017).

Although Diana attempted to bond individually with her racially different student, she did not include any cultural or racial pedagogies that may have helped with learning. It appears that Diana's beliefs on teaching culturally, ethnically, and racially diverse students was grounded in teaching all students the same way. In teaching students in the same pedagogical fashion, she mostly held a color-blind perspective for pedagogy. The pedagogical perspective taken by Diana, limited her in developing into a better culturally competent educator.

Jose

Jose also found it easier teaching culturally similar ESOL students because of language similarities and cultural connections. He maintained that "it's easier because you know the language. I engage with them, pair them up with a mentor buddy, walk around and ask how they're doing and joke with them" (third interview, November 2017). Jose also engaged with his students when he taught non-Spanish speaking ESOL students in a predominately Haitian urban high school in Miami. He elaborated on these experiences: "that was tough and challenging. I clicked with the ones that knew English. I 
enjoyed their sense of humor and they enjoyed mine. They tried teaching me Creole and that was rewarding" (third interview, November 2017).

Jose approached teaching culturally, racially, and linguistically diverse students by making personal connections with them, except that language was a barrier. It was the same approach he took with culturally, ethnically, and linguistically similar students. Jose appeared to validate students of diverse backgrounds' linguistic identity, but he did not bring their cultural backgrounds into pedagogy. Jose realized in is cultural consciousness that teaching linguistically diverse students was "tough", yet he did develop a culturally inclusive pedagogy to remedy some of the issues. It could be surmised that Jose lacked the requisite skills and approaches to instruct for better cultural competence.

\section{Lenny}

Lenny also found that knowing the language of culturally, ethnically, and linguistically similar students helped with communication. He stated, "I spoke Spanish and knew their culture and that helped me work with them" (fourth interview, February 2018). Yet, Lenny's philosophy on teaching culturally, racially, ethnically, and linguistically diverse students was of instructing them in the same fashion as his other students. He declared, "teach all students the same with equal education and figure out how to tailor the delivery of your curriculum to them" (fourth interview, February 2018).

Lenny strongly believed in color-blindness, that is, he attempted to avoid racial differences in his students, and he believed in teaching all students in the same fashion. However, Lenny used his knowledge of Spanish to teach culturally, ethnically, and linguistically similar students in a different way, while advocating for a different pedagogy for different types of students. Lenny was aware of cultural and racial 
differences with his diverse students but did not attempt an inclusive pedagogy. Lenny's low level of cultural consciousness did not change his color-blind teaching belief and lessened his cultural competence.

\section{Yaimi}

Yaimi saw similarities in her own lived experiences when she taught ethnically, culturally, and linguistically similar students. With one Cuban ESOL student, she explained her teaching approach: "I felt my own experience reflected in him since I started the same way. I got him a translator and spoke Spanish because it made him feel comfortable" (third interview, July 2017). However, Yaimi experienced "culture shock" teaching racially and culturally diverse students. She described, "my perception was that they didn't want to learn or value education. They would throw chairs and couldn't put two sentences together. They wouldn't even let me speak. And I would judge" (third interview, July 2017). Yaimi testified, "I had a prejudice toward the attitudes that African Americans in that school because education was serious in my house. Maybe it's because we came from a different culture, a different environment (third interview, July 2017).

Yaimi was the only teacher-participant to express several culturally conscious moments. She related experiences in teaching recently arrived Cuban immigrant students. Yaimi applied her cultural and linguistic similarities to help instruct them. Yet, when she taught racially and culturally diverse students, she admittingly allowed her biases and prejudices to interfere with designing a culturally inclusive pedagogy. For instance, Yaimi did not attempt to provide instruction that legitimizes their cultures, instead she taught them in the same fashion as her other students. Yet, Yaimi understood her efficiencies in teaching culturally and racially different students. Yaimi's cultural 
consciousness was not enough to overcome her lack of skills and knowledge to become a better culturally competent educator.

\section{Summary of Finding \#4}

The teacher-participants in the current study found that cultural and linguistic similarities with their Spanish speaking ESOL students helped to better educate and communicate with them. However, the teacher-participants reported having difficulties teaching culturally, racially, and linguistically diverse students. With their diverse students, the teacher-participants did not sufficiently teach an inclusive pedagogy. The teacher-participants did use different approaches with their Spanish-speaking students. A lack of multicultural knowledge, preconceived notions about their students of diverse backgrounds' culture, and color-blindness were reported in examining each teacherparticipants' cultural consciousness.

\section{Chapter Summary}

The findings and assertions in the chapter points out that the teacher-participants in the current study demonstrated a dominant cultural perspective in Miami. The teacherparticipants' self-identified and strongly affiliated as Cuban-American, despite being from different ages and generations. They all had favorable immigrant experiences. A Cuban cultural environment surrounded their daily lives. In that Cuban sociocultural environment, the teacher-participants learned the norms, traditions, histories, and language, which bonded them to other Cubans in Miami with similar experiences. The teacher-participants reported experiencing little or no discrimination in Miami. They selectively acculturated to English and other American traits, which associated them to the broader American mainstream culture. In Miami, the teacher-participants in the study 
developed a dominant cultural ideology that influenced their educational beliefs, guided their instructional practices, and shaped their perspectives on the official curriculum. More importantly, their dominant ideological perspective shaped their cultural consciousness in teaching culturally, ethnically, racially, and linguistically diverse students.

The findings and assertions showed that the teacher-participants believed in principles of student-centered pedagogy. However, through their own words, they described teaching practices that mostly aligned with teacher-centered instruction. Most of the teacher-participants utilized teacher-directed lectures as their main instructional method for transmission of knowledge. Collaborative task-orient projects and various group activities were also described by the teacher-participants as student-centered; however, in most of these cases, they maintained control of the learning environment.

All the teacher-participants accepted the official curriculum at face value with some reservations. The state standards and district pacing guides were mostly followed because they were viewed as a job requirement. The state assessments were accepted mostly for accountability measures. The social studies textbooks were used for instruction and the American historical narrative was followed without much disruption to the official story line. Although all the teacher-participants accepted the official curriculum, each of them at times rebuked the amount of information, questioned the veracity of the information, and lamented the purposes for them.

In the next chapter the findings are discussed. These include how the teacherparticipants dominant cultural identity influenced their pedagogical practices and curricular decisions. In addition, implication for theory will be discussed. 
Recommendation for research will be pointed out. Recommendations for practice will added. Finally, a conclusion will be discussed. 


\section{CHAPTER VI}

\section{DISCUSSION AND IMPLICATIONS}

The purpose of the present qualitative cross-case analysis was to examine how five Cuban-American social studies teachers in Miami, a city where they are viewed as the dominant culture, demonstrated ethnic and cultural identity, expressed educational beliefs on teaching and learning, promoted culturally diverse pedagogy, and approached the curriculum relative to their cultural consciousness. The final chapter reviews, analyzes, and discusses the findings and implications of this study. The chapter concludes with suggestions for further research. The four main research questions and sub-questions which framed the research study are as follows:

1. How did each teacher-participant describe his or her ethnic and cultural identity?

a. How did each teacher-participant describe his or her immigrant experience?

b. How did each teacher-participant define and characterize his or her cultural and ethnic identity?

c. What encounters and perceptions with ethnic, racial, linguistic or cultural discrimination did each teacher-participant experience inside or outside of Miami and within their ethnic and cultural group?

2. What was each teacher-participant's educational and epistemic beliefs on learning, teaching, and social studies?

3. What was each teacher-participant's view toward the official curriculum? 
4. What was each teacher-participant's perspective on teaching linguistically, racially, and ethnically diverse students and controversial issues?

\section{Discussion of Findings}

In the present study, the findings indicated that the Cuban-Americans social studies teachers developed a dominant cultural ideology in Miami by exhibiting a strong affiliation to their Cuban cultural identity, which influenced their educational beliefs on teaching and learning, pedagogical practices, curricular decisions, and teaching culturally, racially, and linguistically diverse students. Gay (2018) noted that in studying ethnic and cultural groups it is the core characteristics of group behavior that are presented. Therefore, the findings and discussions are approximations of group behavior and not a manifestation of individual beliefs, practices, and decisions. The findings and discussion represent an understanding of different intersections of each teacherparticipant in the study presented in composite constructions of group behavior.

First, the teacher-participants demonstrated characteristics of high ethnic affiliation to Cuban cultural identity (Gay, 2018). In various degrees, the teacherparticipants all self-identified as Cuban-American with a strong affiliation to Cuban traditional cultural characteristics, despite ranging from being born in Cuba to third generation American. They also closely associated with the dominant American mainstream culture by selectively acculturating both Cuban and American cultural traits, such as fluently speaking both English and Spanish (Portes \& Armony, 2018; Portes \& MacLeod, 1996; Stepick et al., 2003). Because each teacher-participant associated with the pre-Mariel group of Cuban immigrants, they each had favorable immigration experiences, mostly disassociated with pan-ethnic labels, and were raised primarily in a 
middle-class Cuban environment. Therefore, the teacher-participants developed a distinctive biculturalism in Miami's Cuban enclave, which safeguarded them against discrimination and assimilation into American culture and allowed for the maintenance of Cuban culture and identity throughout different generations (Grenier \& Perez, 2003; Perez, 1992; Portes \& Armony, 2018; Portes \& Stepick, 1993).

Cobas et al. (2009) inferred that the United States' racial system redefined ethnic groups into racial categories of White and Black. Hispanic and Latina/o/x groups were categorized into pan-ethnic categories replete with widespread stereotypes and generalizations. Bonilla-Silva (2014) labeled the current racial classification system as a tri-racial system with non-Hispanic Whites on top, non-Hispanic Blacks at the bottom, and Honorary Whites in the middle. Bonilla-Silva categorized light-skinned CubanAmericans as Honorary Whites because they served as a middle-ground between nonHispanic Whites and non-Hispanic Blacks. Pedraza's (2007) American Community Survey showed that $86 \%$ of Cubans identified as White.

Aranda et al. (2014) denoted Miami as a racially segregated city. Aranda et al., observed systemic racial patterns and social-class in the residential neighborhoods in Miami. For instance, it was found that non-Hispanic Black Americans, Haitians, and Afro-Cubans lived in the poorest areas. On the other hand, non-Hispanic Whites lived in the wealthiest parts in town. In the affluent areas of Miami, as well as working-class areas, light-skinned Cuban-Americans from the pre-Mariel immigrant groups also resided in large numbers. This suggests that Miami has kept the racial hierarchical system of the United States. In Miami, however, pre-Mariel Cuban-Americans and their offspring 
maintained control over the political power and sociocultural environment in the city making them the dominant cultural power (Portes \& Armony, 2018).

The Cuban-American social studies teachers' in the current study understood that they belonged to the largest ethnic group in Miami. Therefore, the teacher-participants developed a belief that they also belonged to the dominant cultural group. They had internalized the American system of racial classification. Therefore, they reported less instances of discrimination than any other Latina/o/x group in Miami (Aranda et al., 2014). In Aranda et al.'s Making A Life in Multiethnic Miami, the authors reported that non-Cuban Latina/o/xx groups often felt they were discriminated by Cubans in Miami. The implication is that non-Cuban Hispanic groups view Cubans as the dominant cultural group in Miami. The dominant cultural belief led the teacher-participants in the current study to develop a dominant ideology within Miami like non-Hispanic Whites in the United States.

Second, the findings indicated that most of the teacher-participants believed in student-centered instruction, yet they followed teacher-centered instruction in their pedagogical practices. Student-centered instruction has been shown to have positive effects for students of diverse backgrounds because it is consistent with their cultural values, relevant to their lived experiences, and allows for legitimacy of their cultures and histories (Busey \& Russell, 2016; Cuban, 1991; Gay, 2018; Kagan, 1985; LadsonBillings, 1995; Lucey et al., 2014; Nieto, 2004; Weiner, 2013; Yilmaz, 2008). The question then becomes, why did the teacher-participants continuously use teachercentered instructional activities despite the benefits of student-centered instruction on their culturally, ethnically, racially, and linguistically diverse students? 
One reason was put forth by Mascolo (2008), who argued that lectures are forms of active learning because students participated in the learning process. The teacherparticipants believed that by engaging students in lectures they were changing teachercentered instruction into a participatory student-centered activity. Some of the teacherparticipants did use the language of student-centered instruction by calling their "lectures as storytelling, or "lectures but engaging." Weimer (2013) pointed out that students can be active learners in lectures if the stories told are reconstructed and discussed through open-ended and through multiple perspectives. However, Weimar also noted that in most lectures, students were not actively engaged, instead they were passive recipients of information. Therefore, it cannot be said that the teacher-participants were strong proponents of student-centered instruction, despite their belief in its benefits.

Another possible reason for the teacher-participants' ubiquitous use of mostly teacher-centered instruction can be found in the nature of social studies. Busey and Russell's (2016) study of 12 Latina/o/x students revealed that they found social studies to be an ideal subject to learn about diversity-related topics, such as racism, gender, economic inequality, and sexuality. However, the authors also discovered that teachers used mostly teacher-centered instruction because they were not adequately prepared to teach for cultural diversity. In other words, teachers who lacked multicultural knowledge or did not have the pedagogical skills tended to instruct from a pedagogy that did not challenge their teaching beliefs and self-efficacy. Weimer (2013) also found that most teachers liked being the center of action, did not like giving up the teaching role to students, and enjoyed being in control of the learning process. 
Additionally, Pearcy and Duplass, (2011) blamed state tests for why social studies teachers used mostly teacher-centered instruction. Pearcy and Duplass found that the state tests caused time constraints on covering the required information for state tests; therefore, teachers tended to move faster through the curriculum by using teachercentered instruction, a pedagogy familiar to them (Peck \& Herriot, 2015; Windschitl, 2015). Windschitl (2002) also discovered that teachers usually taught in the fashion that they learned from their experiences as students (Pajares, 1992). These explanations are certainly viable since the teacher-participants described similar exercises in their pedagogical practices. But another important reason was in the teacher-participants' lack of cultural consciousness.

Third, the findings showed that the teacher-participants mostly accepted the tenets of the official curriculum. The official knowledge includes the Florida state standards (NGSSS), state assessments, district pacing guides, American history textbooks, and the American historical narrative found in the American history textbooks, which teachers use as guidelines for instruction and curricular decisions (Davis, 2019; Mathews, 2013; Salinas \& Castro, 2010; Spring, 2011). Researchers have found this official knowledge to be representative on the dominant White, Male, Eurocentric American ideology, which often misrepresents, omits, and negatively stereotypes Latinx and other marginalized groups (Acuna, 1988; An, 2016; Apple, 2004; Busey, 2017; Busey \& Walker, 2017; Cruz, 2002; Davis, 2019; Foster, 1999; Heilig et al., 2012; Loewen, 1995; Noboa, 2012; Novoa, 2007; Sleeter \& Stillman, 2005; Zinn, 2003). Researchers have found that social studies teachers who challenge, disrupt, or oppose the official curriculum are better equipped to enact a culturally inclusive pedagogy and become culturally competent 
teachers (Davis, 2018; Salinas \& Castro, 2010). Why did the teacher-participants

subscribe to the dominant cultural perspective of the American historical narrative? A better question to ask is why was Jesse the only teacher-participant to disrupt portions of the official curriculum?

The findings revealed that the teacher-participants in the study did not implement a culturally inclusive pedagogy. The teacher-participants believed in the dominant culture and ideology of the United States. One possible assumption is that teacher-participants were grateful that the United States accepted them and provided support to their families upon arriving as immigrants, that they did not wish to oppose the American storyline. Therefore, the teacher-participants found it difficult to oppose, challenge, or even disrupt the American historical narrative even if they found inaccuracies, biases, misrepresentations in them.

The researcher agrees that the voices of Latina/o/x groups need to be incorporated into the American historical narrative (Cruz, 2002; Davis, 2019; Mathews, 2013). For instance, the teacher-participants had the counter-stories in their family's immigrant experiences. They could have taught about fleeing from Castro, living in a foreign land, organizing to fight against local discrimination, and achieving economic and political success. They could have added Cuban entrepreneurs, Cuban-American members of Congress, governors, and representatives. These were the voices that were left out of the American story. Instead, the teacher-participants did not feel the need to instruct in a culturally competent fashion. They followed the official curriculum and American historical narrative without opposition even if it meant leaving out the successes of their own cultural group. 
Hilburn et al. (2016) stated that when teachers are unaware of their own biases, they tend to teach this official knowledge without contention (Rong, 1998). Gay (2018) and other researchers found that to be culturally competent educators, teachers need to examine their own biases, perspectives, and prejudices (Ladson-Billings, 1995; Salinas \& Castro, 2010). The findings of the current study demonstrated that most of the teacherparticipants have not fully examined their cultural consciousness. Therefore, they held onto the dominant ideology that they have been taught by their parents, their sociocultural environment, and their own unchallenged beliefs. It is through an understanding and realization of their own cultural consciousness that teachers will be able to take the first step toward cultural competency. As Hilburn et al. (2016) so accurately stated, teachers make the final decision in curriculum and decide what is taught and how to teach it, and change begins with a realization of their beliefs (Gay, 2018).

\section{Implications for Theory}

The current study used critical Latino theory's (LatCrit) categories of social and cultural construction, such as immigration experience, cultural and ethnic identity, gender, race, and acculturation. LatCrit was also used to examine pedagogical practices, critically examining textbooks, and curricular decisions to the official curriculum. The current study showed that LatCrit's contextual factors are not static for all Latina/o/x teachers. Perceptions of being the dominant culture and the importance of a cultural place are needed in studying Latina/o/x groups.

Additionally, the study contributes to critical Latino theory (LatCrit) research literature by adding a group of Latina/o/x teachers' beliefs to LatCrit's narratives. Through LatCrit analysis of Cuban-American teachers, the present study opens 
discussion on the suppositions that Latina/o/x groups and teachers are all marginalized throughout the United States. More importantly, the current study allows for further investigation into Latina/o/x groups' cultural consciousness to understand their cultural, ethnic, racial, and linguistic biases. The study broadens the research dimensions of LatCrit analysis and provides a counter story to the story of Latina/o/x groups. It asks the questions why Cuban-Americans were different in their cultural identity, educational beliefs, instructional practices, and curricular decisions than other Latina/o/x groups in the research literature. In so doing, the current study may help open discussion on what it means to be a Latina/o/x teacher, and which cultural, social, racial, and linguistic factors influence teachers' beliefs and perspectives in the United States.

\section{Recommendations for Research}

The current study provides information to educational researchers, CubanAmerican researchers, Latina/o/x scholars, social scientists, and interested readers. First, it is recommended that further research be conducted on Afro-Cubans in Miami to examine if they differ in cultural identity with their light-skinned co-ethnics. The study of racial dynamics may also include the meaning of America as Whiteness or why some Cuban-Americans in Miami closely associate with the dominant American mainstream culture. Further research may also expand to other regions of the United States to examine Cuban-Americans in other geographical places as well as other Latina/o/x national groups. Another recommendation for further research is adding more teacherparticipants who are Female and from the different Cuban immigrant waves to provide a broader scope of analysis of various groups. The absence of the fifth wave of Cuban immigrants, and only one teacher-participant from the fourth wave can provide greater 
research to the field of Cuban-American studies. An additional recommendation for further research concerns the observation of teachers. Although the current study focused on teachers' beliefs, the observation of teachers in the classroom setting is the logical next step in studying cultural consciousness. It is also important for research to incorporate teacher-participants from different universities to examine how they prepare teacher-candidates. For instance, do other universities have different ideologies and methods in training teachers, and if so, how does this influences their educational beliefs, practices, and decisions? Cultural consciousness is a complex matter that requires an indepth study of teachers' cultural identity formation. Future research would be better served if studies were conducted on more ethnically, culturally, and racially diverse teachers.

\section{Recommendations for Practice}

The importance of teachers' understanding of their cultural consciousness was evident from the findings and discussion of the current research. One recommendation for teachers is to study the complexities of their biases and prejudices toward students of diverse backgrounds. It is not enough to say that teachers should instruct all students in the same fashion. Teachers must become aware that some students of diverse backgrounds require a culturally inclusive pedagogy that accounts for their history, culture, language, and race. Therefore, it is recommended that teachers learn the multicultural knowledge, pedagogical skills, and affirming attitude to teach for cultural inclusivity. The process of becoming culturally competent can begin in pre-service training courses in universities but can also be adopted in professional development classes for practicing teachers. What the current study revealed was that the teacher- 
participants were not fully aware of their cultural consciousness. At times, some of them appeared to acknowledge some degree of cultural consciousness but being "near-sighted" to their biases and prejudices is not enough to instruct for cultural competence. It is imperative that teachers, schools, and institutions better develop ways in which teachers can better acknowledge their cultural consciousness. It is hoped that the results of the current study, empowers teachers to examine their cultural biases and prejudices and challenge and change the official curriculum to build cultural bridges between them and their students.

\section{Limitations}

This study's limitations were as follows:

1. Although every effort was made to recruit teacher-participants representative of race, the study recruited no Afro-Cubans, therefore, limiting the study of race as factor to cultural identity formation.

2. Additionally, only one teacher-participant represented Cubans from the postMariel group of immigrants, and no teacher-participant was representative of the fifth wave, which may have skewed the current study toward the cultural identities of the pre-Mariel group of Cuban immigrants.

3. The current study started out with three females and three males as an equal representation of gender. However, one female teacher-participant dropped out of the study after the first interview and because of time constraints the researcher was unable to procure a replacement.

4. Although the study's concern was on the teacher-participants' educational beliefs on teaching, learning, and curricular decisions, a lack of teacher observations 
meant that the truthfulness of their instructional practices must be taken at face value.

5. Since all the teacher-participants received their bachelor's degree from the same large urban university in the region, albeit in different years, that institutions' curriculum may have influenced the teacher-participants' beliefs and perspectives. In other words, the study's teacher-participants may be eschewing the pedagogical beliefs of the university's education department. Consequently, a lack of teacher-participants from other universities also hindered the pedagogical and educational goals from other universities' teaching preparation courses.

\section{Conclusion}

Teachers' beliefs are an important aspect of their teaching, student learning, and curricular decisions. If teachers are to instruct for an inclusive pedagogy and cultural competence, then it is imperative that they become aware of their cultural, ethnic, racial, and linguistic biases and prejudices. Teachers need to examine their cultural consciousness in a thorough manner by describing their cultural and ethnic identity, pedagogical beliefs, and instructional practices, so that they may be better equipped to instruct students who are culturally, ethnically, racially, and linguistically diverse. The current study showed that developing a cultural conscious mindset is essential to becoming a culturally competent educator. Being aware of one's beliefs, biases, and prejudices is needed to effectively instruct in the current multicultural and diverse educational climate of the United States. 


\section{REFERENCES}

Acuña, R. (1988). Occupied America: A history of Chicanos. New York, NY: Harper \& Row.

Adams, M. \& Busey, C.L. (2017). "They want to erase the past": Examining race and Afro-Latin@ identity with bilingual third-graders. Social Studies and the Young Learner 30(1), 13-18.

Almarza, D.J. (2001). Contexts shaping minority language students' perceptions of American history. Journal of Social Studies Research, 25(2), 4-22

An, S. (2016). Asian Americans in American history: An AsianCrit perspective on Asian American inclusion in state U.S. history curriculum standards. Theory and Research in Social Education, 44(2), 244-276. doi: 10.1080/00933104.2016.1170646

Anderson, C.B. (2013). The trouble with unifying narratives: African Americans and the civil rights movement in U.S. history content standards. Journal of Social Studies Research, 37(2), 111-120.

Andrade, R.A. (1990). Latino students: Struggle for identity. Latino Studies Journal, (1), 48-59.

Antrop-Gonzalez, R. (2006). Toward the school as sanctuary concept in multicultural urban education: Implications for small high school reform. Curriculum Inquiry, 36(3), 273-301. doi: 10.1111/j.1467-873X.2006.00359x

Apple, M. W. (1992). The text and cultural politics. Educational Researcher, 21(7), 4-11.

Apple, M.W. (2000). Official knowledge: Democratic education in a conservative age ( $2^{\text {nd }}$ ed.). New York, NY: Routledge.

Apple, M.W. (2004). Ideology and curriculum. New York, NY: Routledge Falmer.

Apple, M.W. (2008). Curriculum planning: Content, form, and the politics of accountability. In M.F Connelly, M.F. He, and J. Phillion (Eds.), The Sage handbook of curriculum and instruction (pp. 25-44). Los Ángeles, CA: Sage.

Aranda, E.M., Chang, R.E., \& Sabogal, E. (2009). Racializing Miami’s immigrant Latinos and color-blind racism in the global city. In J.A. Cobas, J. Duany, \& J.R. Feagin, J.R. (Eds.). How the United States racialize Latinos? White hegemony and its consequences, (pp. 149-165), New York, NY: Routledge.

Aranda, E. M., Hughes, S., \& Sabogal, E. (2014). Making a life in multiethnic Miami: Immigration and the rise of the global city. Boulder, CO: Lynne Reinner Publishers. 
Ashman, A.F., \& Gillies, R.M. (2003). Peer support networks in school and community settings. In R.M. Gillies \& A.F. Ashman (Eds.), Cooperative learning: The social and intellectual outcomes of learning in groups (pp. 196-209). New York, NY: Routledge Falmer.

Au, K.H., \& Blake, K.M. (2003). Cultural identity and learning to teach in a diverse community: Findings from a collective case study. Journal of Teacher Education, 54 (3), 195-205.

Bandura, A. (1986). Social foundations of thought and action: A social cognitive theory. Englewood Cliffs, NJ: Prentice-Hall.

Banks, J.A. (1996). The historical reconstruction of knowledge about race: Implications for transformative teaching. In J.A. Banks (Ed.), Multicultural education transformative knowledge and action: Historical and contemporary perspectives (pp. 64-87). New York: Teachers College Press.

Banks, J. A. (2004). Multicultural education: Historical development, dimensions, and practice. In J.A. Banks \& CA. McGee Banks (Eds.), Handbook on research on multicultural education (2 ${ }^{\text {nd }}$ ed.) (pp. 3-29). San Francisco, CA: Jossey-Bass.

Banks, J.A. (2006). Cultural diversity and education: Foundations, curriculum, and teaching ( $3^{\text {rd }}$ ed.). Boston, MA: Pearson.

Barnes, C. (2006). Preparing pre-service teachers to teach in a culturally responsive way. Negro Education Review, 57(1-2), 85-100.

Barnes, N., Fives, H., \& Dacey, C.M. (2015). Teachers' beliefs about assessment. In H. Fives \& M.G. Gills (Eds.), Instructional handbook on teachers' beliefs (pp. 284-300). New York, NY: Routledge.

Barth, J. (1969). Ethnic groups and boundaries: The social organization of cultural difference. Boston, MA: Little Brown.

Barton, K.C., \& Levstik, L.S. (2004). Teaching history for the common good. Mahwah, NJ: Lawrence Erlbaum.

Bean, F., \& Tienda, M. (1987). The Hispanic population in the United States. New York, NY: Russell Sage Foundation.

Bennet, C.I. (2007). Comprehensive multicultural education: Theory and Practice. Boston, MA: Allyn \& Bacon.

Bloomberg, L.D., Volpe, M. (2012). Completing your qualitative dissertation ( ${ }^{\text {nd }}$ ed.). Thousand Oaks, CA: Sage. 
Bogdan, R.C., \& Biklen, S.K. (2007). Qualitative research for education: An introduction to theories and methods $\left(5^{\text {th }}\right.$ e. $)$. Boston, MA: Pearson.

Bonilla-Silva, E. (2014). Racism without racists: Color-blind racism and the persistence of racial inequality in the United States. Lanham, MD: Rowman \& Littlefield.

Busey, C.L. (2017). Toward a Latin@ critical race theory: Examining race, racism, and Afro-Latinidad in world history and human geography. In P.T. Chandler \& T.S. Hawley (Eds.), Race lessons: Using inquiry to teach about race in social studies, (pp. 231-249). Charlotte, NC: Information Age Publishing.

Busey, C.L., \& Russell III, W.B. (2016). "We want to learn": Middle-school Latino/a students discuss social studies curriculum and pedagogy. RMLA Online, 39(4), 1-20. doi: 10.1080/19404476.2016.1155921

Busey, C.L., \& Walker, I. (2017). A dream and a bus: Black critical patriotism in elementary social studies standards. Theory \& Research in Social Education, 00, 1-33. doi: 10.:1080/009333104.2017.1320251

Castro, A.J. (2010). Themes in the research on pre-service teachers' views of cultural diversity: Implications for researching millennial preservice teachers. Educational Researcher, 39 (3), 198-210.

Chandler, P.T. (2015). What does it mean to "do race" in social studies? Racial pedagogical knowledge. In P.T. Chandler (Ed.), Doing race in social studies: Critical perspectives (pp. 1012). Charlotte, NC: Information Age Publishing.

Charmaz, K. (2006). Constructing grounded theory: A practical guide through qualitative analysis. Thousand Oaks, CA: Sage.

Chen, A. Y. (2016). Demographic imperativeness: Critical issues in preparing minority teacher candidates in teacher education. In J. Keengwe (Ed.), Handbook of research on promoting cross-cultural competence and social justice in education (pp. 101-119). Hershey, PA: IGI Global. doi:10.4018/978-1-5225-0897-7.ch005

Cicchelli, T. (1983). Forms and functions of instruction patterns: Direct and nondirect. Instructional Science, 12, 43-53.

Clausen, C.K. (2016). Exploring technology through issues of social justice. In J. Keengwe (Ed.), Handbook of research on promoting cross-cultural competence and social justice in education (pp. 137-158). Hershey, PA: IGI Global. doi:10.4018/978-15225-0897-7.ch007

Cobas, J.A., Duany, J., \& Feagin, J.R. (Eds.) (2009). How the United States racializes Latinos: White hegemony and its consequences. New York, NY: Routledge. 
Corbin, J., \& Strauss, A. (2008). Basics of qualitative research: Techniques and procedures for developing grounded theory (3rd ed.). Thousand Oaks, CA: Sage.

Cornbleth, C. (2001). Climates of constraint/restraint of teachers and teaching. In W.B. Stanley (Ed.), Critical issues in social studies research for the $21^{\text {st }}$ century (pp.73-95). Greenwich, CT: Information Age.

Cornbleth, C., \& Waugh, D. (1999). The great speckled bird: Multicultural politics and education policymaking. Mahwah, NJ: Lawrence Erlbaum.

Cornell, S., \& Hartmann, D. (1998). Ethnicity and race: Making identities in a changing world. Thousand Oaks, CA: Pine Forge Press.

Cortina, R. (1990). Cubans in Miami: Ethnic identification and behavior. Latino Studies Journal, 1, 60-73.

Creswell, J.W. (2013). Qualitative research design: Choosing among five approaches $\left(3^{\text {rd }}\right.$ ed.). Thousand Oaks, CA: Sage.

Cuban, L. (1991). History of teaching in social studies. In J. P. Shaver (Ed.) Handbook of research on social studies teaching and learning: A project of the National Council for the Social Studies (pp. 197-209). New York, NY: Macmillan.

Cruz, B.C. (2002). Don Juan and rebels under palm trees: Depictions of Latin Americans in US history textbooks. Critique of Anthropology 22(33), 323-342.

Daniels, E.A. (2011). Racial silences: Exploring and incorporating critical frameworks in the social studies. The Social Studies, 102(5), 211-220.

doi:10.1080/00377996.2011.558938

Dantas-Whitney, M., Waldshmidt, E.D. (2009). Moving toward critical cultural consciousness in ESOL and bilingual teacher education. Bilingual Research Journal, 32(1), 60-76 doi: 10.1080/15235880902965888

Davis, E, (2019). (Mis) representation of Latinxs in Florida social studies standards. Social Studies Research and Practice 14(1), 1-13.

Dee, J., \& Henkin, A. (2002). Assessing dispositions toward cultural diversity among pre-service teachers. Urban Education, 37(1), 22-40. doi: 10.1177/0042085902371003

Delgado-Gaitan, C., \& Trueba, H. (1991). Crossing cultural borders: Education for immigrant families in America. Bristol, PA: Farmer Press.

Denton, N., \& Massey, D.G. (1989). Racial identity among Caribbean Hispanics: The effect of double minority status on residential segregation. American Sociological Review, 54, 790-808. 
Denzin, N.K., \& Lincoln, Y.S. (Eds.). (2005). Handbook of qualitative research ( ${ }^{\text {rd }}$ ed.). Thousand Oaks, CA: Sage.

Duany, J. (2003). Puerto Rican, Hispanic, or Latino: Recent debates on national and Pan Ethnic identities. Centro Journal, 15 (3), 256-281.

Duany, J. (2011). Blurred borders: Transnational migration between the Hispanic Caribbean and the United States. Chapel Hill, NC: The University of North Carolina Press.

Eckstein, S.E. (2009). The immigrant divide: How Cuban Americans changed the US and their homeland. New York: Routledge.

Epstein, T. (2001). Racial identity and young people's perspectives on social education. Theory Into Practice, 40(1), pp. 42-47.

Epstein, T. (2009). Interpreting national history: Race, identity, and pedagogy in classrooms and communities. New York: Routledge.

Erickson, F. (1986). Qualitative methods in research and teaching. In M.C. Wittrock (Ed.), Handbook of research on teaching ( $3^{\text {rd }}$ ed., pp. 119-161). New York: Macmillan.

Espiritu, Y.E. (1992). Asian American panethnicity. Philadelphia: Temple University Press.

Estes, J.S. (2016). Preparing teacher candidates for diverse classrooms: The role of teacher preparation programs. In J. Keengwe (Ed), Handbook of research on promoting cross-cultural competence and social justice in education (pp 52-75). Hershey, PA: IGI Global. doi:10.4018/978-1-5225-0897-7.ch003

Evans, R. (1988). Lessons from history: Teacher and student conceptions of the meaning of history. Theory and Research in Social Education, 16(3), 101-138.

Evans, R. (1989). Teacher conceptions of history. Theory and Research in Social Education, 17(3), 210-240.

Fairclough, (1989). Language and power. London, EN: Longman.

Fergus, E., Noguera, P., \& Martin, M. (2010). Construction of race and ethnicity for and by Latinos. In E.G. Murillo, S.A. Villenas, R.T. Galvan, J.S. Muñoz, C. Martínez, M.M. Machado-Casas (Eds.), Handbook of Latinos and education (pp. 171-181), New York: Routledge.

Fernandez, L. (2002). Telling stories about school: Using critical race and Latino critical theories to document Latina/ Latino education and resistance. Qualitative Inquiry, 8(1), 45-65. 
Fives, H., Lacatena, N., \& Gerard, L. (2015). Teachers' beliefs about teaching (and learning). In H. Fives \& M.G. Gill (eds.), International handbook of research on teachers' beliefs (pp. 249-264). New York, NY: Routledge.

Foster, S.J. (1999). The struggle for American identity: Treatment of ethnic groups in the United States history textbooks. Journal of the History of Education Society, 28(3), 251278. doi: 10.1080/00467609928

Fostnot, C.T. (2005). Constructivism: Theory, perspectives, and practice. New York, NY: Teachers College Press.

Galindo, R. (1996). Reframing the past in the present: Chicana teacher role identity as a bridging identity. Education and Urban Society, 29(1), 85-102.

Garcia, C.G. (1996). Havana USA: Cuban exiles and Cuban Americans in South Florida, 1959-1994. Berkeley, CA: University of California Press.

Garcia, J. (1980). Hispanic perspective: Textbooks and other curricular materials. The History Teacher, 14 (1), 105-120. doi: 131.94.16.10

Garcia, O. (2009). Racializing the language practices of US Latinos: Impact on their education. In J.A. Cobas, J. Duany, \& J.R. Feagin (Eds.) How the United States racializes? Latinos: White hegemony and its consequences, (pp 101-114). New York, NY: Routledge.

Gay, G. (2010). Acting on beliefs in teacher education for cultural diversity. Journal of Teacher Education, 61(1-2), 143-152.

Gay, G. (2015). Teachers' beliefs about cultural diversity. In H. Fives \& M.G. Gills (Eds.), Instructional handbook on teachers' beliefs (pp. 436-452). New York, NY: Routledge.

Gay, G. (2018). Culturally responsive teaching: Theory, research, and practice. New York, NY: Teachers College Press.

Gay, G., \& Kirkland, K. (2003). Developing cultural critical consciousness and selfreflection in preservice teacher education. Theory into Practice, 42(3), 181.

German, M., Gonzales, N. A., \& Dumka, L. (2009). Familism values as a protective factor for Mexican-origin adolescents exposed to deviant peers. Journal of Early Adolescence, 29(1), 16-42. https://doi.org/10.1177/0272431608324475

Gimenez, M.E. (1992). U.S. ethnic politics: Implications for Latin Americans. Latin American Perspectives, 19 (4), 7-17. 
Gimenez, M.E. (2014). "Latino/Hispanic"-Who needs a name?: The case against standardized terminology. In A. Darder, \& R.D. Torres (Eds.), Latinos and education: A critical reader ( $2^{\text {nd }}$ ed., pp. 93-104). New York: Routledge.

Grant, S.G. (2001). An uncertain lever: Exploring the influence of state-level testing in New York state on teaching social studies, Teachers College Record, 103(3), 398-426.

Grenier, G. J., \& Moebius, C.J. (2015). A history of little Havana. Charleston, SC: The History Press.

Grenier, G.J., \& Perez, L. (2003). The legacy of Cuban exile: Cubans in the United States. Boston, MA: Allyn and Bacon.

Grenier, G.J., \& Stepick, A. (Eds.) (1992). Miami Now! Immigration, ethnicity, and social change. Gainesville, FL: University Press of Florida.

Hanvey, R.G. (2004). An attainable global perspective. The American Forum for Global Perspectives in Education.

Hargreaves, A. (1994). Changing teachers, changing times: Teachers' work and culture in the postmodern age. Professional Development and Practice Series. New York, NY: Teachers College Press.

Heilig, J.V., Brown, K.D., \& Brown, A.L. (2012). The illusion of inclusion: A critical race theory textual analysis of race and standards. Harvard Educational Review, 82(3), 403-439.

Hess, D.E. (2008). Controversial issues and democratic discourse. In L.S. Levstik \& C.A. Tyson (Eds.), Handbook of research in social studies education (pp. 124-136). New York, NY: Routledge.

Hilburn, J., \& Fitchett, P.G. (2012). The new gateway and old paradox: Immigrants and involuntary Americans in North Carolina history textbooks. Theory \& Research in Social Education, 40(1), 35-65.

Hilburn, J., Journell, W., \& Buchanan, L.B. (2016). A content analysis of immigration in traditional, new, and non-Gateway state standards for U.S. history and civics. The High School Journal, 99(3), 234-251. doi: 10.1353/hsj.2016.008

Hirsch, E.D. (1987). Cultural literacy: What every American needs to know. Boston, MA: Houghton Mifflin.

Hollins, E., \& Guzman, M.T. (2005). Research on preparing teachers for diverse populations. In M. Cochran-Smith \& K. Zeichner (Eds.), Studying teacher education: The report of the AERA Panel on Research and Teacher Education (pp. 477-548). Mahwah, NJ: Lawrence Erlbaum. 
Howard, T (2003). The dis(g)race of the social studies: The needs for racial dialogue in the social studies. In G. Ladson-Billings (Ed.), Critical Race Theory: Perspectives on social studies (pp. 27-43). Greenwich, CT: Information Age Publishing.

Itzigsohn, J., \& Dore-Cabral, C. (2000). Competing identities? Race, ethnicity and pan ethnicity among Dominicans in the United States. Sociological Forum, 15 (2), 225-247.

Journell, W. (2008). When oppression and liberation are the only choices: The representations of African Americans in state social studies standards. Journal of Social Studies Research, 32(1), 40-50.

Journell, W. (2009). Setting out the(un) welcome mat: A portrayal of American history standards. The Social Studies, 100(4), 160-168.

Journell, W. (2010). The influence of high-stakes testing on high school teacher's willingness to incorporate current political events into the curriculum. The High School Journal, 93(3), 111-125.

Journell, W., \& Castro, E.L. (2011). Culturally relevant political education: Using immigration as a catalyst for civic understanding. Multicultural Education, 18(4), 10-17.

Kagan, S. (1985), Learning to cooperate. In R. Slavin, S. Sharan, S. Kagan, R. HertzLazarowitz, C. Webb, and R. Schmuck (Eds.). Learning to cooperate, cooperating to learn (pp. 365-370). New York, NY: Plenum Press

Knight, G.P., \& Bohlmeyer, E.M. (1990). Cooperative learning and achievement: Methods for assessing causal mechanisms. In S. Sharan (Ed). Cooperative learning: Theory and research (pp. 1-22). New York, NY: Praeger Publishers.

Krogstad, J.M. (2015). 5 facts about Latinos. Retrieved from Pew Hispanic Center website: www.pewresearchcenter.org/fact-tank/2015/05/26

Kvale, S. (1996). Interviews: An introduction to qualitative research methodology. Thousand Oaks, CA: Sage.

Ladson-Billings, G. (1995). Toward a critical race theory of education. Teachers College record, 97(1), 47-68.

Ladson-Billings, G. (2003). Critical race theories on social studies: The profession, policies, and curriculum. Charlotte, NC: Information Age Publishers.

Levy, S.A. (2014). Heritage, history, and identity. Teachers College Record, 114(6), 134.

Lincoln, Y.S., \& Guba, E.G. (1985). Naturalistic inquiry. Beverly Hills, CA: Sage. 
Linn, D. (2011). Voices of preservice teachers in the borderlands: Exploring cultural identity through language. Curriculum and Teaching Dialogue, 13(1-2), 63-75.

Loewen, J.W. (1995). Lies my teacher told me: Everything your American history textbook got wrong. New York, NY: The New Press.

Logan, S.R. (2017). The myth of colorblindness: Helping educators recognize the role of the preK-12 ${ }^{\text {th }}$ grade classrooms. In C. Curran \& A.J. Peterson (Eds.), Handbook of research on classroom diversity and inclusive educational practice, (pp. 77-99). Hershey, PA: IG Global. doi:10.4018/978-1-5225-2520-2.ch004

Lopez, D., \& Espritu, Y.E. (1990). Panethnicity in the United States: A theoretical framework. Ethnic and Racial Studies, 13, 198-224.

Lucy, T.A., Sifflet, S.A., \& Weilbacher, G.A. (2014). Patterns of early childhood, elementary, and middle level social studies teaching: An interpretation of Illinois social studies teachers' practices and beliefs. Social Studies, 105(6), 283-290. doi:

10.1080/00377996.2014.945641

Marshall, C., \& Rossman, G.B. (1995). Designing qualitative research ( $2^{\text {nd }} \mathrm{ed}$.). Thousand Oaks, CA: Sage.

Mascolo, M.F. (2009). Beyond student-centered and teacher-centered pedagogy:

Teaching and learning as guided participation. Pedagogy and Human Sciences, 1 (1), pp. 3-27. Retrieved from http://scholarworks.merrimack.edu/phs/vol1/iss1/6

Mason, J.L. (1993). Cultural competence self-assessment questionnaire. Portland, OR: Portland State University, Multicultural Initiative Project.

Massey, D.S. (1993). Latinos, poverty, and the underclass: A new agenda for research.

Mathews, S.S. (2013). Rethinking the immigrant paradigm: West-to-east and south-tonorth perspectives of United States history. The Social Studies, 104, 161-168.

Merriam, S.B. (1998). Qualitative research and case study applications in education: Revised and expanded from case study research in education. San Francisco, CA: JosseyBass.

Merriam, S.B., \& Associates. (2002). Qualitative research in practice: Examples for discussion analysis. San Francisco, CA: Jossey-Bass.

McLaren, P. (2006). Life in schools: An introduction to critical pedagogies in the foundations of education. ( $5^{\text {th }}$ ed.). Boston, MA: Allyn \& Bacon.

Miami Dade County Public Schools. (n.d.). Statistical highlights 2014-2015, 1-6. Retrieved from http://drs.dadeschools.net/StatisticalHighlights/SH141 
Milner H. R. (2003). Reflection, racial competence, and critical pedagogy: How do we prepare preservice teachers to pose tough questions? Race, Ethnicity and Education, 6(2), 193-208. 10.1080/13613320308200

Moore, J. (1990). Hispanic/Latino: Imposed label or real identity? Latino Studies Journal, 1, 33-47.

Moule, J. (2011). Cultural competence. A prime for educators. Belmont, CA: Wadsworth.

National Center for Educational Statistics. (2012). Retrieved from NCES website: https://nces.ed.gov/fastfacts/display/asp?id=16

Nespor, J. (1987). The role of beliefs in the practice of teaching. Journal of Curriculum Studies, 19, 317-328.

Nieto, S. (2004). Affirming diversity: The sociopolitical context of multicultural education. Boston, MA: Pearson.

Noboa, J. (2012). Missing pages from the human story: World history according to Texas standards. Journal of Latinos and Education, 11, 47-62.

Novoa, A. (2007). Teaching modern Latin America in the social science curriculum: an interdisciplinary approach. Social Education, 71(4), 187+.

Olafson, L., Salinas-Grady, C., and Owens, M.C. (2015). Qualitative approaches to studying teachers' beliefs. In H. Fives \& M.G. Gills (Eds.), Instructional handbook on teachers' beliefs (pp. 128-149). New York, NY: Routledge.

Padilla, F. (1984). On the nature of Latino ethnicity. Social Science Quarterly, 65, 651664.

Padilla, F. (1985). Latino ethnic consciousness Notre Dame: University of Notre Dame Press.

Pajares, M.F. (1992). Teachers' beliefs and educational research: Cleaning up a messy construct. Review of Educational Research, 62(3), 307-332.

Patton, M. Q. (1980). Qualitative evaluation methods. Beverly Hills, CA: Sage Publications Inc.

Patton, M.Q. (1990). Qualitative evaluation methods ( $2^{\text {nd }}$ ed.). Thousand Oaks, CA: Sage.

Pearcy, M., \& Duplass, J.A. (2011). Teaching history: Strategies for dealing with breadth and depth in the standards and accountability age. Social Studies 102(3), 110-116. doi: $10.1080 / 00377996.2010 .2010 .525546$ 
Peck, C.L., \& Herriot, L. (2015). Teachers' beliefs about social studies. In H. Fives \& M.G. Gills (Eds.), Instructional handbook on teachers' beliefs (pp. 387-402). New York, NY: Routledge.

Pedraza, S. (2007). Political disaffection in Cuba's revolution and exodus. New York, NY: Cambridge University Press.

Perez, L. (1992). Cuban Miami. In G.J. Grenier, \& A. Stepick (Eds.). Miami Now! Immigration, ethnicity, and social (pp. 83-108). Gainesville, FL: University Press of Florida.

Peshkin, A. (1988). In search of subjectivity—one's own. Educational researcher, 17(7), 17-22.

Pitre, N.J. \& Clarke, V.B. (2016). Cultural self-study as a tool for critical reflection and learning: Integral analysis and implications for pre-service teacher education programs. In J. Keengwe (Ed.), Handbook of research on promoting cross-cultural competence and social justice in education (pp. 76-100). Hershey, PA: IGI Global. doi:10.4018/978-15225-0897-7.ch004

Porter, A.C., \& Freeman, D.J. (1986). Professional orientations: An essential domain for teacher testing. Journal of Teacher Education, 55, 284-292.

Portes, A. (2010). Economic sociology: A systematic inquiry. Princeton, NJ: Princeton University Press.

Portes, A., \& Armony, A.C. (2018). The global edge: Miami in the twenty-first century. Oakland, CA: University of California Press.

Portes, A., \& MacLeod, D. (1996). What shall I call myself? Hispanic identity formation in the second generation. Ethnic and racial Studies, 19 (3), 523-547.

Portes, A., \& Rumbaut, R.G. (2001). Legacies: The story of the immigrant second generation. Los Angeles: University of California Press.

Portes, A., \& Rumbaut, R.G. (2014). Immigrant America: A portrait (4 ${ }^{\text {th }}$ ed.). Oakland, CA: University of California Press.

Portes, A., \& Stepick, A. (1993). City on the edge: The transformation of Miami. Berkeley, CA: University of California Press.

Poyo, G. (2002). "Integration without assimilation": Cuban Catholics in Miami, 19601980. U.S. Catholic Historian, (20)4, pp. 91-109. 
Rong, X.L. (1998). The new immigration: Challenges facing social studies professionals. Social Education, 62(7), 393-399.

Rubin, H.J., \& Rubin, I.S. (2012). Qualitative interviewing: The art of hearing data ( $3^{\text {rd }}$ ed.). Ls Angeles, CA: Sage.

Rueda R., \& Monzo L. D. (2002). Apprenticeship for teaching: Professional development issues surrounding the collaborative relationship between teachers and paraeducators. Teaching and Teacher Education, 18(5), 503-521. 10.1016/S0742-051X(02)00013-6

Rumbaut, R.G. (2009). Pigments of our imagination: On the racialization and racial identities of "Hispanics" "and "Latinos". In J.A., Cobas, J. Duany, \& J.R. Feagin (Eds.) How the United States racializes? Latinos: White hegemony and its consequences. (pp 15-36) New York, NY: Routledge.

Russell M. \& Russell J. A. (2014). Preservice science teachers and cultural diversity awareness. Electronic Journal of Science Education, 18(3), 1-20.

Saldaña, J. (2013). The coding manual for qualitative researchers. ( $2^{\text {nd }}$ ed.). Thousand Oaks, CA: Sage.

Salinas, C., \& Castro, A.J. (2010). Disrupting the official curriculum: Cultural biography and the curriculum decision making of Latino preservice teachers. Theory and Research, 38 (3), 428-463. DOI: 10.1080/00933104.2010.10473433

Sanchez, R.M. (2007). Integrating community in culturally conscientious classrooms. Multicultural Education, 15, 50-52.

Scheiner-Fisher, C., \& Busey, C. (2013). Fostering dialogue for the social studies classroom: How to teach controversial and taboo topics. The Southern Social Studies, $39(1), 15-21$.

Schlesinger, A. M. (1992). The disuniting of America. New York: Norton.

Seidman, I. (2013). Interviewing as Qualitative research: A guide for researchers in education and the social sciences ( ${ }^{\text {th }}$ ed.). New York: Teachers College Press.

Sharan, S. (1990) (Ed.). Cooperative learning: Theory and research. New York, NY: Praeger Publishers.

Sharan, S., Shaulov, S. (1990). Cooperative learning, motivation to learn, and academic achievement. In S. Sharan (Ed). Cooperative learning: Theory and research (pp. 173202). New York, NY: Praeger Publishers. 
Shares, D. K. (2017). Becoming a culturally competent educational leader. In C. Curran \& A.J. Peterson (Eds.), Handbook of research on classroom diversity and inclusive educational practice, (pp. 54-76). Hershey, PA: IG Global. doi:10.4018/978-1-52252520-2.ch003

Shear, S.B., Knowles, R.T., Soden, G.J., \& Castro, A.J. (2015). Manifesting destiny: Re/presentations of indigenous peoples in K-12 US history standards. Theory \& Research in Social Education, 43(1), 68-101.

Shneyderman, A. (2015). Miami Dade County Public Schools Immigrant students and their academic and demographic characterestics:2014-2015. Retrieved from http://drs.dadeschools.net/AdditionalReports/M451Tr

Sleeter, C.E. (2008). Preparing White teachers for diverse students. In M. Cochran-Smith, S. Feiman-Nemser, \& D.J. McIntyre (Eds.), Handbook of research on teacher education: Enduring questions in changing contexts ( $3^{\text {rd }}$ ed., pp. 559-582). New York, NY: Routledge.

Sleeter, C., \& Stillman, J. (2005). Standardizing knowledge in a multicultural society. Curriculum Inquiry, 35(1), 27-46.

Solorzano, D., \& Delgado-Bernal, B. (2001). Examining transformational resistance through a critical race and LatCrit theory framework: Chicana and Chicano students in an urban context. Urban Education, 36, 308-342.

Spring, J. H. (2011). The politics of American education. New York: Routledge.

Stake, R.E. (1995). The art of case study research. Thousand Oaks, CA: Sage.

Stake, R.E. (2005). Qualitative case studies. In N.K. Denzin \& Y.S. Lincoln (Eds.), Sage handbook of qualitative research ( $3^{\text {rd }}$ ed., pp. 443-466). Thousand Oaks, CA: Sage.

Stake, R. E. (2006). Multiple case study analysis. New York: The Guilford Press.

Stake, R., \& Trumball, D. (1982). Naturalistic generalizations. Review Journal of Philosophy and Science, 7(1), 1-12.

Stanley L. S. (1996). The development and validation of an instrument to assess attitudes toward cultural diversity and pluralism among preservice physical educators. Educational and Psychological Measurement, 56(5), 891-897. 10.1177/0013164496056005017

Stanley, W.B., \& Longwell, H. (2004). Ideology, power, and control in social studies teacher education. In S.A. Adler (Ed.), Critical issues in social studies teacher education (pp. 9189-229). Greenwich, CT: Information Age.

Stepick, A., Grenier, G., Castro, M., \& Dunn, M. (2003) This land is our land: Immigration and power in Miami. Berkeley, CA: University of California Press. 
Su, Y., An, S., \& Forest, V. (2015). Immigration, imagined communities, and collective memories of Asian American experiences: A content analysis of Asian American experiences in Virginia U.S. history textbooks. Journal of Social Studies Research, 39(1), 39-51.

Tatto, T. (1996). Examining values and beliefs about teaching diverse students: Understanding the challenges for teacher education. Educational Evaluation and Policy Analysis, 18(2), 155-180.

Tatto, M. T., \& Coupland, D. B. (2003). Teacher education and teachers' beliefs: Theoretical and measurement concerns. In J. Rath \& A. C. McAninch (Eds.), Advances in teacher education series (pp. 123-181). Greenwich, CT: Information Age.

Tatum, B.D. (2017). "Why are all the Black kids sitting together in the cafeteria?" And other conversations about race. New York, NY: Basic Books.

Tellez, K. (1999). Mexican-American preservice teachers and the intransigency of elementary school curriculum, Teaching and Teacher Education, 15(5), 555-570.

United States Census Bureau. (2015). Retrieved from Florida Quick Facts: quickfacts.census.gov/qfd/states/12html

United States Department of Education. Retrieved from US Department of Education website: www.ed.gov

Urrieta, L. (2005). The social studies of domination: Cultural hegemony and ignorant activism. The Social Studies, 96(5), 189-192.

Valdes, G. (1996). Con respeto: Bridging the distances between culturally diverse families and schools. New York: Teachers College Press.

Valenzuela, A. (1999). Subtractive schooling: U.S.-Mexican youth and the politics of caring. Albany, NY: State University of New York Press.

VanSledright, B. (2002). In search of America's past: Learning to read history in elementary school. New York, NY: Teachers College Press.

VanSledright, B. (2010). The challenge of rethinking history education: On practice, theories, and policy. New York, NY: Routledge.

Vidal de Haymes, M. (1997). The golden exile. Journal of Poverty, (1)1, pp. 65-79. doi: 10.1300/J134v01n01 05.

Villegas, A.M., \& Lucas, T. (2002). Preparing culturally responsive teachers: Rethinking the curriculum. Journal of Teacher Education, 53(1), pp. 20-32. 
Vogler, K., \& Virtue, D. (2007). “Just the facts ma'am: Teaching social studies in the era of standards and high-stakes testing. The Social Studies, 98(2), 54-58.

Weimer, M. (2013). Learner-centered teaching: Five key changes to practice. Boston, MA: John Wiley \& Sons, Inc.

Weinstein, C. (1989). Teacher education students' preconceptions of teaching. Journal of Teacher Education, 40(2), 53-61.

Weisman, E.M. (2001). Bicultural identity and language attitudes: Perspectives of four teachers. Urban Education, 36(2), 203-225.

Windschitl, M. (2002). Framing constructivism in practice as the negotiating of dilemmas: An analysis of the conceptual, pedagogical, cultural, and political challenges facing teachers. Review of Educational Research, 72(2), 131-175.

Wortham, S., Murillo, E.G., \& Hamann, E.T. (Eds.). (2002). Education in the new Latino diaspora: Policy and the politics of identity. Westport, CT: Ablex.

Yilmaz, K. (2008). Social studies teachers' views pf learner-centered instruction. European Journal of Teacher Education, 31(1), 35-53.

Zinn, H. (2003). A people's history of the United States: 1492-Present. Harpers Collins. 
VITA

\section{VICTOR M. BARRIOS}

Born, Barranquilla, Colombia

B.A., History Florida International University

Miami, Florida

B.A., Social Studies Education Florida International University, Miami, Florida

1999-2009

Social Studies High School Teacher

Miami-Dade County Public Schools

Miami, Florida

2001

M.S., Social Studies Education

Florida International University

Miami, Florida

2014-2016

Adjunct Professor

Florida International University

Miami, Florida

2014-2019

Doctoral Candidate

Florida International University

Miami, Florida

2019

PhD Curriculum and Instruction

Florida International University

Miami, Florida

\section{PUBLICATIONS AND PRESENTATIONS}

Barrios, V.M. (2019, December). An examination of Cuban-American social studies teachers' cultural consciousness relative to identity, educational beliefs, and curricular decisions: A critical Latino theoretical perspective. (Doctoral dissertation). Florida International University, Miami, Fl.

Barrios Jr., V. M., Mathews, S.A. (2019, November). Cuban-American social studies teachers' cultural identity, pedagogical beliefs, and curricular decisions relative to their cultural consciousness. Paper presented at the annual meeting of the College and University Faculty Assembly of the National Council for the Social Studies. Austin, Tx.

Barrios, V. M. (2017, February). Toward an understanding of Cuban-American teachers' cultural consciousness. Paper presented at $11^{\text {th }}$ annual meeting of the Conference on Cuba and Cuban-American studies. Miami, Fl. 
Barrios Jr., V.M. (2016, November). Using Critical Latino theory to incorporate PanEthnic Latino voices in American History Textbooks. (peer-reviewed American History Journal).

Mathews, S.A., \& Barrios Jr., V.M. (under review, May 2014). Negotiating geography on the borderlands: A critical examination of state geography standards. (peer-reviewed geography education journal).

Mathews, S.A. \& Barrios Jr., V. M. (2013, June). Interrogating Place, Space, Power and Identity: An Examination of Florida's Geography Standards. 12 $2^{\text {th }}$ Annual South Florida Educational Research Conference, Miami, Fl.

Mathews, S.A. \& Barrios Jr., V.M. (2012, November). Negotiating geography on the borderlands: A critical examination of state geography standards. Paper presented at the annual meeting of the College and University Faculty Assembly of the National Council for the Social Studies. Washington, D.C. 